\title{
NADPH Oxidases: The Vital Performers and Center Hubs during Plant Growth and Signaling
}

\author{
Chun-Hong Hu ${ }^{1,2,+}$, Peng-Qi Wang ${ }^{3,+}{ }^{\text {, Peng-Peng Zhang }}{ }^{1}$, Xiu-Min Nie ${ }^{1}$, Bin-Bin Li ${ }^{1}$, Li Tai ${ }^{1}$, \\ Wen-Ting Liu ${ }^{1}$, Wen-Qiang $\mathrm{Li}^{1}$ and Kun-Ming Chen ${ }^{1, *(1)}$ \\ 1 State Key Laboratory of Crop Stress Biology in Arid Areas, College of Life Sciences, Northwest A\&F \\ University, Yangling 712100, Shaanxi, China; ourcarrot@163.com (C.-H.H.); 15256849763@163.com (P.-P.Z.); \\ niexiumin1019@163.com (X.-M.N.); libinbin@nwafu.edu.cn (B.-B.L.); 15591861258@163.com (L.T.); \\ lwt001975@163.com (W.-T.L.); wqli@nwsuaf.edu.cn (W.-Q.L.) \\ 2 College of Life Science and Agronomy, Zhoukou Normal University, Zhoukou 466000, Henan, China \\ 3 School of Life Sciences, Tsinghua University, Beijing 100084, China; wpq19@mails.tsinghua.edu.cn \\ * Correspondence: kunmingchen@nwsuaf.edu.cn or kunmingchen@163.com.cn; Tel.: +86-29-8703-1358; \\ Fax: +86-29-8709-2262 \\ + These authors contributed equally to this work.
}

Received: 18 January 2020; Accepted: 10 February 2020; Published: 13 February 2020

\begin{abstract}
NADPH oxidases (NOXs), mostly known as respiratory burst oxidase homologs (RBOHs), are the key producers of reactive oxygen species (ROS) in plants. A lot of literature has addressed ROS signaling in plant development regulation and stress responses as well as on the enzyme's structure, evolution, function, regulation and associated mechanisms, manifesting the role of NOXs/RBOHs as the vital performers and center hubs during plant growth and signaling. This review focuses on recent advances of $\mathrm{NOX} / \mathrm{RBOHs}$ on cell growth, hormone interaction, calcium signaling, abiotic stress responses, and immunity. Several primary particles, including $\mathrm{Ca}^{2+}, \mathrm{CDPKs}, \mathrm{BIK} 1, \mathrm{ROPs} / \mathrm{RACs}$, CERK, FER, ANX, SnRK and SIK1-mediated regulatory mechanisms, are fully summarized to illustrate the signaling behavior of $\mathrm{NOX} / \mathrm{RBOHs}$ and their sophisticated and dexterous crosstalks. Diverse expression and activation regulation models endow NOXs/RBOHs powerful and versatile functions in plants to maintain innate immune homeostasis and development integrity. NOXs/RBOHs and their related regulatory items are the ideal targets for crop improvement in both yield and quality during agricultural practices.
\end{abstract}

Keywords: NADPH oxidases (NOXs/RBOHs); reactive oxygen species (ROS); activity regulation; plant signaling; crop improvement

\section{Introduction}

Reactive oxygen species (ROS) such as superoxide anion $\left(\cdot \mathrm{O}_{2}^{-}\right)$and hydrogen peroxide $\left(\mathrm{H}_{2} \mathrm{O}_{2}\right)$ are known to participate in regulation of a wide range of biological processes involved in plant development and growth, as well as adaptation to biotic and abiotic stresses [1-5]. NADPH oxidases (NOXs), also well known as respiratory burst oxidase homologs (RBOHs), are key enzymes for ROS production in plants. As the molecular "hubs" during ROS-mediated signal transduction pathways, NOXs/RBOHs in plants have recently received considerable attention, and more and more NOX/RBOH gene homologs have been identified in a variety of plant species [6-8]. The functions and regulatory mechanisms of the NOXs/RBOHs in plants have been successively reported. Recently, we identified 46 NOX family genes in wheat genome, and a systematic analysis in their transcriptional expressions reveals their vital but diverse roles in plant growth regulation and stress responses [8]. To date, more than 150 protein members of the NOXs/RBOHs family have been identified and/or characterized 
in various plant species (Supplementary Table S1) and among them, at least 56 members have been fully elucidated in functions. These NOXs are expressed in whole plants or specific organs/tissues relying on development stage and are functioning in many developmental processes and stress responses (Supplementary Table S1). In addition, recent advances in plant cell growth, hormone interaction and calcium signaling, as well as biotic and abiotic stress responses, have shown that NOXs/RBOHs may act as the center hubs of multiple signaling pathways of plants. Many important signaling systems functioning in plant immunity and/or hormonal and abiotic stress responses, including, OsCERK1/OsCEBiP(OsLyp4/6)-OsRLCK176/185, FLS2(EFR)/BAK1-BIK1, CERK1/LYK5(LYM1/3)-BIK1, FER context and hormonal signaling stuffs, are all directly or indirectly associated with NOXs/RBOHs activation regulation. In this review, we focus on the major advances of NOXs/RBOHs on their structure, biological function, activity regulation and signaling pathways involved in plant growth regulation and stress responses. Based on these results, we summarized the major signaling models involved in regulation of NOXs/RBOHs activity and maintenance of intracellular ROS balance in plants, hoping to provide valuable information for further studies in this field and important cues for crop improvement by bioengineering and molecular breeding during agricultural practices.

\section{Protein Structure and Evolution of Plant NOXs/RBOHs}

\subsection{Highly Conservative Structure}

NADPH oxidases (NOXs) are key enzymes of ROS generation and thus play crucial roles in a variety of biological processes in different kingdoms of life [9-11]. Since the first NADPH oxidase was identified in human phagocytic cells, more and more NOXs/RBOHs were identified in many other species including animals, higher plants and fungi $[5,7,8]$. In fungi, there are four types of NOXs assigned as NOXA, NOXB, NOXC and FRE [12]. In animals, there are seven types of NOXs, named as NOX1, NOX2, NOX3, NOX4, NOX5, DUOX1 and DUOX2 [11]. However, in plants, only NOX5-like-type NOXs were found except the ancestral NOXs, ferric reduction oxidases (FROs), which are considered as the isoforms of yeast ferric-chelate reductases (FREs) [6,7,11]. All NOX family members are transmembrane proteins that transport electrons across biological membranes to reduce oxygen to superoxide anion $\left(\cdot \mathrm{O}_{2}^{-}\right)$[10]. In accordance with this preserved function, there are conserved structural properties of NOX enzymes that are common to all family members.

The earliest and most comprehensive studies about NOXs were largely carried out in phagocytic cells, in which their functions involve the destruction of pathogenic microorganisms by producing ROS [13]. The phagocytic cell, NADPH oxidase, is a protein complex that is comprised of several protein components, which can be divided into two groups. The first is a membrane-bound NADPH-binding flavocytochrome $b_{558}$, which is comprised of a glycosylated transmembrane protein gp91 ${ }^{\text {phox }}$ ( $\beta$ subunit) and a non-glycosylated p22 ${ }^{\text {phox }}$ subunit ( $\alpha$ subunit). The gp91 phox contains the entire electron transport chain from NADPH to molecular oxygen to produce $\cdot \mathrm{O}_{2}{ }^{-}$outside the plasma membrane $[14,15]$. The second group comprises four regulatory proteins: $\mathrm{p} 47^{\mathrm{phox}}, \mathrm{p} 67^{\text {phox }}$ and $\mathrm{p} 40^{\mathrm{phox}}$ phosphoproteins and Rac1 or Rac2 (small GTP (Guanosine triphosphate)-binding protein). These four regulatory proteins could be translocated to the plasma membrane and form an enzyme complex with the first group after being activated. In this process, Rac1 or Rac2 is independently activated and translocated to assemble with the oxidase effector system, each of them endows the enzyme with guanine nucleotide sensitivity as it interacts with the activator component, p67phox , in a GTP-dependent manner. The p47 $7^{\text {phox }}$ component acts as a critical phosphorylation-dependent adaptor molecule that enables the interactions between p67phox and the flavocytochrome [16]. Further studies have shown that NADPH oxidase is also present in many other types of mammalian cells where the level of ROS generated by it is much lower and the processes of ROS generation last much longer. In this case, ROS can be used as regulatory and signal molecules for modulation of metabolic processes, leading to various biological effects [17].

Although NOXs have many isoforms (homologs), the full spectrum is only found in the animal kingdoms. A mammal genome generally contains seven genes encoding gp91 ${ }^{\text {phox }}$ homologs: five close 
relatives of gp91 ${ }^{\text {phox }}$ homologs (Nox1-Nox5), and two distant relatives of gp91 ${ }^{\text {phox }}$ homologs (Duox1 and Duox2) $[10,18]$. All of them share FAD (flavin adenine dinucleotide) - and NADPH-binding sites in the C-terminal domain, two heme binding sites, a functional oxidase domain responsible for $\cdot \mathrm{O}_{2}{ }^{-}$production, and some degree of sequence similarity. However, Nox5, Duox1 and Duox2 are different kinds relative to Nox1-4: Nox5 possesses four sites (motifs) of the EF hand type (elongation factor), while both Duox1 and Duox2 possess two sites of the EF hand type, which are characteristic of specific calcium-binding domains [17]. Moreover, except for Duox1 and Duox2 which possess an extra transmembrane domain with peroxidase activity, all of these homologs contain six transmembrane domains.

In stark contrast to the multienzyme complex of NADPH oxidase in mammals, plants only possess NOX5-like NOXs, which are also called respiratory burst oxidase homologs (RBOHs), even though multiple members exist in different species $[6,11,19]$. The typical NOXs all possess four conserved domains, namely NADPH_Ox (Pfam accession number PF08414), Ferric_reduct (PF01794), FAD_binding_8 (PF08022) and NAD_binding_6 domain (PF08022). At the same time, the distribution of amino acid residues in every domain is quite similar but not identical among the NOX/RBOH members [8]. However, further studies indicate some exceptions. The cytoplasm of tomato suspension culture cells contains protein components similar to animal p67phox and p40phox, which are activated by a fungal elicitor and can move to the plasmalemma and incorporate into the membrane cytoskeleton $[17,20]$. Furthermore, our recent research showed that some members have one more NADPH_Ox domain, such as TaNOX3 and TaNOX6 possessing two NADPH_Ox domains in wheat [8]. Besides the typical NOXs, some ferric reduction oxidases (FROs), which are considered as the isoforms of yeast FREs, were also found in high plants [6]. It was identified that FROs are closely related to typical plant NOXs but differences still exist: FROs contain six membrane-spanning domains, two hemes and conserved motifs involved in NADPH and FAD binding but lack NADPH_Ox domain and several calcium-binding EF-hand motifs that the typical NOX proteins possess $[10,19,21]$. Moreover, another new type of NOXs was put forward and assigned as NOX-likes, which have an NADPH_Ox domain but lack one or two other domains that typical NOXs possess [8].

\subsection{Complex Evolution History}

The typical NOX family, being identified only in terrestrial plants, underwent a complex evolution. According to our previous study, NOXs and FROs in plants can be divided into four well-conserved groups represented as NOX, FRO I, FRO II and FRO III, and an evolution model was constructed [7]. In this model, all FRO family members originated from a common ancestor which contains only the Ferric_reduct domain. During the evolutionary process, this ancestor obtained FAD_binding_8 and NAD_binding_6 domains first by gene fusion and duplication, and then clustered into FRO I, FRO II and FRO III subfamilies. FRO III mainly exists in fungi and FRO I, perceived as ancient NOX, mainly exists in animals and in two kinds of algae (rhodophytes and chlorophytes). After that, FRO I obtained another important domain-NADPH_Ox and converted into the typical NOXs in plants. FRO IIs exist both in chlorophytes and land plants but NOXs only exist in land plants. Clearly, the gene constructions become more and more complicated from FROs to NOXs over the course of evolution. In addition to domain gain and gene duplication, gene fusion as well as exon shuffling might also be involved in the evolution for biological diversity and functional divergence of the NOX gene family [7,22-25]. More recently, we found that TaFROs encoded by the genes located on Chr 1 are much closer to the typical TaNOXs in phylogenetics than those on Chr 2, and the TaFROs on Chr 2 might be more ancient forms of TaNOXs in wheat [8].

\section{NOXs/RBOHs in Plant Development}

The wide existence of NOXs/RBOHs in plants in some way indicates their great importance. Experiments from recent studies did show that NOXs/RBOHs play important and diverse roles in many areas including development regulation as well as the response to biotic and abiotic stresses and hormone signaling (Figure 1). 


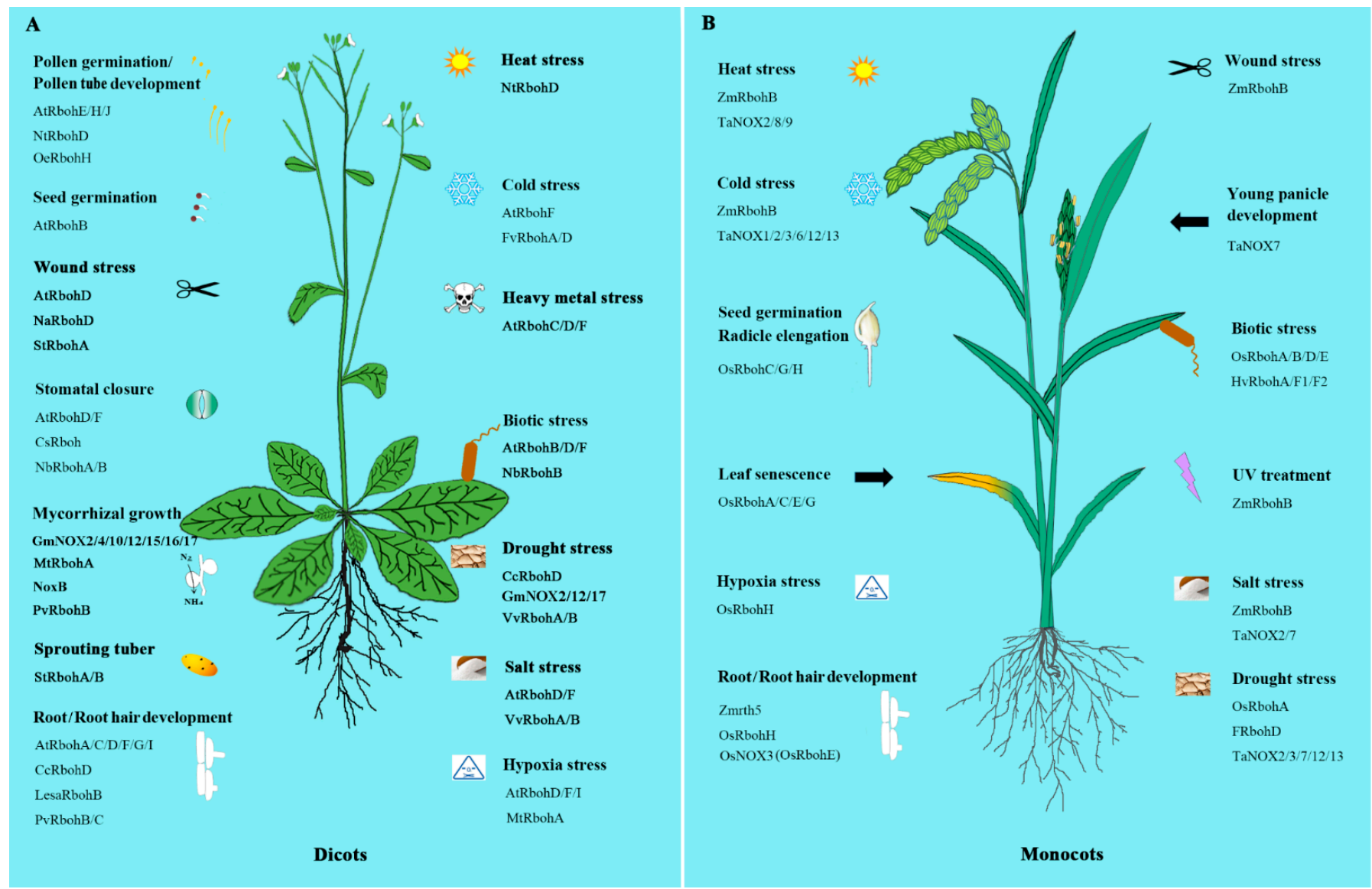

Figure 1. The involvement of NADPH oxidases/respiratory burst oxidase homologs (NOXs/RBOHs) in dicots and monocots. A. The NOXs/RBOHs in dicots. B. The NOXs/RBOHs in monocots. All the acronyms of Rbohs, NOXs, NoxB and rth5 represent the NOX/RBOH homologues from various species. Just as, AtRbohs represent the NOX/RBOH homologues from Arabidopsis thaliana, CsRbohs from Cucumis sativus, FRbohs from Festuca arundinacea, FvRbohs from Fragaria $x$ ananassa, GmRbohs from Glycine max, HvRbohs from Hordeum vulgare, LesaRbohs from Lepidium sativum, MtRbohs from Medicago truncatula, NaRbohs from Nicotiana attenuate, NbRbohs from Nicotiana benthamiana, NoxB from Fusarium oxysporum, NtRbohs from Nicotiana tabacum, OeRbohs from Olea europaea L, OsRbohs from Oryza sativa L, PvRbohs from Phaseolus vulgaris, StRbohs from Solanum tuberosum, TaNOXs from Triticum aestivum, VvRbohs from Vitis vinifera, ZmRbohs and Zmrth5 from Zea mays. Please refer to Supplementary Table S1 for the detailed information of NOXs/RBOHs in the supplementary data. 


\subsection{Pollen Germination and Pollen Tube Growth}

NOX enzyme, by producing ROS, is needed to sustain the normal rate of pollen tube growth and this is likely to be a general mechanism in the control of tip growth of polarized plant cells [26,27]. NOXs generate tip-localized, pulsating amounts of $\mathrm{H}_{2} \mathrm{O}_{2}$ that functions, possibly through $\mathrm{Ca}^{2+}$ channel activation, to maintain a steady, tip-focused $\mathrm{Ca}^{2+}$ gradient in pollen tube tip during growth [28]. On the other hand, pollen NOX can be activated by $\mathrm{Ca}^{2+}$ and $\mathrm{Ca}^{2+}$ can increase its activity in vivo [26,29]. This process would happen especially when the pollen grains are hydrated under mild conditions, so the activity of pollen NOX could be concentrated in those insoluble fractions, which could facilitate the exposure of tissues to ROS produced by this enzyme. It is worth mentioning that the extent of this exposure could differ among the plant families according to where the NOX resides in pollen grains and during hydration in the mucosa [30]. In addition, pollen NOX can also be activated by low abundant signaling phospholipids, such as phosphatidic acid (PA) and phosphatidylinositol 4, 5-bisphosphate in vitro and in vivo, so there is a possible synergism between $\mathrm{Ca}^{2+}$ and phospholipid-mediated NOX activation in pollen [29]. In plants, ROP/RAC GTPases (the subfamily of Rho-type GTPases, which belong to the Rat sarcoma superfamily of small GTP-binding proteins) are also necessary for normal pollen tube growth by regulating ROS production [29]. Besides these items mentioned above, $\mathrm{O}_{3}$ was also indicated to increase ragweed pollen allergenicity through stimulation of ROS-generating NADPH oxidase [31]. Recently, two NOXs/RBOHs, AtRbohH and AtRbohJ, have been shown to localize at the plasma membrane of pollen tube tip and the ROS production by the NOXs/RBOHs presumably plays a critical role in the positive feedback regulation that maintains the pollen tube tip growth [32,33]. Furthermore, apoplastic ROS derived from AtRbohH and AtRbohJ are involved in pollen tube elongation by affecting the cell wall metabolism [33]. More intriguing is that ectopic expressing of AtRbohC/hair root2 (hrd2) in pollen tubes could restore atrbohH and atrbohJ defects in tip growth of pollen tubes [34], which implies that AtRbohC/hrd2 also plays roles in regulating the development of pollen tubes. Moreover, AtRbohE was also suggested to be critical for programmed cell death (PCD) and pollen development in Arabidopsis thaliana L. [35]. Meanwhile, OeRbohH, possessing a high degree of identity with AtRbohH/J, plays an important role in pollen germination and pollen tube growth in olive [36]. Genetic interference with the temporal ROS pattern by manipulating NOX/RBOH genes, affected the timing of tapetal PCD (programmed cell death) and resulted in aborted male gametophytes [35]. All in all, we still cannot figure out how many factors are related to the regulation of pollen NOX. Nevertheless, what we already know is that pollen NOXs play a significant part in the regulation of pollen germination.

\subsection{Root and Root Hair Development}

The elongation of roots and root hairs is essential for uptake of minerals and water from the soil. $\mathrm{Ca}^{2+}$ influx from the extracellular store is required for cell elongation in roots [37]. It was suggested that plasma membrane NOXs/RBOHs and $\mathrm{H}^{+}$-ATPases $\left(\mathrm{a} \mathrm{H}^{+}\right.$pump by coupling with energy of ATP hydrolysis on plasma membranes) are functionally synchronized and they work cooperatively to maintain the membrane electrical balance while mediating plant cell growth through wall relaxation [38]. Observations on maize roots indicate that the activities of plasma membrane-associated NADPH oxidase respond both to gravity and to imposed centrifugal forces [39]. In an early study, AtRHD2, a NADPH oxidase in Arabidopsis, was reported as controlling root development by making ROS that regulates plant cell expansion through the activation of $\mathrm{Ca}^{2+}$ channels [40]. Further, both AtRbohC/RHD2 and ROP (RHO of plants) GTPases were found to be required for normal root hair growth by regulating ROS production [41]. Coincidentally, the maize (Zea mays L.) roothairless5 (rth5) which encodes a monocot-specific NADPH oxidase, was found to be responsible for establishing the high levels of ROS in the tips of growing root hairs [42]. In rice, OsNOX3 was also reported to play critical roles in root hair initiation and elongation by regulating the content of superoxide and hydrogen peroxide in root hair tips [27]. In addition, both AtRbohD and AtRbohF are essential for ABA (abscisic acid)-promoted ROS production in Arabidopsis roots, and ROS subsequently activate $\mathrm{Ca}^{2+}$ signaling 
as well as reduce auxin sensitivity of roots, thus positively regulating ABA-inhibited primary root growth [43]. Moreover, AtRbohD and AtRbohF negatively modulate lateral root development by changing the peroxidase activity and increasing the local generation of $\cdot \mathrm{O}_{2}{ }^{-}$in primary roots in an auxin-independent manner [44]. Similar results were also acquired in the legume-rhizobia symbiosis and legumes use different RBOHs for different stages of nodulation [45,46]. Moreover, nitric oxide (NO) can activate NADPH oxidase activity, resulting in increased generation of $\cdot \mathrm{O}_{2}{ }^{-}$, which subsequently induces growth of adventitious roots and acts downstream of auxin action in the process of root growth and development [47]. These results suggest a vital role of NOXs/RBOHs in root and root hair development in plants.

\subsection{Seed Germination}

NOXs/RBOHs also play important roles in seed germination. The functional mechanism has been proposed in many plant species, such as Arabidopsis thaliana L. rice (Oryza sativa L.) and barley (Hordeum vulgare L.). AtRbohB is a major producer of $\cdot \mathrm{O}_{2}{ }^{-}$in germinating seeds, and inhibition of the $\mathrm{O}_{2}{ }^{-}$production by diphenylene iodonium (DPI) leads to a delay in seed germination of Arabidopsis and cress [48]. In rice, OsNOX5, 7 and 9 might play crucial roles in radicle and root elongation during seed germination by regulating $\mathrm{ROS}$ production [49]. Similarly, $\cdot \mathrm{O}_{2}^{-}$produced by NADPH oxidase also regulates seed germination and seedling growth in barley [50,51]. Moreover, NOX/RBOH-mediated ROS production promotes gibberellic acid (GA) biosynthesis in barley embryos through regulation of HvKAO1 and HvGA3ox1 proteins, while GA induces and activates NOXs/RBOHs for ROS production in aleurone cells to induce $\alpha$-amylase activity of the cells and therefore increases seed germination $[5,52,53]$.

\subsection{Plant-Microorganism Ineractions}

Phaseolus vulgaris NADPH oxidase is crucial for successful rhizobial colonization and probably maintains proper infection thread growth and shape [54]. Moreover, it also has critical roles in reducing arbuscular mycorrhizal fungal (AMF) colonization. Overexpression of PvRbohB augments nodule efficiency by enhancing nitrogen fixation and delaying nodule senescence but impairs AMF colonization [55]. A Medicago truncatula NADPH oxidase, MtRbohA, has similar effects. It is significantly upregulated in Sinorhizobium meliloti-induced symbiotic nodules, while hypoxia prevailing in the nodule-fixing zone may stimulate MtRbohA expression, which would, in turn, lead to the regulation of nodule functioning [56]. Moreover, NoxA, a NADPH oxidase isoform in the grass endosymbiont Epichloë festucae, was identified as essential for the establishment of systemic compatible infections in host plants [50]. ROS produced by NoxA or NoxB (from Fusarium oxysporum) regulate hyphal growth of a fungal pathogen towards roots of the host plants to maintain a mutualistic and symbiotic interaction [57,58]. Recently, four GmNOXs from soybean genome (Glycine max) also showed strong expression in nodules, pointing to their probable involvement in nodulation [59]. All these results suggest that, NOXs/RBOHs, regulated by several different factors, play a significant role in mutualistic and symbiotic processes between plant and microorganism.

\subsection{Fungal Development}

When it comes to fungi, NOXs/RBOHs participate in a wide range of biological processes from their growth, differentiation and reproduction, to rhizobial colonization. In Aspergillus nidulans, NoxA plays crucial roles in fungal physiology and differentiation by generating ROS [60]. Moreover, genetic analysis of $\triangle$ nox 2 (lacking the NADPH oxidase 2 gene), $\triangle$ nox 1 (lacking the NADPH oxidase 1 gene) and a transcription factor deletion mutant $\Delta$ ste 12 in Sordaria macrospora, reveals that the mutation of NOXs could lead to ascospore germination defect [61]. In yeast, NoxA, NoxB and their associated regulators (BemA, Cdc24 and NoxR) have distinct or overlapping functions for the regulation of different hyphal morphogenesis processes [57]. Furthermore, in Neurospora crassa, NOX-1 elimination results in complete female sterility, decreased asexual development and reduced hyphal growth; 
whereas, a lack of NOX-2 does not affect any of these processes but led to the production of sexual spores that failed to germinate [62]. In this study, the function of NOX-generated ROS acting as critical cell differentiation signals highlights a novel role for ROS in the regulation of fungal growth [62]. The function of NOX-generated ROS in regulating the reproductive process was also found in other fungi. In Botrytis cinerea, NOX complexes are essential for conidial anastomosis tubes' formation and fusion [63].

\subsection{Other Aspects}

Besides functioning in the regulation of pollen germination, root development and seed germination, as well as fungal development, NOXs/RBOHs have other effects as well. It was suggested that solar ultraviolet irradiation regulates anthocyanin synthesis in apple peel by modulating the production of ROS via NADPH oxidase [64]. Moreover, chloroplastic NADPH oxidase-like activity mediates perpetual $\mathrm{H}_{2} \mathrm{O}_{2}$ generation, which probably induces apoptotic-like cell death of B. napus leaf protoplasts [65]. Furthermore, it was reported that among the seven homologues of NADPH oxidases in potato, the expression of $S t R b o h A$ and $S t R b o h B$ was detected in particular when dormancy break [66]. These results suggest very extensive roles of NOXs/RBOHs in the plant kingdom, participating in various important biological processes.

\section{NOXs/RBOHs in Stress Tolerance}

\subsection{Roles in Plant Immunity}

In the traditional sense, biotic stress response works as plant immunity. Besides the external barriers of the plant cell wall, the innate immune system of plants plays an indispensable role in plant immunity under biotic stresses. There are two layers of plant immune recognition. The first layer of innate immunity is initiated by the perception of pathogen-associated molecular patterns (PAMPs) by the surface-localized pattern recognition receptors (PRRs), leading to PTI (PAMP-triggered immunity) [67]. As many pathogens have acquired the ability to inject virulence effector proteins into host cells to achieve more effective infection, the second layer of plant immune recognition that involves intracellular immune receptors forms. The intracellular immune receptors that are most often the nucleotide-binding domain and NLR (leucine-rich repeat containing receptor) proteins can recognize those effectors and elicit a second layer of defense, defined as ETI (effector-triggered immunity) [68]. Correlational studies are mostly carried out in Arabidopsis, tobacco and rice.

It was reported that Arabidopsis AtRbohD and AtRbohF gene expressions are differentially modulated by PAMPs, which contributes to fine-tune NOX/RBOH-dependent ROS production and signaling in Arabidopsis immunity [69]. Moreover, AtRbohD exists in complex with the receptor kinases ELONGATION FACTOR-TU RECEPTOR (EFR) and FLAGELLIN SENSING 2 (FLS2), which are the PRRs for bacterial EF-Tu and flagellin, respectively. The plasma-membrane-associated kinase Botrytis-induced kinase1 (BIK1), which is a direct substrate of the PRR complex, directly interacts with and phosphorylates RbohD upon PAMP perception [70]. It was also reported that AtRbohD triggers death in cells damaged by fungal infection but simultaneously inhibits death in neighboring cells through the suppression of free SA (salicylic acid) and ET (ethylene) levels [71]. In addition, AtRbohF appears to be a key player not only in HR (hypersensitive type of resistance) -related cell death but also in regulating metabolomic responses and resistance [72,73]. RbohD-dependent ROS accumulation stimulates autophagosome formation and limits HR-related cell death [72,73]. A double mutant of atrbohf and atrbohd resulted in an almost complete loss of resistance to AG8 (a pathogenic bacterium), while single NADPH oxidase mutant had no such effect, suggesting that AtRbohs may correlate and function together in the resistance to some pathogens [74]. Furthermore, overexpressed StRbohA, a potato NADPH oxidase, in Arabidopsis enhances the ROS-mediated defense mechanisms [75]. Transient and stable expression of a DN (a dominant negative form) of the Arabidopsis AtRop1 in 
potato reduces pathogen development, which is associated with increased NOX/RBOH-mediated $\mathrm{H}_{2} \mathrm{O}_{2}$ production and JA (jasmonate) signaling [76].

In tobacco, Nicotiana benthamiana L. NbRbohB is responsible for both the transient PTI ROS burst and the robust ETI ROS burst. It is worth mentioning that MAPKs are involved in the ETI ROS burst by transactivation of NbRbohB, but not in the PTI ROS burst [77]. However, the potato $\mathrm{NtRbohD-mediated} \mathrm{H}_{2} \mathrm{O}_{2}$ production does not seem determinant for either hypersensitive response development or the establishment of acquired resistance but it is most likely involved in the signaling pathways associated with the protection of the plant cells [78,79]. In rice, OsRbohA and OsRbohE were reported as participating in ROS-dependent immune responses [80]. In addition, inoculation of rice with Xanthomonas oryzae pv. oryzae (Xoo) strain PXO99 can improve the expression levels of two rice NOX genes, OsRbohA and OsRbohB, further suggesting that the NOX/RBOH genes take part in plant immunity [68]. Moreover, rice blast disease initiated by pathogen invasion needs NADPH oxidase to produce $\cdot \mathrm{O}_{2}{ }^{-}$[81]. In barley, it was reported that $\mathrm{HvRbohF2}$ plays an important role in penetration resistance to Blumeria graminis $\mathrm{f}$. sp. hordei and the control of leaf cell death [82], while HvRbohA facilitates cellular accessibility to the fungus [83]. All these results further suggest the importance of NOXs/RBOHs in plant immunity.

NOXs/RBOHs also function in elicitor-induced and pathogen-induced stomatal closure [84,85]. The bacterial pathogen Pseudomonas syringae pv. tomato synthesizes the polyketide toxin coronatine, which inhibits stomatal closure by MAMPs (microbe-associated molecular patterns) and by ABA. In this process, inhibition of NOX/RBOH-dependent ROS synthesis in guard cells plays an important role [86]. Several studies further indicate that the addition of ATP can trigger ROS production in an RbohD-dependent manner and lead to the rapid closure of leaf stomata in response to bacterial pathogen infections [85,87-90]. In addition, NOX-dependent ROS synthesis by pathogen helps the pathogen infect plants $[81,91]$ and a coordinated balance of generating, sensing and detoxification of ROS serves a key role in pathogen colonization and fungal virulence $[86,92,93]$. NOXs/RBOHs also positively regulate Rhizobium infection and its release into the nodule cells [94,95]. These results suggest that NOXs/RBOHs play vital roles in both response to the invasion of pathogen and facilitation of Rhizobium infection in plants.

\subsection{Roles in Abiotic Stress Tolerance}

NOXs/RBOHs also widely participate in the responses of plants to a number of abiotic stresses, which include salt, hypoxia, heavy metals, drought, wounding and extreme temperature stresses, and play a fundamental role in the stress tolerance.

\subsubsection{Salinity Stress}

Salinity stress, which induces both ionic and osmotic damages, seriously impairs plant growth, ions uptake and yield production [96]. Plants are equipped with a series of defense responses against salinity stress, such as regulation of ion transport including $\mathrm{Na}^{+}$and $\mathrm{K}^{+}$, accumulation of compatible solutes and expression of stress-related genes $[96,97]$. Maintaining cellular $\mathrm{Na}^{+} / \mathrm{K}_{+}$homeostasis is pivotal for plant survival in saline environments. By comparing the Arabidopsis double mutants atrbohD1/F1 and atrbohD2/F2 with wild-type and the single null mutant atrbohD1 and atrbohF1 plants in response to $\mathrm{NaCl}$ treatments, Ma et al. [98] proposed that ROS produced by both AtRbohD and AtRbohF function as signal molecules to regulate $\mathrm{Na}^{+} / \mathrm{K}_{+}$homeostasis, thus improving the salt tolerance of the plant. In addition, the double mutants were shown to be more sensitive to salt and less efficient for $\mathrm{K}_{+}$selective uptake [99]. The early $\mathrm{H}_{2} \mathrm{O}_{2}$ generation by the NOXs under salt stress could be the beginning of a reaction cascade that triggers the antioxidant response in plants to overcome the subsequent ROS production, thereby mitigating the salt stress-derived injuries. Further, it was identified that expression of $A t R b o h D$ and $A t R b o h F$ are highly induced under salinity stress, and AtRbohF plays a role in the regulation of xylem loading of $\mathrm{Na}^{+}$to protect leaves from salinity stress in Arabidopsis [96]. In addition, it was suggested that salinity-induced elevation of $\left[\mathrm{Ca}^{2+}\right]_{\mathrm{cyt}}$ 
corresponds to the plasma membrane (PM) $\mathrm{Ca}^{2+}$ influx, as well as $\mathrm{Ca}^{2+}$ release from intracellular $\mathrm{Ca}^{2+}$ stores plays important roles in ROS signaling and salt tolerance. Moreover, salinity-induced $\mathrm{Na}^{+}$accumulation in the cytosol triggers $\left[\mathrm{Ca}^{2+}\right]_{\text {cyt }}$ elevation, leading to activation of NOXs/RBOHs and apoplastic $\mathrm{H}_{2} \mathrm{O}_{2}$ accumulation [96]. AtRbohs contributing to $\mathrm{H}_{2} \mathrm{O}_{2}$ production in response to $\mathrm{NaCl}$ or mannitol stress can also increase proline accumulation in plants [100]. In addition, mild salt stress $(10 \mathrm{mM} \mathrm{NaCl})$ stimulates biphasic increases in AtRbohD expression and ROS production, whereas, in the increased tolerance to $\mathrm{NaCl1}$ (itn1) mutant, $A t R b o h D$ expression is suppressed, which is accompanied by a corresponding reduction in ROS accumulation under salt stress [101,102], suggesting that ITN1 may negatively regulate AtRbohD-dependent ROS production to balance the function of ROS. Moreover, AtRbohD-dependent ROS production transmits long-distance signals in salt stress [103] and may play a role in regulating rapid systemic acquired acclimation (SAA) or systemic response caused by abiotic stresses $[102,104]$.

There are also some studies carried out in other plant species. In a living cell of spinach (Spinacia oleracea L.) leaf, a large quantity of ROS could be produced by NOXs/RBOHs in epidermic tissue under bisulfite stress [105]. Moreover, it was suggested that pumpkin-grafted cucumber plants increase their salt tolerance via a mechanism involving the root-sourced NOX/RBOH-dependent $\mathrm{H}_{2} \mathrm{O}_{2}$ production, which enhances $\mathrm{Na}^{+}$exclusion from the root and promotes an early stomatal closure [106]. NaCl-induced ROS production can also be decreased by the introduction of a NADPH oxidase in Torulopsis glabrata, resulting in a significant increase in growth under hyperosmotic stress conditions [107]. Similarly, ROS-generating activity of $\mathrm{NOXs/RBOHs}$ is negatively affected by $\mathrm{NaCl}$ in maize [108]. All the results address the significant role of NOXs/RBOHs in salt stress defense of plants.

\subsubsection{Hypoxic Stress}

Submergence has an adverse effect on internal oxygen availability, sugar status and survival. Plants suffer from oxygen deficiency (hypoxia) and energy starvation under flooding conditions. Higher plants have evolved complex adaptive mechanisms to flooding that are induced by changes in the cellular redox state and phytohormones [109]. It was reported that the transcript levels of five Arabidopsis $R B O H$ genes (AtRbohA, B, D, G and I) are increased under hypoxia and the transcript levels of $A t R b o h D$ are significantly increased, in particular at an early stage in the hypoxia response; meanwhile, ethylene modulates $\mathrm{H}_{2} \mathrm{O}_{2}$ signaling via regulation of the expression of the NOX/RBOH genes in the hypoxia pathway [110]. A more recent study further explained the role of NOXs/RBOHs in hypoxia response [111]. The expression of AtRbohI can also be increased by hypoxia, and AtRbohI could regulate the expression of genes involved in ethylene biosynthesis and downstream of hypoxia signaling [109]. In rice, the differential transcriptional expression of $N O X / R B O H$ genes was also observed under submergence. The regulation of OsRbohs expression and ROS production maintaining a homeostasis are helpful to rice seedlings facing different levels of submergence [112]. For example, OsRbohH expression under oxygen-deficient conditions is greater in cortical cells than in cells of other root tissues. In addition, the ROS production by OsRbohH, which is induced by CDPK5 and/or CDPK13, is essential for ethylene-induced aerenchyma formation in rice roots under oxygen-deficient conditions [113].

\subsubsection{Heavy Metal Stress}

Cadmium $(\mathrm{Cd})$, lead $(\mathrm{Pb})$, nickel $(\mathrm{Ni})$ and arsenic $(\mathrm{As})$ are the main environmental pollutants that can cause a great increase in ROS production of plants. Under Cd stress, several NOXs/RBOHs differentially regulate ROS metabolism, redox homeostasis and nutrient balance in Arabidopsis thaliana [114]. Similar results were reported in other studies. Seedlings of pea (Pisum sativum L.) treated with $\mathrm{Cd}\left(\mathrm{NO}_{3}\right)_{2}$ show a growth reduction in all organs, and the activities of NADPH oxidase are increased in root protein extracts [115]. In sunflower leaves, $\mathrm{Cd}$ treatment can regulate NADPH oxidase activity and the putative NOX/RBOH gene expression [116]. Moreover, NADPH oxidase responding to $\mathrm{Cd}$ stress might be involved by affecting the activity of $\mathrm{PM} \mathrm{H}^{+}$-ATPase (a protein localized 
in the PM that can produce a proton-motive force) [117]. A further study indicates that $\mathrm{H}^{+}$-ATPase and NADPH oxidase are key factors in activation of some elements of the brassinosteroid (BR)-induced pathway under $\mathrm{Cd}$ stress [118]. $\mathrm{Pb}$ and $\mathrm{Ni}$ have also been reported to have the ability to stimulate oxidative burst in plants. In Vicia faba L. roots, $\mathrm{Pb}$ treatment could trigger a rapid and dose-dependent increase in ROS production by NOX-like enzyme [119]. Ni induces ROS production in wheat roots and $\mathrm{Ca}^{2+}$ may be involved in the NADPH oxidase-mediated ROS production under Ni stress [120]. In addition, NOXs are also involved in the response of plants to As toxicity. Arsenic can induce the uptake and translocation of $\mathrm{P}, \mathrm{S}, \mathrm{Cu}, \mathrm{Zn}$ and $\mathrm{Fe}$ in the wild-type plants, while the AtRbohC-deficient plants show quite lower uptake levels of the nutrient elements such as $\mathrm{Zn}, \mathrm{Fe}, \mathrm{Cu}, \mathrm{P}$ and $\mathrm{S}$ but higher uptake levels of K, suggesting that NADPH oxidase could be critical in regulating the transport and translocation of As and macro/micronutrients [121].

\subsubsection{Wound Response}

A little early study in tomato (Solanum lycopersicum L.) shows that the NOX/RBOH-supplied ROS intermediates the wound response of the plant [122]. After that, a potato NADPH oxidase gene, StRbohA, was found to be responsible for the wound-induced oxidative burst in potato tubers. Loss of its expression increases the susceptibility to microbial infection and contributes to the age-induced loss of wound-healing ability [123]. In Arabidopsis, AtRbohD is required for efficient local and systemic wound-induced ROS production [103]. Moreover, it was indicated that the transcripts of NaRbohD in Nicotiana attenuata are rapidly and transiently elicited by wounding, and are amplified when Manduca sexta oral secretions are added to the wounds, suggesting that NaRbohD-based defenses play an important role in late herbivore-elicited responses of a plant [124].

\subsubsection{Temperature Response}

Many studies have reported that NOXs/RBOHs could respond to cold stress or high temperature. In maize, the activity of NADPH oxidase was found to be increased after $2 \mathrm{~h}$ of cooling of seedlings but reversed to the control level after $24 \mathrm{~h}$ of cooling [125]. In Arabidopsis, low-temperature treatment can induce expression of the AtSRC2 gene in roots, which is in proportion to the levels of ROS produced partially by AtRbohF. AtSRC2 is an activator of $\mathrm{Ca}^{2+}$-dependent AtRbohF-mediated ROS production and may play a role in cold responses [126]. Similarly, a recent study proposed that the expression levels of FvRbohA and FvRbohD in strawberry are quickly induced by cold, followed by an increase in NADPH oxidase activity [127]. Conversely, at high temperature $\left(30^{\circ} \mathrm{C}\right)$, the total NADPH oxidase activity and NtRbohD expression are all suppressed in tobacco mosaic virus (TMV)-inoculated leaves of tobacco, which resulted in less ROS production and enhanced susceptibility to pathogen and suppression of HR-type necrosis [128,129].

\subsubsection{Drought Stress}

It was indicated that NADPH oxidase is involved in the ABA-induced production of ROS in maize. When the maize seedlings were subjected to water stress, ABA was accumulated and then triggered the NOX/RBOH-mediated ROS production, resulting in the induction of antioxidant defense systems against oxidative damage in the plants [130]. In rice, drought can induce the total activity of NADPH oxidases [131]. Further, it was found that the transcript of OsRbohA was stimulated by drought, ablation of OsRbohA impairs the tolerance of plants to various water stresses, whereas its overexpression enhances the tolerance [21]. However, more recently, a study showed that the transcription level of a NADPH oxidase gene, $F R b o h D$, and content of $\mathrm{H}_{2} \mathrm{O}_{2}$ are increased in a drought-sensitive cultivar of fescue (Festuca arundinacea Schreb) under drought, but lower levels of $F R b o h D$ transcription and $\mathrm{H}_{2} \mathrm{O}_{2}$ concentration in leaves might contribute to drought stress tolerance for a drought-tolerant cultivar [132]. These results suggest critical roles of $\mathrm{NOXs} / \mathrm{RBOHs}$ in plant drought tolerance and enhanced expression of the protein genes by bioengineering approaches may improve the stress tolerance. 


\subsubsection{Hormonal Response}

As a kind of stress-responsive protein, the functional characteristics of NADPH oxidase in plants under a number of phytohormonal treatments have been widely investigated. For example, NADPH oxidase activity of plants could be stimulated by the active auxins 2,4-dichlorophenoxyacetic acid (2,4-D), indole-3-acetic acid (IAA) and $\alpha$-naphthaleneacetic acid ( $\alpha$-NAA) [133], while the activity is unaffected by benzoic acid and the inactive auxin analogs 2,3-dichlorophenoxyacetic acid (2,3-D) and $\beta$-naphthaleneacetic acid ( $\beta$-NAA) [134], suggesting the plant NOXs are auxin-responsive. According to our recent study, the Arabidopsis NOX/RBOH genes, AtRbohB and $A t R b o h D$, are strongly upregulated by methyl jasmonate (MeJA) treatments but markedly downregulated by ABA, zeatin and IAA treatments; whereas, almost all the rice NOX genes exhibit great upregulation under hormonal treatments such as ABA, MeJA and salicylic acid (SA) [7]. In pear, the transcription of most PbRbohs could also be regulated by ABA, MeJA and SA treatments [135]. Then, the relationships between ABA level, ROS generation as well as $N O X / R B O H$ gene expression in senescing leaves of rice are further clarified, in which OsNox2, OsNox5, OsNox6 and OsNox7 are probably involved in the ABA-induced $\cdot \mathrm{O}_{2}{ }^{-}$generation in the initial stage of leaf senescence. Conversely, OsNox1, OsNox3 and OsFRO7 are not associated with ABA-induced $\cdot \mathrm{O}_{2}{ }^{-}$generation during leaf senescence [136]. In another study, ABA was suggested to induce the rapid accumulation of ROS via NOXs/RBOHs in suspension culture cells of tobacco, and NOXs/RBOHs and $\mathrm{H}_{2} \mathrm{O}_{2}$ appear to be important components in the ABA signal transduction pathway in plants [137]. Moreover, treatment with ABA significantly increases the activity of NADPH oxidase and a crosstalk between $\mathrm{Ca}^{2+}$ and ROS originated from NOXs leads to the induction of antioxidant enzyme activity in maize [138]. NOXs/RBOHs were also reported to have the responsibility to react to ethephon. According to the study, ethephon-mediated leaf senescence, $\mathrm{H}_{2} \mathrm{O}_{2}$ elevation and senescence-associated gene expression are all alleviated by NADPH oxidase inhibitor DPI and reduced glutathione, suggesting that ROS generated from NOXs/RBOHs likely serves as an oxidative stress signal participating in ethephon signaling [139]. The rapid and pronounced responses of NOXs/RBOHs to hormonal treatments, conferred their wide but powerful roles for multi-stress tolerance of plants.

\section{Regulations of NOXs/RBOHs in Plants}

\subsection{Transcriptional Regulation}

It is well known that transcriptional regulation is a fundamental mechanism in all cellular systems. It is mediated by interaction between transcription factors (TFs) and specific cis-acting regulatory elements (CAREs) of the promoter sequence from target genes. We have systemically analyzed the cis-elements in the promoters from the members of the whole NOX/RBOH gene family in Arabidopsis, rice and wheat, and elaborately constructed their tissue and inducible expression profiles $[7,8]$. Analysis for the cis-regulatory elements shows that there are more than 30 stress or hormone responsive elements in the $N O X / R B O H$ gene promoters randomly distributing in the promoter sequences, suggesting different expression regulatory patterns of the $\mathrm{NOX} / \mathrm{RBOH}$ genes. The unique tissue- or development-specific expression patterns, diverse inducible expression profiles and distinct promoter activities $[7,8,19]$ further indicate the complex spatio-temporal transcriptional regulations between the $N O X / R B O H$ family gene members under different circumstances. Another study also identified many cis-elements in Arabidopsis and rice $\mathrm{NOX} / \mathrm{RBOH}$ gene promoters, which have different response behaviors to various life regimes such as oxidative stress, increased calcium, hormones application as well as cellular differentiation and growth [140]. In addition, a range of cis-elements responsible for different kinds of ROS have been dissected in Arabidopsis using microarray expression data which can be grouped into two categories: common ROS-related and ROS-specific cis-elements [141,142]. Common ROS-related elements involve GCN4_motif, TATCCAT/C_motif and G-Box, while W-box is one of the main ROS-specific elements. GCN4_motif may play a role in reproductive growth and development, while TATCCAT/C_motif may function under starvation. G-Box and other motifs such as ABRE (the ABA-responsive element), TGA-element (the auxin-responsive element), ERE and GCC-box (the ethylene-responsive elements), 
GARE-motif, P-box and TATC-motif (the GA-responsive elements), CGTCA-motif and TGACG-motif (the JA-responsive elements) as well as TCA element (the SA-responsive element) are also widely distributed in $\mathrm{NOX} / \mathrm{RBOH}$ family genes which are involved in hormone signaling, responses to light and other biological processes, including biotic and abiotic stresses, leaf senescence, and seed development [140]. W-box, as one of the main ROS-specific elements, mainly functions in pathogen responses by binding with WRKY (a protein that binds preferentially to W box (TTGACC/T) on the sequence of promoters) transcriptional factors. It has been reported that MAPKs are instrumental for transcriptional reprogramming by directly or indirectly controlling the activity of transcription factors following PAMP perception [143-145]. For example, WRKY8 is phosphorylated by MAPKs, and then binds to the $\mathrm{W}$-box in the $N b R b o h B$ gene promoter to positively regulate the expression of $N b R b o h B$ in Nicotiana benthamiana. The promoter analysis of StRbohC, a tobacco NbRbohB ortholog, shows that W-box cis-element regulates the gene expression [146]. Consistently, Yoshioka et al. [77] reported that W-box in NbRbohB promoter is the target sequence of WRKY transcription factors. Further research showed that the transcriptional activity of WRKY8 is dependent on SIPK and WIPK (SIPK, salicylic acid-induced protein kinase; WIPK, wound-induced protein kinase) by phosphorylation. The phosphorylated WRKY8 increases its DNA transcriptional activation and binds to the W-box sequence [147]. Together, these results imply that MAPKs-mediated phosphorylation of WRKYs perhaps is a general matter endowing the transcriptional activation of WRKYs to bind to and regulate the expression of $N O X / R B O H$ genes, and the conserved W-box cis-element in the sequence of their promoters serves as a scaffold linking WRKYs.

\subsection{Activity Regulation}

A large number of studies have shown that the functions of NOXs/RBOHs in plants are regulated by lots of signaling particles including $\mathrm{Ca}^{2+}$, receptor-like protein kinases (RLKs), receptor-like cytoplasmic kinases (RLCKs), calcium-dependent protein kinases (CDPKs) [70,148,149], BIK1 [70], mitogen-activated protein kinase (MAPK) cascades [149-152], open stomata 1 (OST1) [153], POP/RAC small GTPases [154,155] and hormones (like ABA and ET). It is obvious that the activity regulation of NOXs/RBOHs is multiple and complex, being in the center of many important signal transduction pathways of plants.

\subsection{1. $\mathrm{Ca}^{2+}$-Regulated Protein Kinases-Mediated Regulation}

$\mathrm{Ca}^{2+}$ has long been recognized as an essential and conserved secondary messenger in plants, contributing to signaling transduction. According to recent studies, $\mathrm{Ca}^{2+}$ exerts important functions in the process of NOX/RBOH-mediated signaling in plants. Plant NOXs/RBOHs usually have two or more EF-hand motifs in the hydrophilic N-terminal regions, suggesting that their activation is dependent on $\mathrm{Ca}^{2+}$. In rice, a structural and biochemical analysis not only verified the fact but further figured out that $\mathrm{Ca}^{2+}$ only binds directly to the first but not the second EF-hand motif that OsRbohB possesses [156]. Therefore, a certain concentration of $\mathrm{Ca}^{2+}$ in the cytoplasm is a prerequisite for the activation of NOXs/RBOHs. In addition, $\mathrm{Ca}^{2+}$ binding can also activate CDPKs to phosphorylate OsRbohB for ROS production [157]. In turn, ROS generated at the plasma membrane are presumably released into the apoplastic spaces, where the resultant $\operatorname{ROS}\left(\mathrm{H}_{2} \mathrm{O}_{2}\right)$ then activate the hyperpolarization-activated $\mathrm{Ca}^{2+}$ channels to facilitate $\mathrm{Ca}^{2+}$ influx causing the second $\mathrm{Ca}^{2+}$ elevation in the cytosol [41,157-159]. Therefore, there is a circulatory pathway of positive regulation of NOXs/RBOHs for ROS generation during polar cell growth or hypoxia response. The OsRbohB-dependent ROS production is necessary for $\mathrm{Ca}^{2+}$ influx, and then the induced ROS in turn may trigger $\mathrm{Ca}^{2+}$ efflux from intracellular $\mathrm{Ca}^{2+}$ stores in vivo. Similar results were also obtained in other studies $[160,161]$. These results showed that $\mathrm{H}_{2} \mathrm{O}_{2}$-mediated plasma membrane $\mathrm{Ca}^{2+}$ influx perhaps is a general mechanism for maintaining intracellular $\mathrm{Ca}^{2+}$ dynamic balance and laying a certain molecular foundation for the activation of NOXs/RBOHs. 
Studies performed on other plant species also demonstrate that $\mathrm{Ca}^{2+}$ and its regulated protein kinases could activate NOXs/RBOHs and regulate ROS accumulation in plants. For instance, NADPH oxidase from tomato and tobacco can be activated by adding $\mathrm{Ca}^{2+}$ in vitro, suggesting that elicitor-induced ROS production by plant NOXs/RBOHs might be dependent on $\mathrm{Ca}^{2+}$ [162]. RbohC/RHD2 is required for $\mathrm{Ca}^{2+}$ influx via the stimulation of $\mathrm{Ca}^{2+}$ channels and for the generation of a tip-focused gradient of cytosolic free calcium $\left[\mathrm{Ca}^{2+}\right]_{\text {cyt }}$ in root hairs of Arabidopsis, which is essential for polar growth [41]. In addition, another study shows that the conformational change conducted by $\mathrm{Ca}^{2+}$ binding to the EF-hand region and direct phosphorylation of AtrbohD synergistically activate its ROS producing activity [158]. As the primary $\mathrm{Ca}^{2+}$-regulated kinases, CDPKs become the focus for dissecting the activity and phosphorylation of NOXs/RBOHs. Increasing evidence shows that AtCDPK4, AtCDPK5, AtCDPK6 and AtCDPK11 are the positive regulators of AtRbohD under flg22 treatment [148]. Among these CDPKs, AtCDPK5 was found to be involved in the phosphorylation of Ser39, Ser148, Ser163 and Ser347 of AtRbohD [79]. Similar studies were also carried out in tomato, tobacco and potato, suggesting that phosphorylation regulation of NOXs/RBOHs in a CDPK-dependent pattern widely exists in various species $[156,163,164]$. Intriguingly, CDPKs perhaps also play negative roles in the regulation of NOXs/RBOHs activity. For example, OsCPK12 (also, namely, OsCDPK9) promotes the tolerance of rice to salt stress by reducing the accumulation of ROS. At the same time, overexpression of OsCPK12 repressed the expression level of OsRbohI $[165,166]$. Therefore, $\mathrm{Ca}^{2+}$ and CDPKs may regulate the activity of $\mathrm{NOX} / \mathrm{RBOH}$ respectively or synergistically.

In addition to $C D P K / C P K$, there is another $\mathrm{Ca}^{2+}$-regulated kinase represented by calcineurin B-like (CBL)-interacting protein kinases (CIPKs), which becomes activated upon interaction with CBL $\mathrm{Ca}^{2+}$ sensor proteins $[167,168]$. Recent studies demonstrate that tomato CIPK6 interacts with CBL10 and its in vitro activity is enhanced in the presence of CBL10 and $\mathrm{Ca}^{2+}$. CBL10 and CIPK6 contribute to ROS generation by direct phosphorylation of NbRbohB during ETI [169]. In Arabidopsis, CIPK26 specifically interacts with the plasma membrane-localized $\mathrm{Ca}^{2+}$ sensors, CBL1 and CBL9, and they work together to phosphorylate the N-terminus of AtRbohF for ROS production [170]. Moreover, many studies have shown that CBL-CIPK complexes contribute to the tolerance of plants to various abiotic stresses such as salt, cold and drought [171-173]. However, although the activation mechanisms for AtRbohD and AtRbohF are similar, AtRbohD has significantly greater ROS-producing activity than AtRhohF [174], implying their functional diversity, at least in part. A further study shows that protein phosphorylation is a prerequisite for $\mathrm{Ca}^{2+}$-dependent activation of the NOXs/RBOHs, and so NOX/RBOH phosphorylation is the initial trigger for the plant $\mathrm{Ca}^{2+}$-ROS signaling network [174]. These results identify an interconnection between CBL-CIPK-mediated $\mathrm{Ca}^{2+}$ and ROS signaling in plants, and $\mathrm{Ca}^{2+}$-binding and phosphorylation mediated by CDPK/CIPK synergistically activate the ROS-producing enzyme activity of NOXs/RBOHs in the $\mathrm{Ca}^{2+}$-regulated signaling pathway.

\subsubsection{RLKs and RLCKs-Mediated Regulation}

Receptor-like kinases (RLKs) belong to a very large protein family with crucial roles in plant growth control, development regulation, cellular signal recognition and transduction. The typical RLKs include three major domains: an extracellular domain, a transmembrane domain, and an intracellular kinase domain; receptor-like cytoplasmic kinases (RLCKs) only possess a cytoplasmic kinase domain $[175,176]$. Interestingly, it becomes increasingly clear that RLKs are key PRRs for recognition of PAMPs, and the RLCKs often associate with RLKs functionally and physically to relay intracellular signaling via trans-phosphorylation events [177]. Many studies have shown that some RLKs and/or RLCKs can interact with NOXs/RBOHs directly or indirectly and phosphorylate the proteins for transmitting pathogen signals during plant immunity $[178,179]$. The major signaling pathways are also been summarized in Figures 2-4.

It was reported that botrytis-induced kinase1 (BIK1), a protein of the RLCKVII subfamily member, can directly bind to multiple RLKs/PRRs in the resting state, such as flagellin sensing 2 (FLS2), elongation factor-Tu receptor (EFR) and PEP (Phosphoenolpyruvic acid) 1 receptor (PEPR1/2), which recognize 
a conserved 22 amino acid peptide of bacterial flagellin (flg22), a conserved N-terminal peptide sequence of the bacterial elongation factor-Tu (termed elf18 or elf26), and the endogenous AtPep1 (an endocrine peptide), respectively [180-182]. These RLKs all associate with the regulatory LRR-receptor kinase, BRI1-associated receptor kinase 1 (BAK1) (also known as SERK3). AtRbohD-dependent ROS production in response to flg22 or elf18 is abolished in fls2 or efr mutants [183], implying that FLS2/EFR is required for the ROS production from AtRbohD during plant response to flg22/elf18. Two other RLKs, PEPR1 and PEPR2 (belong to the membrane-localized receptor kinases), coupling with the shared receptor LRR-RK BAK1 in a pH-dependent manner, can act as receptors of AtPeps, a kind of endogenous peptide. AtPeps can elicite immune responses similar to those induced by pathogens [184]. Arabidopsis chitin-elicitor receptor kinase1 (CERK1), which is independent of BAK1 or related molecules [185], directly binds chitin through its LysM domain by homodimerization [186]. Actually, OsCERK1 not only participates in the activation of NOXs/RBOHs during chitin-induced immunity $[185,187]$ but also in the activation during bacterial peptidoglycan (PGN)-induced immunity. In addition, other RLK members, like malectin-like receptor kinase FERONIA (FER) and ANX1/2 (ANXURs), are also involved in plant immunity, while functioning in other biological processes such as development and reproduction [188]. FER promotes the association of FLS2 and BAK1 in response to flg22 and elf18 treatments, while ANX1 and possibly ANX2 negatively regulate PTI by putatively competing with FLS2 for interaction with BAK1 $[189,190]$. That is to say, FER and ANX1 regulate FLS2-BAK1 complex formation in opposite ways. Together, FLS2, EFR, PEPR1/2, FER, ANXs and CERK1 are the upstream PRRs participating in the regulation of NOX/RBOH-mediated ROS production in plant immune response. In Arabidopsis, BAK1 serves as a co-receptor of FLS2 for flg22 recognition. BAK1 and FLS2 locate on plasma membrane in FLS2-BAK1 heterodimer form, which act as 'molecular glue' involved in immune signaling [191]. FER also acts as a RALF (rapid alkalinization factors)-regulated scaffold that modulates receptor kinase complex assembly [189]. RALFs, rapid alkalinization factors, are the secreted peptides. The members, RALF23/33, can repress FER signaling during PTI responses [189], whereas LLG1 as a cooperator of FER facilitates the formation of FER-FLS2-BAK1 ligand-induced receptor complex for immunity [190]. The FER-FLS2-BAK1 receptor complex can activate BIK1 directly by BAK1, and subsequently, BIK1 phosphorylates RbohD for ROS production to trigger immune responses. This signaling pathway might also trigger immune responses via MAPKs and WRKY46 [190].

In addition, increasing members of RLCKs, such as PBS1-like kinase (PBL1), brassinolide-signaling kinase 1 (BSK1), pattern triggered immunity compromised receptor-like cytoplasmic kinase (PCRK1) and botrytis induced kinase 1 (BIK1), were also identified as mediating the BAK1-dependent PTI signaling in Arabidopsis [180-182,192]. Among the receptor kinase members, both BAK1 and BIK1 become the focus of multiple signals (Figure 2). For example, AtRbohD-dependent ROS production is compromised in bak1 or bik1 mutants in response to both flg22 and elf18 treatments [182,193]. When flg22 or elf18 were recognized by FLS2 or EFR respectively, the latter rapidly recruited the co-receptor BAK1 (or other SERKs: SOMATIC EMBRYOGENESIS RECEPTOR KINASES), and then induced trans-phosphorylation events between BIK1 and the FLS2-BAK1 complex $[193,194]$. To be clearer, BIK1 is a substrate of BAK1, whereas BAK1 and FLS2 are also substrates of BIK1, for phosphorylation [180]. After that, the rapidly phosphorylated BIK1 (GTP-BIK1) directly phosphorylates AtRbohD to produce ROS [182,195]. PBL1, a highly homologous receptor-like cytoplasmic kinase of BIK1, as the molecular chaperone of BIK1, is also important for PTI signaling, potentially via interactions with FLS2 at rest state [187]. BIK1 and PBL1 play a positive role in the RbohD-dependent ROS production but are not required for MAPK activation [181,196]. Besides controlling RbohD, BIK1 and PBL1 are also required for the PAMP- and/or DAMP-triggered cytosolic $\mathrm{Ca}^{2+}$ burst prior to ROS production $[178,197,198]$. By contrast, the exact roles of the other RLCKs in plant signaling are not as clear as BIK1 and PBL1. For example, BSK1 and PCRK1 are also genetically required for PAMP-triggered ROS burst and may thus also directly phosphorylate RbohD, but more systematic biochemical and functional characterization is required to fully address their role in PTI signaling. 
As discussed above, the regulation imposed by BIK1 is a common regulatory mechanism for RbohD, in which BIK1 is the central immune regulator for multiple signaling from upstream to downstream to trigger an oxidative burst from NOXs/RBOHs (Figure 2). Therefore, given the importance of BIK1 in immune signaling, its protein stability is tightly regulated to ensure appropriate and robust immune activation. A previous study reported that BIK1 stability is positively regulated by heterotrimeric $\mathrm{G}$ proteins and negatively regulated by the CPK28 $[198,199]$. A more sophisticated study reveals that PUB25 and PUB26 (two E3 ligases homologous) are the crucial factors which directly target BIK1 for degradation by the ubiquitin proteasome system. The activity of PUB25/26 is negatively or positively regulated by the directly binding with $G$ protein or the phosphorylation from CDPK28, respectively. Interestingly, PUB25/26 specifically target non-activated BIK1 (GDP-BIK1), suggesting that activated BIK1 (GTP-BIK1) is maintained for immune signaling [195]. In addition, a member of MAP4K, SIK1, was recently identified to be able to phosphorylate and enhance BIK1 stability at a resting state by coupling with heterotrimeric $\mathrm{G}$ proteins [200].

The immune response is also mediated by CERK1 in conjunction with two OsCEBiP homologs, LYM1 and LYM3, which can directly bind to PGN [208], but do not contribute to chitin signaling in Arabidopsis [201]. However, a recent study demonstrated that LysM-containing receptor-like kinase5 (LYK5) binds chitin at a much higher affinity than CERK1 [202]. LYK5 is genetically required for a chitin-induced response and forms a chitin-dependent complex with CERK1 [202,209]. Coincidently, PBL27 (the Arabidopsis homolog of BIK1) was found to connect the chitin receptor complex CERK1-LYK5 and a MAPK cascade. PBL27 can phosphorylate and activate AtMAPKKK5 $[203,204]$. These findings provide a phospho-signaling pathway: AtCERK1-PBL27-AtMAPKKK5-AtMKK4/5-AtMPK3/6, in plant immunity. Whether LYK5 and CERK1 are organized into a sandwich-type receptor system similar to CEBiP and CERK1 in rice (Figure 3), and whether the receptor complex LYM1-LYM3-CERK1 activating downstream signaling components was also mediated by AtPBL27, remains to be clarified. As shown in Figure 2, all these receptors and coreceptors are finally associated with NOXs/RBOHs activation directly or indirectly, implying the highly complicated regulatory mechanisms of NOXs/RBOHs in plant immunity.

Two RLCKs in rice, namely OsRLCK185 and OsRLCK176, the homologs of BIK1, can be directly phosphorylated by OsCERK1 during PGN- and/or chitin-induced immunity, and they may also participate in the activation of NOXs/RBOHs and triggering MAPK cascades [201,210,211]. Moreover, the phosphorylation of OsRLCK176 and OsRLCK185 by OsCERK1 is associated with OsLYP4 or OsLYP6 under PGN induction, but associated with OsLYP4, OsLYP6 or CEBiP (LysM-RLP, CHITIN ELICITOR-BINDING PROTEIN) under chitin treatment, suggesting OsLYP4 and OsLYP6 as dual functional PRRs sensing bacterial PGN and fungal chitin (Figure 3) [212]. Meanwhile, different patterns of hetero-oligomeric receptor complexes are assembled under the induction of different ligands. In other words, although LYP4 associates with LYP6, as well as with CEBiP, these complexes partially dissociate following ligand detection [211]. In addition, CEBiP can form a homodimer upon chitin binding that is followed by heterodimerization with CERK1, creating a signaling-active sandwich-type receptor system $[213,214]$. As shown in Figure 3, the phosphorylated OsRLCK185 by OsCERK1 not only participates in downstream of the activation of NOXs/RBOHs, but also enhances chitin-induced activation of OsMPK3 and OsMPK6 [187]. Further studies more clearly show that the phosphorylation of OsRLCK185 by OsCERK1 can trigger a MAPK signaling cascade: OsMAPKKK18/24-OsMKK4-OsMPK3/6 [215-217]. Similar to OsRLCK185, the phosphorylated OsRLCK176 by OsCERK1 might also regulate multiple defense responses triggered by PGN and chitin, such as the activation of MAPKs, ROS generation from NOXs/RBOHs and the expression of defense-related genes [211]. Therefore, the phosphorylated OsRLCK185 and OsRLCK176 can trigger downstream immune responses by activating both MAPK cascades and NOXs/RBOHs-mediated ROS production, but the functional mechanism for how the two RLCKs activate NOXs for ROS production, remains unclear. 


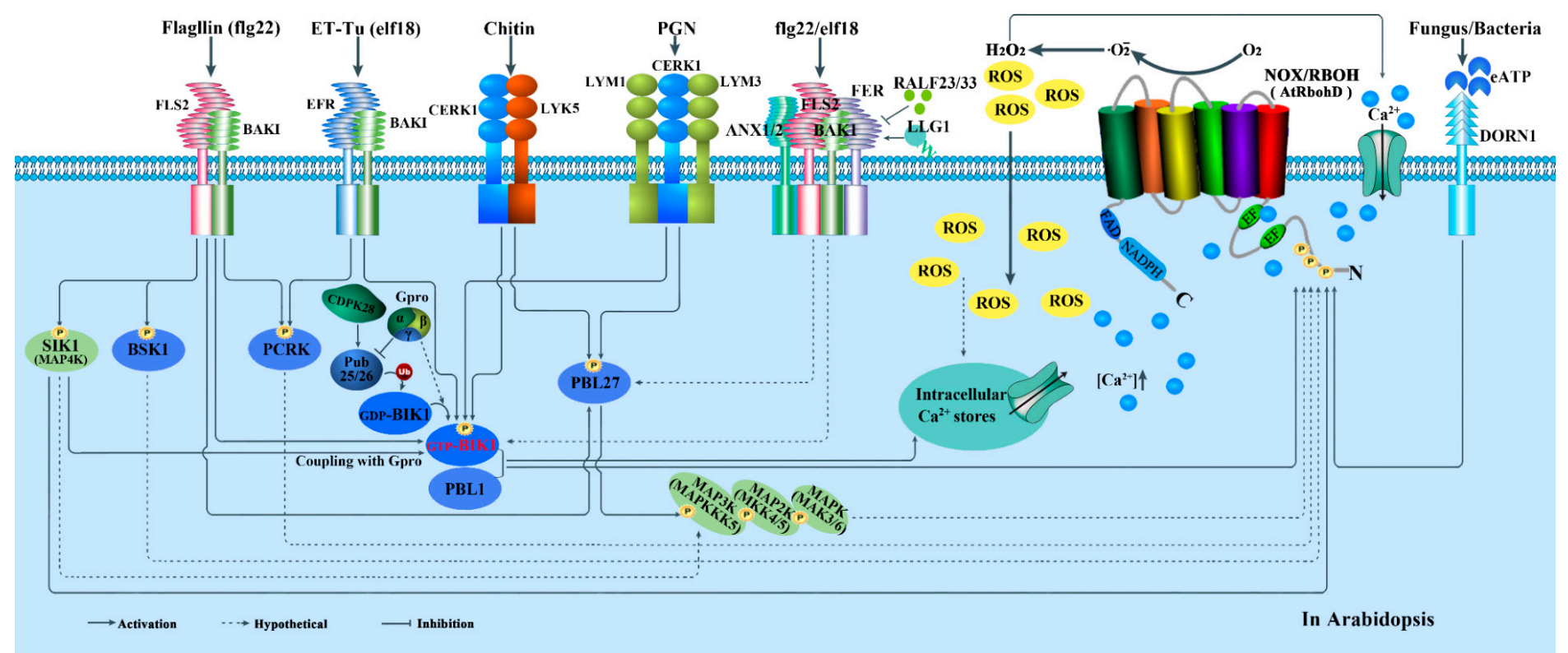

Figure 2. Multiple regulatory signaling pathways of NADPH oxidases (NOXs/RBOHs) in plant immunity of Arabidopsis. Botrytis-induced kinase1 (BIK1), a protein of the RLCKVII subfamily member, is the central immune regulator for multiple signaling pathways from upstream to downstream to trigger an oxidative burst from RbohD. BIK1 can directly bind to multiple RLKs/PRRs in the resting state, such as flagellin sensing 2 (FLS2), elongation factor-Tu receptor (EFR), and PEP 1 receptor (PEPR1) [180-182]. These RLKs all associate with the regulatory LRR-receptor kinase BRI1-associated receptor kinase 1 (BAK1) (also known as SERK3) and form the immune receptor complexes upon bacterial flagellin (flg22), bacterial elongation factor-Tu (elf18 or elf26) or the endogenous AtPep1 (and related peptides) by interacting with them. When flg22 or elf18 are recognized by FLS2 or EFR respectively, the latter rapidly recruit the co-receptor BAK1 for trans-phosphorylation events between BIK1 and BAK1 [193,194]. Other RLK members, FER (FERONIA) and ANX1/2 (ANXURs), belonging to malectin-like receptor kinases, also known as Catharanthus roseus $\mathrm{L}$. receptor-like kinase 1-like proteins (CrRLK1Ls), also participate in NOXs/RBOHs regulation during plant immune response [188]. FER acts as a Rapid Alkalinization Factors (RALF)-regulated scaffold that modulates receptor kinase complex assembly [189], while ANX1 and possibly ANX2 negatively regulate pathogen-associated molecular pattern (PAMP)-triggered immunity (PTI) by putatively competing with FLS2 for interaction with BAK1 [190]. Where, RALF23/33, the secreted peptides, play the negative role in repressing FER signaling during PTI responses [189]. In addition, a LORELEI-like GPI-anchored protein 1 (LLG1), as a cooperator of FER, facilitates FER-FLS2-BAK1 ligand-induced receptor complex formation to activate BIK1, and subsequently phosphorylates the ROS-producing RbohD [190]. Another important immune complex composes of CERK1 (the homologs of BAK1) and two LysM proteins, LYM1 and LYM3 (the homologs of LYP4 and LYP6 in rice), upon recognizing PGN (peptidoglycan) by directly binding to LYM1 and LYM3 [200], but this immune complex does not contribute to chitin signaling 
in Arabidopsis [201]. Meanwhile, a new LysM-containing receptor like kinase 5 was found that binds chitin at a much higher affinity than CERK and forms a chitin-dependent complex with CERK1 [202]. These immune complexes in which AtCERK1 is involved also activate BIK1 by phosphorylation directly. The activated BIK1 (GTP-BIK1) by immune complexes then directly phosphorylates and activates AtRbohD [182,195]. However, AtCERK1-associated PBL27 (an ortholog of OsRLCK185) is not involved in chitin-induced ROS production [203], but it regulates the activation of the MAPK cascade by phosphorylation of AtMAPKKK5 [204] and supervenes with tier phosphorylation events: between AtMAPKKK5 and AtMKK4/5 and AtMPK3/6 in PAMPs signaling [203]. Besides BIK1 and PBL27, there are other RLCKs, such as BSK1, PCRK1, and PBL1, that are also genetically required for a PAMP-triggered ROS burst. PBL1, a close homolog of receptor-like cytoplasmic kinases of BIK1, acting as the molecular chaperone of BIK1, is also important for PTI signaling potentially via interactions with FLS2 at rest state [187]. BIK1 and PBL1 play a positive role in the RbohD-dependent ROS production but are not required for MAPK activation [181,196]. Besides controlling RbohD, BIK1 and PBL1 are also required for the PAMP and/or DAMP-triggered cytosolic Ca ${ }^{2+}$ burst that precedes ROS production $[99,178,197]$. Just recently, SIK1, a mitogen-activated protein kinase kinase kinase kinase (MAP4K) family member, was found to directly interact with and phosphorylate RbohD to promote the extracellular ROS burst upon flagellin perception. Moreover, SIK1 interacts with and stabilizes BIK1 by direct phosphorylation at rest state [200]. In other words, SIK1 positively regulates immunity not only by binding to and activating RbohD directly, but also indirectly through the BIK1 mediated ways. In yeast and humans, MAP4Ks can directly activate MAPK cascades [205,206]. In addition, in parallel with ROS production, PTI also induces MAPK activation [191,207]. Two regulation pathways of NOX/RBOH activity mediated by MAPK might exist in plant immune response: elicitor-MAP4K (SIK1)-RbohD or/and elicitor-MAP4K (SIK1)-MAPK cascades-RBOH. The regulation imposed by BIK1 is a common regulatory mechanism for RbohD during immune response, and in which BIK1 is the central immune regulator for multiple signaling from upstream to downstream to trigger an oxidative burst from RbohD. Therefore, its protein stability is tightly regulated to ensure appropriate and robust immune activation. PUB25 and PUB26 (E3 ligases homologous) are the crucial factors which directly target BIK1 for degradation by the ubiquitin proteasome system, while the activity of PUB25/26 were negatively or positively regulated by the directly binding with G protein or the phosphorylation from CDPK28, respectively. Interestingly, PUB25/26 specifically target non-activated BIK1 (GDP-BIK1), suggesting that activated BIK1 (GTP-BIK1) is maintained for immune signaling [195]. The member of MAP4K, SIK1, can also phosphorylate directly and enhance BIK1 stability at a resting state by coupling with heterotrimeric G proteins [200]. In addition, ATP can also be released into the extracellular matrix and referred to as extracellular ATP (eATP), functioning in signaling. Its mediated stomata close is NOX-dependent under bacterial and fungal infection, and during the process, a L-type lectin receptor-like kinase (LecRKI.9) DORN1 acts as the receptor of eATP to directly phosphorylate downstream of AtRbohD [85]. BAK1, BRI1-associated receptor kinase 1; BIK1, botrytis-induced kinase1; BSK1, brassinolide-signaling kinase1; CDPK, calcium-dependent protein kinase; CERK, chitin-elicitor receptor kinase; DAMP, damage associated molecular pattern; DORN1, a L-type lectin receptor-like kinase; eATP, extracellular ATP; EFR, elongation factor-Tu receptor; elf18, a bacterial elongation factor-Tu; FLS2, flagellin sensing 2; flg22, a bacterial flagellin; $\mathrm{G}_{\text {pro }}$, GTP-binding protein; LLG1, LORELEI-like GPI-anchored protein 1; LRR, leucine-rich repeat; LYK, LysM-containing receptor-like kinase; MAPK, mitogen-activated protein kinase; PAMP, pathogen-associated molecular pattern; PBL, PBS-like kinase; PCRK1, pattern-triggered immunity compromised receptor-like cytoplasmic kinase 1; Pep, plant elicitor peptide; PEPR1, phosphoenolpyruvic acid 1 receptor; PGN, peptidoglycan; PRR, pattern recognition receptor; PTI, PAMP-triggered immunity; RALF, rapid alkalinization factors; RLCK, receptor-like cytoplasmic kinases; RLK, receptor-like protein kinase; SIK1, MAP4K, salt inducible kinase 1. 
Recruitment of regulatory receptor kinases seems to be specified by the type of PRR ectodomain. Accordingly, BAK1 is dispensable for chitin-triggered responses, whereas CERK1 does not participate in flg22-mediated signaling $[185,218]$. However, CERK1 also associates with BIK1 and is required for chitin-induced responses [181]. As such, a connection is established between chitin- and flg22-mediated signaling. In addition, the activated BIK1 phosphorylates the residues Ser39, Ser339, Ser343 and Ser347 within the N-terminal part of RbohD, while both BIK1 and CPKs phosphorylate Ser347 [67], implying that there is a crosstalk between BIK1 and CPKs-mediated regulation of RbohD activity.

\subsubsection{Rho-Type GTPases-Mediated Regulation}

Plants have a subfamily of Rho GTPases, which belongs to the Rat sarcoma (Ras) superfamily of small GTP-binding proteins and is called ROPs (Rho of plants) or RACs (for the sequence similarity shared with animal Racs, a Rho subfamily). The modules of ROP/RAC-NOX/RBOH mediate multiple extracellular signals ranging from hormones, pathogen elicitors and abiotic stresses, and regulate diverse cellular processes which are important for polarized cell growth, differentiation, development and reproduction (Figures 3 and 4) [154,223]. For example, the activated OsRac1 interacts with the N-terminus of OsRbohB and thereby stimulates ROS generation [222]. Duan et al. [223] also proposed that ROP activity is correlated with $\mathrm{NOX} / \mathrm{RBOH}$-catalyzed ROS accumulation during polar root hair and pollen tube growth. Furthermore, structural analyses of OsRbohB, coupled with in vitro binding and NMR (nuclear magnetic resonance) titration assays, showed that OsRac1 binds the coiled-coil of the N-terminal region of OsRbohB $[67,156,223]$. In Arabidopsis, it was reported that AtROP1, an OsRac1 homolog, plays an important role in AtRbohH/AtRbohJ-regulated pollen tube growth [32], while AtROP2 is required for AtRbohC/RHD2-dependent ROS formation during root hair growth [41].

The ROP/RAC small GTPases serve as a two-state molecular switch depending on its GDP- or GTP-bound conformation [224]. Recently, emerging evidence demonstrates that guanine nucleotide exchange factor (GEF) enhances the release of GDP from ROP/RAC, thereby promoting the binding of GTP. Moreover, GEFs exclusively exert their actions in large molecular complexes linking RLKs to the activation of small GTPase $[28,223,225]$. FER (FERONIA) as an upstream regulator for the ROP/RAC-signaled pathway that controls RbohC-dependent ROS-mediated root hair development. Moreover, FER can be pulled down by ROP2 GTPase in a guanine nucleotide-regulated manner, implying a dynamic signaling complex involving FER, a ROPGEF and a ROP/RAC [223]. Further, it was reported that the glycosylphosphatidylinositol-anchored protein (GPI-AP) LORELEI (LRE) and the seedling-expressed LLG1 physically interact with FER. They are not only co-transported with FER from the endoplasmic reticulum to the plasma membrane, but also exist as components of the FER-ROPGEF-ROP/RAC-NOX/RBOH signaling pathway [226]. Here, the rapid alkalinization factors (RALFs), play the positive roles of activating (RALF1 during root elongation but RALF23 during seedling growth) [227] (Figure 4) but not repressing (RALF23/33 during PTI responses but RALF22/23 during salt tolerance) FER signaling (Figure 2) $[189,228]$.

Once activated, the GTP-bound ROP/RACs could recruit NOXs/RBOHs to mediate downstream ROS-dependent processes of plant growth and reproduction [226]. In addition, ANX1 and 2, the closest homologues of FER, may activate ROP GTPases through RopGEFs, preceding the activation of the NOX/RBOH-catalyzed ROS accumulation during pollen tube growth [28]. In brief, with the cooperators LLG1 (LRE) and RALFs, FER/ANX-GEF, being the upstream regulators, activate ROP/RACs directly, and the activated ROP/RACs subsequently activate NOXs/RBOHs for ROS production to regulate plant growth and reproduction. To sum up, all the results, combined with those mentioned earlier, demonstrate that the membrane receptor complex FER(ANX)-FLS2-BAK1 is not only involved in BIK1-mediated activity regulation of NOXs/RBOHs during plant immune response, but also participates in ROP GTPases-mediated activity regulation of NOXs/RBOHs during normal plant development and reproduction. 


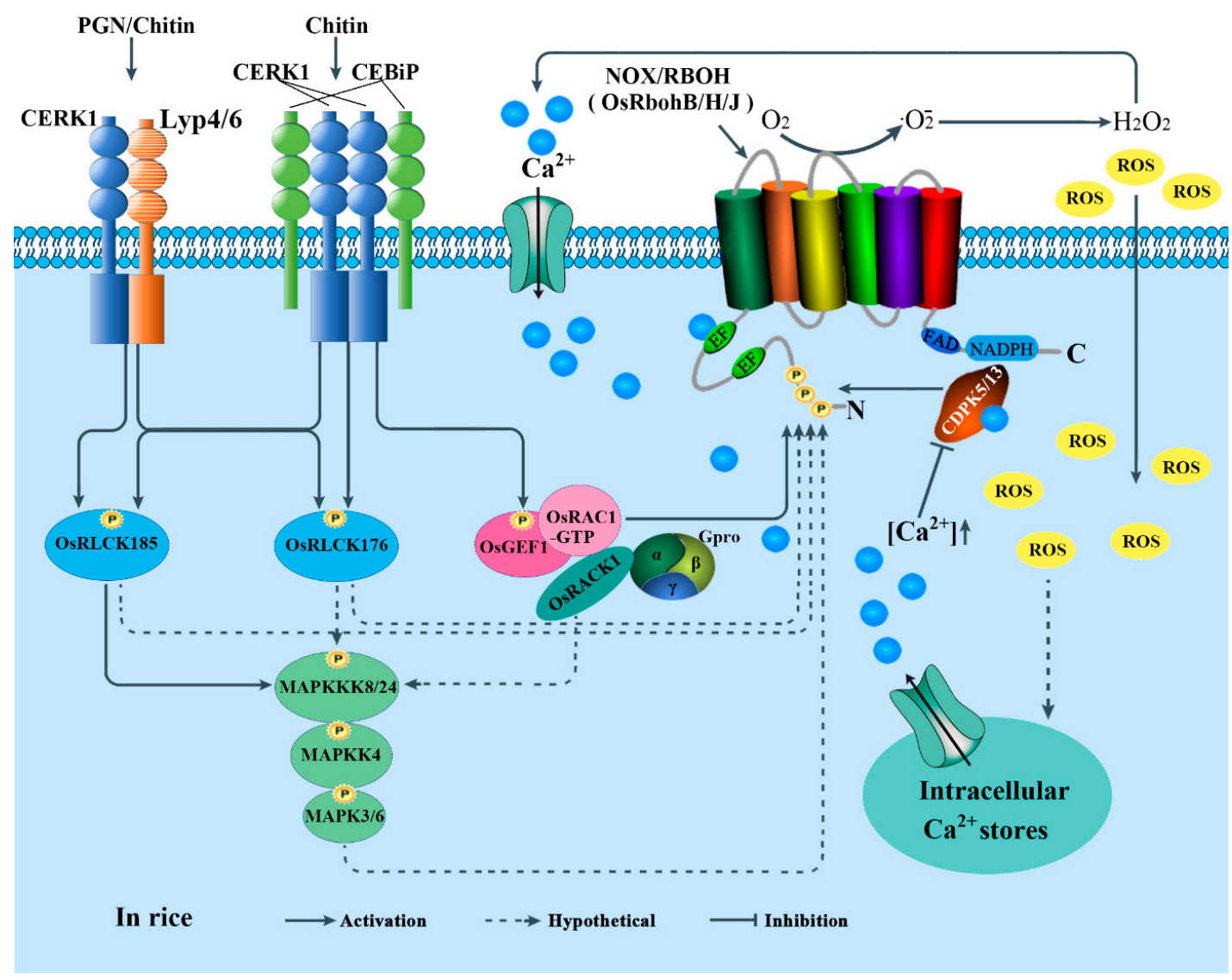

Figure 3. The activity regulation of NADPH oxidases (NOXs/RBOHs) in plant immunity of rice. Two receptor-like cytoplasmic kinases (RLCKs), OsRLCK185 and OsRLCK176, can be directly phosphorylated by a plasma membrane-localized receptor-like kinase, OsCERK1 [201,210,211], which is associated with receptor-like kinases OsLYP4 or OsLYP6 when induced by PGN, but associated with OsLYP4, OsLYP6 or OsCEBiP under chitin treatment [211]. In addition, OsCEBiP can form a homodimer upon chitin binding that is followed by heterodimerization with OsCERK1, creating a signaling-active sandwich-type receptor system [213,214]. Then, the phosphorylated OsRLCK185 triggers a MAPK cascade: OsMAPKKK18/24-OsMKK4-OsMPK3/6, to activate the downstream proteins directly, or perhaps act as the upstream of NOXs/RBOHs to enhance ROS production $[215,216]$. Similar to OsRLCK185, OsRLCK176 also activates MAPK cascades [211], but the mechanism remains to be addressed as well. A ROP/RAC GTPase, OsRAC1, is also involved in the OsCERK1/OsCEBiP-mediated immune signaling, it activates OsRbohB for ROS production by directly interacting with the $\mathrm{N}$-terminus of the NADPH oxidase [201,213]. Two other regulator factors, OsGEF1 and OsRACK1, also participate in this signaling pathway. OsGEF1 mediates the change between the RAC-GDP inactive form and the RAC-GTP active form as a molecular switch for the signaling [179,204], coupling with OsRACK1 [219], after being phosphorylated by OsCERK1 [28]. In addition, OsRACK1 also functions as a scaffolding protein linking heterotrimeric $G$ proteins and the MAPK cascade [220]. Phosphorylation functions in important roles in activating NOXs/RBOHs and contributes to oxidative burst. However, the phosphorylation of NOXs/RBOHs is not sufficient for full activation of the proteins [221]. The binding of influx $\mathrm{Ca}^{2+}$ to EF-hand region and the phosphorylation in the N-terminal region of OsRbohB by CDPK5/13 perhaps induce the conformational change in EF-hand region of the NOX/RBOH and therefore, expose the site for interaction with RAC GTPase in the N-terminal region, and subsequently activate OsRbohB for ROS production. In turn, the ROS produced by the NOX/RBOH and other components induce more $\mathrm{Ca}^{2+}$ influx and the elevated $\mathrm{Ca}^{2+}$ in cytosolic play a positive role to induce more $\mathrm{Ca}^{2+}$ efflux from intracellular $\mathrm{Ca}^{2+}$ stores. Meanwhile, $\mathrm{Ca}^{2+}$ accumulation reaches a threshold, 
which may serve as a negative feedback mechanism to terminate the OsRAC1-OsRbohB interaction and ROS production [222]. These results imply that CDPK and RAC synergistically regulate the activity of NOXs/RBOHs in $\mathrm{Ca}^{2+}$-dependent manner. Furthermore, the $\mathrm{Ca}^{2+}$-related negative feedback mechanism exerts an important function in regulating the RAC-NOX/RBOH interaction for maintaining the ROS homeostasis in rice plants. CDPK, calcium-dependent protein kinase; CEBiP, chitin elicitor-binding protein; CERK, chitin-elicitor receptor kinase; $\mathrm{G}_{\text {pro }}$, GTP-binding protein; GEF, guanine nucleotide exchange factors; LYP, homologs of LysM proteins in rice; MAPK, mitogen-activated protein kinase; PGN, peptidoglycan; RACK, receptor for activated C-kinase; RLCK, receptor-like cytoplasmic kinases; ROP/RAC GTPase, a subfamily of Rho-type GTPases, which belongs to the Rat sarcoma (Ras) superfamily of small GTP-binding proteins; SIK1/MAP4K, salt inducible kinase 1.

In rice, the most typical elicitor in RLK/GEF/RAC-mediated regulation of NOXs/RBOHs signal pathways during plant immunity is chitin. Chitin is one of the best characterized PAMPs in pathogenic and non-pathogenic fungi. Instead of FER in Arabidopsis, two PRRs, OsCEBiP and OsCERK1, in which OsCEBiP acts as a receptor-like protein (RLP), directly binds to chitin. The two immune proteins could form a receptor complex to transduce the chitin signals to the downstream components upon fungal infection [201,213]. Here, a homolog of Arabidopsis GEF, OsRacGEF1, which was identified as the specific GEF for OsRac1, mediates the change between the Rac-GDP inactive form and the Rac-GTP active form as a molecular switch [204]. OsRacGEF1 interacts with the cytoplasmic domain of OsCERK1, and is directly phosphorylated by OsCERK1 [179]. Besides OsRacGEF1, there is another regulator factor, OsRACK1 (a rice homolog of human Receptor for Activated C-kinase 1), which interacts with OsRac1 [219]. OsRACK1 functions as a scaffolding protein linking heterotrimeric G proteins and MAPK cascade [220], and therefore, OsRac1 plays a role at the downstream of heterotrimeric G protein [229]. The OsRac1 activated by chitin or heterotrimeric $\mathrm{G}$ protein then directly regulates OsNOXs/RBOHs for ROS production. These results imply a model OsRacGEF1-OsRac1-mediated signaling involved in the activation of NOXs/RBOHs in rice (Figure 3).

As mentioned above, phosphorylation plays important roles in activating NOXs/RBOHs and oxidative burst. However, the phosphorylation is not sufficient to fully activate NOXs/RBOHs [221]. The conformational change in the EF-hand region of NOXs/RBOHs induced by $\mathrm{Ca}^{2+}$ binding to the EF-hand motifs might be essential. It was reported that $\mathrm{Ca}^{2+}$ binding to the EF-hand motifs and phosphorylation by CDPK synergistically activate AtRbohD to produce ROS [158]. This prompts us to speculate that a crosstalk between multiple signaling components might play crucial roles in full activation of NOXs/RBOHs in plants. In rice, it was suggested that at the initial stage of the oxidative burst, CDPKs, in a $\mathrm{Ca}^{2+}$-dependent manner, may sensitize NOXs/RBOHs for activation by phosphorylating their $\mathrm{N}$-terminal region, thus inducing a conformational change and exposing the site for interaction with Rac GTPase [222]. Moreover, in cytosol, $\mathrm{Ca}^{2+}$ flux has diphase change and plays a dual role in NOX/RBOH-mediated oxidative burst. In the initial stage of oxidative burst, cytosolic $\mathrm{Ca}^{2+}$ influx may be required by CDPK to phosphorylate NOXs/RBOHs and recruit Rac GTPases, both of which synergistically contribute to ROS burst. In turn, ROS and other components induce more $\mathrm{Ca}^{2+}$ influx, and the elevated $\mathrm{Ca}^{2+}$ in cytosol induces its efflux from the intracellular stores. When $\mathrm{Ca}^{2+}$ accumulation reaches a threshold, it may serve as a negative feedback mechanism to terminate the OsRac1-OsRbohB interaction and ROS production from OsRbohB [222]. These results imply that CDPKs and RACs synergistically regulate the activity of NOXs/RBOHs in a $\mathrm{Ca}^{2+}$-dependent manner. Furthermore, the $\mathrm{Ca}^{2+}$-related negative feedback mechanism exerts an important function in regulating the RAC-NOX/RBOH interaction and maintaining the homeostasis of ROS in plants. Interestingly, a negative regulatory model was reported in vertebrates. In which, HACE1, a HECT domain and Ankyrin repeat domain containing E3 ubiquitin-protein ligase 1, directly targets Rac1 for degradation of the preformed signaling complex, and therefore negatively regulates Rac1-dependent NADPH oxidases in a ubiquitin-dependent manner [230]. Whether a similar negative regulatory model exists in plants for the RACs-mediated regulation of NOXs/RBOHs, needs further studies. 


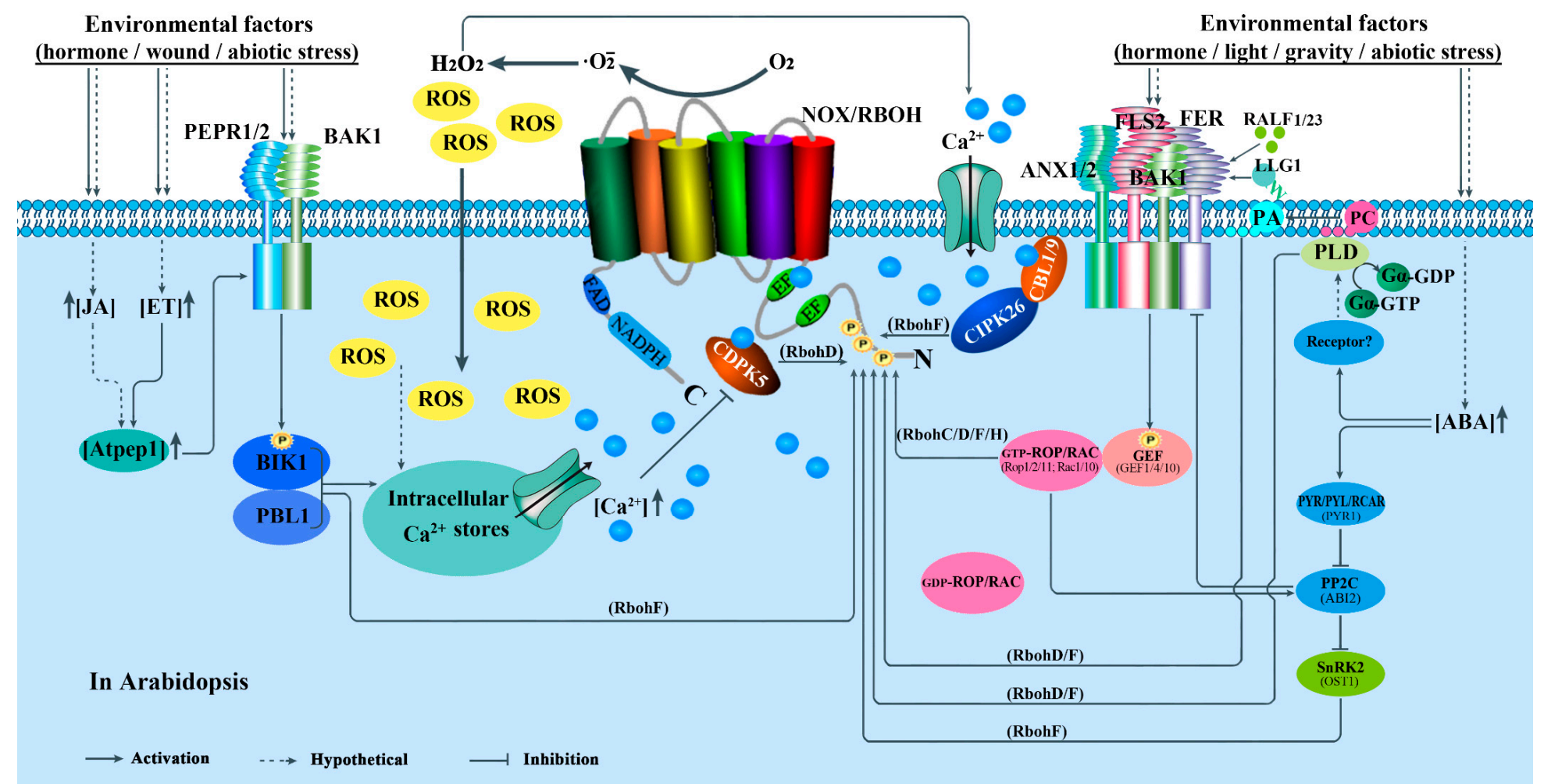

Figure 4. Regulatory signaling pathways of NADPH oxidases (NOXs/RBOHs) in plant development and abiotic stress tolerance. RAC/ROP-NADPH oxidases (NOXs/RBOHs) mediate multiple extracellular signals ranging from hormones, pathogen elicitors and abiotic stresses, and regulate diverse cellular processes important for polarized cell growth, differentiation, development and reproduction [153,223]. Similar to BIKI, ROP/RAC is also recruited by the membrane receptor complex FER (ANX)-FLS2-BAK1. However, the functions of them are different. BIK1-mediated regulation of NOXs/RBOHs is mainly involved in plant immune response, while ROP GTPases-mediated regulation of NOXS/RBOHs mainly participates in plant normal development and reproduction or response to abiotic stresses. LLG1 and RALFs still act as the molecular chaperones of FER to regulate the formation of receptor complex; however, coupling with LLG1, RALFs here play a positive role to facilitate the binding of FER to BAK1 during root elongation (RALF1) or seedling growth (RALF23) [227]. As a molecular switch, GEF is also required for the change between the ROP/RAC-GDP inactive form and ROP/RAC-GTP active form [224]. Once activated, the GTP-RAC/ROPs will interact with NOXs/RBOHs (such as $\mathrm{Rboh} / \mathrm{D} / \mathrm{F} / \mathrm{H} / \mathrm{J})$ directly, to mediate downstream ROS-dependent processes of plant growth and reproduction [32,226]. During these processes, the $\mathrm{Ca}^{2+}$ binding in EF-hand region and the phosphorylation of NOXs/RBOHs mediated by CDPKs (CDPK26) perhaps can enhance the interaction between GTP-RAC/ROPs and 
NOXs/RBOHs. In addition to CDPK/CPK, there is another $\mathrm{Ca}^{2+}$-regulated kinase represented by calcineurin B-like (CBL)-interacting protein kinases (CIPKs), which becomes activated upon interaction with $\mathrm{CBL} \mathrm{Ca}^{2+}$ sensor proteins [167,168]. CIPK26 interacts with the plasma membrane-localized Ca ${ }^{2+}$ sensors CBL1 and/or CBL9, they work together to phosphorylate the N-terminus of AtRbohF for ROS production. However, the phosphorylation of NOXs/RBOHs is not sufficient for full activation of the NOXs/RBOHs [221], implying that some additional determinants are required to activate NOXs/RBOHs synergistically with CIPK26. ABA-induced ROS accumulation originates from two NOX/RBOH proteins, AtRbohD and AtRbohF, playing an important role in stomatal closure [231,232]. OST1, a member of the sucrose non-fermenting 1 (SNF1)-related protein kinase 2 family (SnRK2s), is upstream of AtRbohF by phosphorylation $[153,233]$. Treating with flg22 leads to ABA accumulation in plant cells, which can be perceived by the PYR/PYL/RCAR receptors, such as pyrabactin resistance protein 1 (PYR1), and induce a complex of PYR/PYL/RCAR-PP2C formation. The complex then suppress the activity of A-type protein phosphatase 2Cs (PP2Cs), which releases active SnRK2s [234], such as OST1 [235], and therefore leads to NOXs/RBOHs-mediated ROS production for stomatal closure. In addition, an intriguing case shows that the ROP/RAC GTPases, ROP11/ARAC10, not only interact with several GEFs such as GEF1, GEF4 and GEF10, but also interact with and activate the phosphatase activity of ABI2 (ABA insensitive 2) after being activated by FER-GEFs [234]. On the other hand, ABI2 can directly interact and dephosphorylate FER, providing a negative feedback mechanism for FER-mediated signaling [236]. Thus, a crosstalk mediated by ABI2 links two signaling pathways: the FER involved in growth-promoting and the ABA participating in growth-inhibiting, during regulation of NOXs/RBOHs activity. On ABA inhibition of stomatal opening, PLDa1, a member of phospholipase D, can be activated by binding to GPA1 (a-subunit of heterotrimeric G protein) and regulates its function by promoting the conversion of GTP-bound G $\alpha$ to a GDP-bound G $\alpha$, thus phosphatidylcholine (PC) was hydrolyzed to PA $[237,238]$. Then, the second messenger PA binds to and activates AtRbohD [237]. Whether the ABA-stimulated PLD activity is mediated through an ABA receptor, needs further verification. In contrast, RbohF-mediated ethylene-induced ROS production and stomatal closure are independent from flg22-mediated stomatal closure [148,239]. In this case, AtPep1, a 23-amino acid endogenous peptide, initially identified as a DAMP in Arabidopsis [240], plays a critical role in flagellin-inducing plant immunity [241]. Both ET and AtPep1 treatments can induce BIK1 phosphorylation by Pep1 receptor kinases, PEPR1, and also likely PEPR2. It is to say, similar to AtPep-triggered responses, ethylene-induced ROS production from activated RbohF is dependent on BIK1-mediated phosphorylation by Pep1/2 receptor kinases. Similar to ET, JA and MeJA also seem to enhance the AtPep-triggered responses in plants [184,242]. ABI2, ABA insensitive 2; BAK1, BRI1-associated receptor kinase 1; BIK1, botrytis-induced kinase1; CBL, calcineurin B-like; CDPK, calcium-dependent protein kinase; CIPK, calcineurin B-like-interacting protein kinases; DAMP, damage associated molecular pattern; ET, ethylene; FLS2, flagellin sensing 2; GEF, guanine nucleotide exchange factor; GPA1, G protein $\alpha$ subunit 1; JA, jasmonate; LLG1, LORELEI-like GPI-anchored protein 1; MeJA, methyl jasmonate; OST1, open stomata 1; PA, phosphatidic acid; PC, phosphatidylcholine; Pep, plant elicitor peptide; PEPR1, phosphoenolpyruvic acid 1 receptor; PLDa1, phospholipase D alpha; PP2C, protein phosphatase 2C; PYR, pyrabactin resistance protein; PYL, PYR-LIKE; RCAR, regularity components of ABA receptor; RALF, rapid alkalinization factors; ROP/RAC GTPase, a subfamily of Rho-type GTPases, which belongs to the Rat sarcoma (Ras) superfamily of small GTP-binding proteins; SnRK2, sucrose non-fermenting 1 (SNF1)-related protein kinase 2. 


\subsubsection{MAPK Cascades-Mediated Regulation}

MAPK cascades are one of the most important and highly conserved signaling cascades, which consist of three tier components, MAPKKKs, MAPKKs and MAPKs, widely participating in plant growth and development, as well as in responses to a number of biotic and abiotic stresses [243-246]. It is well known that both abiotic and biotic stress factors can activate MEKK1 (a MAPKKK), which subsequently initiates a signaling of MEKK1-MKK1/2/4/5-MPK3/4/6 in Arabidopsis and acts as upstream of NOXs/RBOHs to stimulate $\mathrm{H}_{2} \mathrm{O}_{2}$ production [151,247-249]. In addition, the activation of MPK3 and MPK6 by flg22 is not affected in the rbohD mutant, suggesting that these MAPKs act as the upstream of RbohD-mediated oxidative burst in Arabidopsis [250,251]. Similar results are also found in Nicotiana benthamiana [150] and maize [152]. Coincidentally, SIK1, a mitogen-activated protein kinase kinase kinase kinase (MAP4K) family member, was found to directly interact with and phosphorylate RbohD to promote the extracellular ROS burst upon flagellin perception. Moreover, SIK1, similar to BIK1, associates with the PRR FLS2 at a resting state, and interacts with and stabilizes BIK1 by direct phosphorylation at rest state [200]. In other words, SIK1 positively regulates immunity not only by binding to and activating RbohD directly, but also in an indirect BIK1-mediated way. In yeast and humans, MAP4Ks can directly activate MAPK cascades $[205,206]$. In addition, in parallel with ROS production, PTI also induces MAPK activation [191,207]. These results prompt us to speculate that two pathways mediated by MAPK: elicitor-MAP4K (SIK1)-RbohD and elicitor-MAP4K (SIK1)-MAPK cascades-NOX/RBOH, also execute important roles in NOXs/RBOHs regulation.

\subsubsection{Hormone-Mediated Regulation}

There is now a substantial body of studies concerning hormones that participate in plant immunity and abiotic stress responses, such as ABA, JA, SA and ET. [148,237,252,253]. Intrinsic to their participation in plant stress responses is the interplay between ROS and these hormones, as well as hormone-dependent ROS balance through the regulation of NOX/RBOH-based ROS-producing activity and ROS-scavenging capacity. The entire picture addressing this regulation has been summarized in Figure 4.

ABA has been the focus of intense investigation since it was identified in the 1960s as an endogenous small molecule growth inhibitor and regulator of plant stress physiology. It was reported that NOX/RBOH-dependent ROS production in guard cells plays an important role in ABA-mediated stomatal closure [231], and ABA-induced ROS accumulation mainly originates from two NOX proteins, AtRbohD and AtRbohF, during stomatal closure [232]. Stomatal closure in guard cells is a basic defensive strategy of plants to prevent biotic and abiotic stresses. OST1 is a member of the sucrose non-fermenting 1 (SNF1)-related protein kinase 2 family (SnRK2s). A mutation in the OST1 gene impairs ABA-triggered ROS production in guard cells, suggesting that OST1 acts upstream of NOX/RBOH in this signaling cascade [233]. In addition, further experiments proved that flg22 treatment could induce stomatal closure in wild-type plants but not in the ost1 mutant of Arabidopsis [232], and OST1-mediated ROS generation in guard cells involves the phosphorylation of AtRbohF by OST1 [153]. In this process, ABA can be perceived by the pyrabactin resistance protein 1 (PYR1), then the PYR1 receptor complex leads to suppression of protein phosphatase 2Cs (PP2Cs), which function as negative regulators of OST1 [235]. The OST1 mediate phosphorylation of AtRbohF, but the protein might also be phosphorylated during the signaling transduction [153]. Considering the highly conserved serine residues on other $\mathrm{NOX} / \mathrm{RBOH}$ proteins, it is reasonable to believe that they can be phosphorylated by OST1 and/or other members of the SnRK2 family kinase proteins in the regulation of stomatal movement of plants. Up to now, it has been widely accepted that in the absence of ABA, the activated $\mathrm{ABI}$, a key member of PP2C protein kinases, interacts with and inhibits a SnRK2-type protein kinase by arresting SnRK2 and forming PP2C-SnRK2 (ABI2-SnRK2) complexes, which act as a positive regulator of ABA responses. Increased levels of ABA induce an interaction of PP2C with PYR/PYL/RCAR receptors that triggers the deactivation of PP2Cs to release active SnRK2s [234], thereby activating downstream signaling, such as OST1-mediated phosphorylation of AtRbohF for stomatal closure [153]. 
Besides OST1 and the associated components, a number of components in ABA signaling have also been characterized, including $\mathrm{G}$ proteins, protein kinases/phosphatases and receptors, involved in regulation of NOXs/RBOHs for ROS production. For example, ABA stimulates phospholipase D (PLD) activity probably through a putative ABA receptor. On ABA inhibition of stomatal opening, PLDa1 binds to GPA1 ( $\alpha$-subunit of heterotrimeric $G$ protein) and regulates its function by promoting the conversion of GTP-bound $G \alpha$ to a GDP-bound $G \alpha$, thus producing PA [238]. Subsequently, the second messenger PA directly binds to and activates AtRbohD to regulate ROS production [237]. Moreover, during the ABA-mediated stress response, MAPK cascades may act both upstream and downstream of the ROS production. For instance, a study in maize revealed that ABA activates a $46 \mathrm{kDa}$ MAPK, which not only acts downstream of $\mathrm{H}_{2} \mathrm{O}_{2}$ production, but also positively regulates $\mathrm{NOX/RBOH} \mathrm{[151].} \mathrm{Another} \mathrm{intriguing} \mathrm{case} \mathrm{shows} \mathrm{that} \mathrm{FER} \mathrm{mutation} \mathrm{can} \mathrm{cause} \mathrm{ABA} \mathrm{hypersensitivity}$ in stomatal closing [234], implying that a crosstalk between the FER-mediated growth-promoting and ABA-mediated growth-inhibiting signaling pathways perhaps exists. A further study indicates that the ROP/RAC GTPases ROP11/ARAC10 not only interact with several GEFs such as GEF1, GEF4 and GEF10, but also interact with and activate the phosphatase activity of ABI2 (ABA insensitive 2) after being activated by FER-GEFs [234]. As mentioned above, when the concentration of ABA increases, it induces PYR/PYL/RCAR receptors to interact with and arrest PP2C, and subsequently triggers the deactivation of PP2Cs to release active SnRK2s for stomatal closure [234]. On the other hand, ABI2 can directly interact and dephosphorylate FER, providing a negative feedback mechanism for FER-mediated signaling [236]. Therefore, ABI2 acts as a center regulation factor involved in the regulation of ABA signaling and FER signaling by interacting with PYR/PYL/RCAR receptors and PP2Cs or by interacting with ROP/ARAC and FER, respectively. This may be the crucial point as to why FER-mediated signaling can inhibit the ABA pathway. ABA- and stress-hypersensitive responses in fer mutant can be partially rescued by the abi2-1 gain-of-function mutation.

Increasing evidences also reported that an ethylene receptor 1 (ETR1) and ethylene insensitive 2 (EIN2)-mediated signaling is required for the AtRbohD-dependent ROS accumulation during flagellin-induced intracellular response [148]. AtPep1, a 23-amino acid endogenous peptide, which was initially identified as a DAMP in Arabidopsis [240], plays a critical role in flagellin-inducing plant immunity [241]. Both ET and Pep1 treatments can induce BIK1 phosphorylation by Pep1 receptor kinases, PEPR1 and also likely PEPR2, which, when coupled with the shared receptor LRR-RK BAK1 [184], can trigger an innate immunity in Arabidopsis [182]. It is to say, similar to AtPeps-triggered responses, ethylene-induced ROS production from activated RbohF depends on BIK1-mediated phosphorylation by Pep1/2 receptor kinases. This prompts us to speculate that ET accumulation in plants under the treatments of exogenous factors including ET and AtPep1, can lead to endogenous AtPeps accumulation, which can be perceived by the receptor PEPR1/1 and then triggers BIK1-mediated NOX/RBOH phosphorylation for ROS production and stomatal closure.

ET not only potentiates the accumulation of ROS, but also together with the produced ROS, regulates stress-induced cell death [254]. RbohF, but not RbohD, mediates ethylene-induced ROS production and stomatal closure. Interestingly, RbohF seems to not be involved in flg22-mediated stomatal closure $[148,239]$. Moreover, a number of studies have shown that immune responses serve to amplify PTI signaling $[182,240,255,256]$ via the pathways of JA/ET and/or SA [240,256]. JA seems to enhance all AtPep-triggered responses [184]. In addition, treatment with MeJA contributes to $\mathrm{H}_{2} \mathrm{O}_{2}$ production through AtrbohD and AtrbohF in a coronatine-insensitive1 (COI1) depended way [242]. COI1 is a LRR (Leu-rich repeat)/F-box motif-containing protein that determines the substrate specificity of the SCF-type E3 ubiquitin ligase [257]. In addition, another study shows that BR can also enhance NADPH oxidase activity and thereby elevates $\mathrm{H}_{2} \mathrm{O}_{2}$ levels in apoplast [258]. Although these results highlight the roles of plant hormones in the regulation of NOXs/RBOHs activity during plant development and resistance, the mechanisms and associated components still remain to be addressed further. 


\subsubsection{Other Kinds of Particles-Mediated Regulation}

Besides those common signaling particles mentioned above, there are also other various kinds of particles functioning in the regulation of NOXs/RBOHs activity. For instance, ATP-mediated stomata close is NOX-dependent. Addition of ATP leads to the rapid closure of leaf stomata and enhances resistance of plants to the bacterial pathogen, Psuedomonas syringae. At the same time, a L-type lectin receptor-like kinase (LecRKI.9) DORN1, the receptor of ATP, can directly phosphorylate NADPH oxidase RbohD, while mutation of DORN1 phosphorylation sites on RbohD eliminates the ability of ATP to induce stomatal closure [84]. In addition, a 14-3-3 protein, identified as an interactor, plays a positive role in inducing ROS production from NtRbohD $[67,259]$. Moreover, it was found earlier that the activity of NOXs/RBOHs can be inhibited by cAMP [260]. It was reported that the NADPH-oxidase activity is finely regulated spatially and temporally by cellular signaling events that trigger the translocation of the cytosolic subunits to its membrane partner involving post-translational modifications and activation by second messengers, such as arachidonic acid (AA), while trans-AA isomers inhibit NADPH-oxidase activity by direct interaction with enzyme components [261]. Moreover, a report shows that one of the biological effectors, nitric oxide (NO), regulates the activities of NOX proteins by S-nitrosylation [262]. In vitro analysis further showed that AtRbohD can be specifically S-nitrosylated at Cys 890 of the C-terminal portion by NO and S-nitrosylation could inhibit AtRbohD-dependent ROS production in response to Pst DC3000 expressing effector AvrB [263]. Therefore, it is not hard to notice that, with the development of the studies on the regulation of NOXs/RBOHs, more and more particles will be identified to be associated with their activity, even though the complete relationship of those particles in the process of $\mathrm{NOX} / \mathrm{RBOH}$ regulation still remains to be figured out.

\section{Conclusions and Perspectives}

Currently, NADPH oxidases, being ROS producers, multiple signaling centers and diverse function implementers in plants, are becoming the focus of studies. Increasing members of them have been identified and reported. The highly conservative structure and complex evolution history endow them with stable functions donating ROS and versatile functions, involved in pollen gemination and root development, seed germination, fungal development, symbiosis between plants and microorganisms, stress response, etc. Over the past decade, several important regulation pathways addressing NOX/RBOH activity, such as $\mathrm{Ca}^{2+}{ }_{-}, \mathrm{CDPK}-, \mathrm{BIK1} 1$, Rac1- and/or SIK1-mediated signaling, became more and more clear. The high flexibility in NOXs/RBOHs regulation allows plant cells not only to prevent unintended signaling activation but also to modulate signaling amplitude and fine-tune immune responses, as well as to keep development integrity. However, numerous questions still remain to be answered in the future, for instance, the spatiotemporal dynamics of RAC-dependent activation, diphase $\mathrm{Ca}^{2+}$ flux change, the crosstalks between different signal pathways, the mechanisms of the messenger ROS transmit signals and NOX/RBOH-based ROS homeostasis and its exact meaning. In addition, increasing yield and improving quality are the foundations of agricultural development and the ultimate aim of scientific research. However, almost all of the results currently obtained are just on the basis of model plants, and only a few field crops have been considered for deep research. Therefore, new breakthroughs in NOX/RBOH research based on field crops such as wheat have become an urgent and charming expectation for sustainable agriculture.

Supplementary Materials: The following are available online at http://www.mdpi.com/2073-4409/9/2/437/s1, Table S1: The detailed information about the members of NADPH oxidases (NOXs/RBOHs) gene family in plants.

Author Contributions: K.-M.C. proposed the concept and content; C.-H.H. and P.-Q.W. collected data and wrote the manuscript; P.-P.Z., X.-M.N., B.-B.L. and L.T. collected data and checked the English throughout the text; W.-T.L. and W.-Q.L. defined all the abbreviations in the text. All authors contributed to the reviewing and editing of the manuscript. All authors have read and agreed to the published version of the manuscript.

Funding: The National Natural Science Foundation of China, Grant no. 31770204 and 31270299.

Acknowledgments: This work was supported by the National Natural Science Foundation of China (grant no. 31770204 and 31270299). 
Conflicts of Interest: The authors declare no conflict of interest.

\section{Abbreviations}

Full-Name

abscisic acid

ABA insensitive

ABA-responsive element

arbuscular mycorrhizal fungal

ANXUR

$\alpha$-naphthaleneacetic acid

BRI1-associated receptor kinase 1

botrytis-induced kinase1

brassinosteroid

brassinolide-signaling kinase

cis-acting regulatory element

calcineurin B-like

calcium-dependent protein kinase

chitin elicitor-binding protein

chitin-elicitor receptor kinase

calcineurin B-like-interacting protein kinase

coronatine-insensitive

damage associated molecular pattern

dominant negative form

diphenylene iodonium

dual oxidase

elongation factor-tu receptor

ethylene

effector triggered immunity

ethylene receptor

flavin adenine dinucleotide

FERONIA

flagellin sensing 2

ferric reduction oxidase

guanine nucleotide exchange factors

glycosylphosphatidylinositol-anchored protein

the $\alpha$ subunit of $G$ protein

guanosine triphosphate

hypersensitive type of resistance

a $\mathrm{H}^{+}$pump by coupling with enerty of ATP hydrolysis on plasma membranes

indole-3-acetic acid

jasmonate

L-type lectin receptor-like kinase

lorelei-like GPI-anchored protein 1

leucine-rich repeat

LysM-containing receptor-like kinase

mitogen-activated protein kinase

methyl jasmonate

leucine-rich repeat containing receptor

nitric oxide

NADPH oxidase

superoxide anion

open stomata
Abbreviation

ABA

ABI

ABRE

AMF

ANX

$\alpha$-NAA

BAK1

BIK1

BR

BSK

CARE

CBL

CDPK

CEBiP

CERK

CIPK

COI

DAMP

DN

DPI

DUOX

EFR

ET

ETI

ETR

FAD

FER

FLS2

FRO

GEF

GPI-AP

GPA1

GTP

HR

$\mathrm{H}+-$ ATPases

IAA

JA

LecRK

LLG1

LRR

LYK

MAPK

MeJA

NLR

$\mathrm{NO}$

NOX

$\cdot \mathrm{O}_{2}{ }^{-}$

OST 
phosphatidic acid PA

pathogen-associated molecular pattern $\quad$ PAMP

PBS1-like kinase PBL1

phosphatidylcholine $\quad$ PC

programmed cell death $\quad$ PCD

pattern-triggered immunity compromised receptor-like $\quad$ PCRK

cytoplasmic kinase

phosphoenolpyruvic acid $\quad$ PEP

PEP 1 receptor $\quad$ PEPR1

plasma membrane $\quad$ PM

phospholipase D alpha $\quad$ PLDA

peptidoglycan $\quad$ PGN

protein phosphatase 2C $\quad$ PP2C

pattern recognition receptor $\quad$ PRR

PAMP-triggered immunity PTI

PYR-LIKE PYL

pyrabactin resistance protein $\quad$ PYR

receptor for activated $\mathrm{C}$-kinase $\quad$ RACK

rapid alkalinization factors RALF

respiratory burst oxidase homolog $\quad \mathrm{RBOH}$

regularity components of ABA receptor RCAR

receptor-like cytoplasmic kinases $\quad$ RLCK

receptor-like protein kinase RLK

receptor-like kinase-like proteins $\quad$ RLKL

reactive oxygen species ROS

Rho-type GTPases belong to the Rat sarcoma (Ras) superfamily ROP/RAC

of small GTP-binding proteins, and plants have a sole

subfamily of Rho-type GTPases, called ROPs (Rho of plants) or

RACs (for the sequence similarity they share with animal Racs, a Rho subfamily).

salicylic acid

systemic acquired acclimation

salt inducible kinase

SIK

somatic embryogenesis receptor kinase $\quad$ SERK

salicylic acid-induced protein kinase $\quad$ SIPK

sucrose non-fermenting SNF

SNF1-related protein kinase family $\quad$ SnRK

transcription factor $\quad$ TF

wound-induced protein kinase WIPK

a protein that it has an atypical zinc-finger structure at the WRKY

$\mathrm{C}$-terminus and bind preferentially to the core sequence of $\mathrm{W}$

box (TTGACC/T) on the DNA sequence of some promoters

2,4-dichlorophenoxyacetic acid

$2,4-\mathrm{D}$

\section{References}

1. Gapper, C.; Dolan, L. Control of Plant Development by Reactive Oxygen Species. Plant Physiol. 2006, 141, 341-345. [CrossRef]

2. Torres, M.A. Ros in Biotic Interactions. Physiol. Plant. 2010, 138, 414-429. [CrossRef] [PubMed]

3. Mittler, R.V.; Suzuki, S.; Miller, N.; Tognetti, G.; Vandepoele, V.B.; Gollery, K.; Shulaev, M.; Van Breusegem, V.F. Ros Signaling: The New Wave? Trends Plant Sci. 2011, 16, 300-309. [CrossRef] [PubMed]

4. Marino, D.; Dunand, C.; Puppo, A.; Pauly, N. A Burst of Plant NADPH Oxidases. Trends Plant Sci. 2012, 17, 9-15. [CrossRef] [PubMed]

5. Kaur, G.; Sharma, A.; Guruprasad, K.; Pati, P.K. Versatile Roles of Plant NADPH Oxidases and Emerging Concepts. Biotechnol. Adv. 2014, 32, 551-563. [CrossRef] [PubMed] 
6. Sagi, M.; Fluhr, R. Production of Reactive Oxygen Species by Plant NADPH Oxidases. Plant Physiol. 2006, 141, 336-340. [CrossRef] [PubMed]

7. Chang, Y.L.; Li, W.Y.; Miao, H.; Yang, S.Q.; Li, R.; Wang, X.; Li, W.Q.; Chen, K.M. Comprehensive Genomic Analysis and Expression Profiling of the Nox Gene Families under Abiotic Stresses and Hormones in Plants. Genome Biol. Evol. 2016, 8, 791-810. [CrossRef]

8. Hu, C.H.; Wei, X.Y.; Yuan, B.; Yao, L.B.; Ma, T.T.; Zhang, P.P.; Wang, X.; Wang, P.Q.; Liu, W.; Tai, L.; et al. Genome-Wide Identification and Functional Analysis of NADPH Oxidase Family Genes in Wheat during Development and Environmental Stress Responses. Front. Plant Sci. 2018, 9, 906. [CrossRef]

9. Torres, M.A.; Dangl, J.L. Functions of the Respiratory Burst Oxidase in Biotic Interactions, Abiotic Stress and Development. Curr. Opin. Plant Biol. 2005, 8, 397-403. [CrossRef]

10. Bedard, K.; Krause, K.H. The Nox Family of Ros-Generating NADPH Oxidases: Physiology and Pathophysiology. Physiol. Rev. 2007, 87, 245-313. [CrossRef]

11. Bedard, K.; Lardy, B.; Krause, K.H. Nox Family NADPH Oxidases: Not Just in Mammals. Biochimie 2007, 89, 1107-1112. [CrossRef] [PubMed]

12. Aguirre, J.; Rios-Momberg, M.; Hewitt, D.; Hansberg, W. Reactive Oxygen Species and Development in Microbial Eukaryotes. Trends Microbiol. 2005, 13, 111-118. [CrossRef] [PubMed]

13. Babior, B.M.; Lambeth, J.D.; Nauseef, W. The Neutrophil NADPH Oxidase. Arch. Biochem. Biophys. 2002, 397, 342-344. [CrossRef] [PubMed]

14. Lambeth, J.D. Nox Enzymes and the Biology of Reactive Oxygen. Nat. Rev. Immunol. 2004, 4, 181-189. [CrossRef]

15. Cross, A.R.; Segal, A.W. The NADPH Oxidase of Professional Phagocytes-Prototype of the Nox Electron Transport Chain Systems. BBA Bioenerg. 2004, 1657, 1-22. [CrossRef] [PubMed]

16. Leto, T.L.; Geiszt, M. Role of Nox Family NADPH Oxidases in Host Defense. Antioxid. Redox Sign. 2006, 8 , 1549-1561. [CrossRef] [PubMed]

17. Glyan'ko, A.K.; Ischenko, A.A. Structural and Functional Characteristics of Plant NADPH Oxidase: A Review. Appl. Biochem. Microbiol. 2010, 46, 463-471. [CrossRef]

18. Rada, B.; Leto, T. Oxidative Innate Immune Defenses by Nox/Duox Family NADPH Oxidases. In Contributions to Microbiology; Egesten, A., Schmidt, A., Herwald, H., Eds.; Karger: Basel, Switzerland, 2008; pp. 164-187.

19. Wang, G.F.; Li, W.Q.; Li, W.Y.; Wu, L.C.; Zhou, Y.; Chen, K.M. Characterization of Rice NADPH Oxidase Genes and Their Expression under Various Environmental Conditions. Int. J. Mol. Sci. 2013, 14, 9440-9458. [CrossRef]

20. Xing, T.; Higgins, V.J.; Blumwald, E. Race-Specific Elicitors of Cladosporium Fulvum Promote Translocation of Cytosolic Components of NADPH Oxidase to the Plasma Membrane of Tomato Cells. Plant Cell 1997, 9 , 249-259.

21. Wang, X.; Zhang, M.M.; Wang, Y.J.; Gao, Y.T.; Li, R.; Wang, G.F.; Li, W.Q.; Liu, W.T.; Chen, K.M. The Plasma Membrane NADPH Oxidase Osrboha Plays a Crucial Role in Developmental Regulation and Drought-Stress Response in Rice. Physiol. Plant. 2016, 156, 421-443. [CrossRef]

22. Morgante, M.; Brunner, S.; Pea, G.; Fengler, K.; Zuccolo, A.; Rafalski, A. Gene Duplication and Exon Shuffling by Helitron-Like Transposons Generate Intraspecies Diversity in Maize. Nat. Genet. 2005, 37, 997-1002. [CrossRef] [PubMed]

23. Van de Peer, Y.; Fawcett, J.A.; Proost, S.; Sterck, L.; Vandepoele, K. The Flowering World: A Tale of Duplications. Trends Plant Sci. 2009, 14, 680-688. [CrossRef] [PubMed]

24. Kaessmann, H. Origins, Evolution, and Phenotypic Impact of New Genes. Genome Res. 2010, 20, 1313-1326. [CrossRef] [PubMed]

25. Magadum, S.; Banerjee, U.; Murugan, P.; Gangapur, D.; Ravikesavan, R. Gene Duplication as a Major Force in Evolution. J. Genet. 2013, 92, 155-161. [CrossRef]

26. Potocky, M.; Jones, M.A.; Bezvoda, R.; Smirnoff, N.; Zarsky, V. Reactive Oxygen Species Produced by NADPH Oxidase Are Involved in Pollen Tube Growth. New Phytol. 2007, 174, 742-751. [CrossRef]

27. Wang, S.S.; Zhu, X.N.; Lin, J.X.; Zheng, W.J.; Zhang, B.T.; Zhou, J.Q.; Ni, J.; Pan, Z.C.; Zhu, S.H.; Ding, W.N. OsNOX3, encoding a NADPH oxidase, regulates root hair initiation and elongation in rice. Biol. Plant. 2018, 62, 732-740. [CrossRef] 
28. Boisson-Dernier, A.; Lituiev, D.S.; Nestorova, A.; Franck, C.M.; Thirugnanarajah, S.; Grossniklaus, U. Anxur Receptor-Like Kinases Coordinate Cell Wall Integrity with Growth at the Pollen Tube Tip via NADPH Oxidases. PLoS Biol. 2013, 11, e1001719. [CrossRef]

29. Potocky, M.; Pejchar, P.; Gutkowska, M.; Jimenez-Quesada, M.J.; Potocka, A.; Alche Jde, D.; Kost, B.; Zarsky, V. NADPH Oxidase Activity in Pollen Tubes Is Affected by Calcium Ions, Signaling Phospholipids and Rac/Rop Gtpases. J. Plant Physiol. 2012, 169, 1654-1663. [CrossRef]

30. Wang, X.L.; Takai, T.; Kamijo, S.; Gunawan, H.; Ogawa, H.; Okumura, K. NADPH Oxidase Activity in Allergenic Pollen Grains of Different Plant Species. Biochem. Biophys. Res. Commun. 2009, 387, 430-434. [CrossRef]

31. Pasqualini, S.; Tedeschini, E.; Frenguelli, G.; Wopfner, N.; Ferreira, F.; D'Amato, G.; Ederli, L. Ozone Affects Pollen viability and $\mathrm{Nad}(\mathrm{P}) \mathrm{H}$ Oxidase Release from Ambrosia Artemisiifolia Pollen. Environ. Pollut. 2011, 159, 2823-2830. [CrossRef]

32. Kaya, H.; Nakajima, R.; Iwano, M.; Kanaoka, M.M.; Kimura, S.; Takeda, S.; Kawarazaki, T.; Senzaki, E.; Hamamura, Y.; Higashiyama, T.; et al. $\mathrm{Ca}^{2+}$-Activated Reactive Oxygen Species Production by Arabidopsis Rbohh and Rbohj Is Essential for Proper Pollen Tube Tip Growth. Plant Cell 2014, 26, 1069-1080. [CrossRef] [PubMed]

33. Kaya, H.; Iwano, M.; Takeda, S.; Kanaoka, M.M.; Kimura, S.; Abe, M.; Kuchitsu, K. Apoplastic Ros Production Upon Pollination by Rbohh and Rbohj in Arabidopsis. Plant Signal. Behav. 2015, 10, e989050. [CrossRef] [PubMed]

34. Kaya, H.; Takeda, S.; Kobayashi, M.J.; Kimura, S.; Iizuka, A.; Imai, A.; Hishinuma, H.; Kawarazaki, T.; Mori, K.; Yamamoto, Y.; et al. Comparative Analysis of the Reactive Oxygen Species-Producing Enzymatic Activity of Arabidopsis NADPH Oxidases. Plant J. 2019, 98, 291-300. [CrossRef] [PubMed]

35. Xie, H.T.; Wan, Z.Y.; Li, S.; Zhang, Y. Spatiotemporal Production of Reactive Oxygen Species by NADPH Oxidase Is Critical for Tapetal Programmed Cell Death and Pollen Development in Arabidopsis. Plant Cell 2014, 26, 2007-2023. [CrossRef]

36. Jimenez-Quesada, M.J.; Traverso, J.A.; Potocky, M.; Zarsky, V.; Alche, J.D. Generation of Superoxide by Oerbohh, a NADPH Oxidase Activity During Olive (Olea Europaea L.) Pollen Development and Germination. Front. Plant Sci. 2019, 10, 1149. [CrossRef]

37. Cramer, G.R.; Jones, R.L. Osmotic Stress and Abscisic Acid Reduce Cytosolic Calcium Activities in Roots of Arabidopsis Thaliana. Plant Cell Environ. 1996, 19, 1291-1298. [CrossRef]

38. Majumdar, A.; Kar, R.K. Congruence between Pm H+ $\mathrm{H}^{+}$-Atpase and NADPH Oxidase During Root Growth: A Necessary Probability. Protoplasma 2019, 255, 1129-1137. [CrossRef]

39. Bacon, E.; Morre, D.J. Plasma Membrane Nadh Oxidase of Maize Roots Responds to Gravity and Imposed Centrifugal Forces. Plant Physiol. Biochem. 2001, 39, 487-494. [CrossRef]

40. Foreman, J.; Demidchik, V.; Bothwell, J.H.; Mylona, P.; Miedema, H.; Torres, M.A.; Linstead, P.; Costa, S.; Brownlee, C.; Jones, J.D. Reactive Oxygen Species Produced by NADPH Oxidase Regulate Plant Cell Growth. Nature 2003, 422, 442-446. [CrossRef]

41. Jones, M.A.; Raymond, M.J.; Yang, Z.; Smirnoff, N. NADPH Oxidase-Dependent Reactive Oxygen Species Formation Required for Root Hair Growth Depends on Rop Gtpase. J. Exp. Bot. 2007, 58, 1261-1270. [CrossRef]

42. Nestler, J.; Liu, S.Z.; Wen, T.J.; Paschold, A.; Marcon, C.; Tang, H.M.; Li, D.L.; Li, L.; Meeley, R.B.; Sakai, H.; et al. Roothairless5, Which Functions in Maize (Zea Mays L.) Root Hair Initiation and Elongation Encodes a Monocot-Specific NADPH Oxidase. Plant J. 2014, 79, 729-740. [CrossRef]

43. Jiao, Y.; Sun, L.; Song, Y.; Wang, L.; Liu, L.; Zhang, L.; Liu, B.; Li, N.; Miao, C.; Hao, F. Atrbohd and Atrbohf Positively Regulate Abscisic Acid-Inhibited Primary Root Growth by Affecting $\mathrm{Ca}^{2+}$ Signalling and Auxin Response of Roots in Arabidopsis. J. Exp. Bot. 2013, 64, 4183-4192. [CrossRef] [PubMed]

44. Li, N.; Sun, L.; Zhang, L.; Song, Y.; Hu, P.; Li, C.; Hao, F.S. Atrbohd and Atrbohf Negatively Regulate Lateral Root Development by Changing the Localized Accumulation of Superoxide in Primary Roots of Arabidopsis. Planta 2015, 241, 591-602. [CrossRef] [PubMed]

45. Montiel, J.; Arthikala, M.K.; Quinto, C. Phaseolus Vulgaris Rbohb Functions in Lateral Root Development. Plant Signal. Behav. 2013, 8, e22694. [CrossRef] [PubMed]

46. Montiel, J.; Fonseca-García, C.; Quinto, C. Phylogeny and Expression of NADPH Oxidases during Symbiotic Nodule Formation. Agriculture 2018, 8, 179. [CrossRef] 
47. Tewari, R.K.; Kim, S.; Hahn, E.J.; Paek, K.Y. Involvement of Nitric Oxide-Induced NADPH Oxidase in Adventitious Root Growth and Antioxidant Defense in Panax Ginseng. Plant Biotechnol. Rep. 2008, 2, 113-122. [CrossRef]

48. Muller, K.; Carstens, A.C.; Linkies, A.; Torres, M.A.; Leubner-Metzger, G. The Nadph-Oxidase Atrbohb Plays a Role in Arabidopsis Seed after-Ripening. New Phytol. 2009, 184, 885-897. [CrossRef] [PubMed]

49. Li, W.Y.; Chen, B.X.; Chen, Z.J.; Gao, Y.T.; Chen, Z.; Liu, J. Reactive Oxygen Species Generated by NADPH Oxidases Promote Radicle Protrusion and Root Elongation During Rice Seed Germination. Int. J. Mol. Sci. 2017, 18, 110. [CrossRef]

50. Tanaka, A.; Christensen, M.J.; Takemoto, D.; Park, P.; Scott, B. Reactive Oxygen Species Play a Role in Regulating a Fungus-Perennial Ryegrass Mutualistic Interaction. Plant Cell 2006, 18, 1052-1066. [CrossRef]

51. Yushi, I.; Tawaratsumida, T.; Zheng, S.J.; Yuasa, T.; Iwaya-Inoue, M. NADPH Oxidases Act as Key Enzyme on Germination and Seedling Growth in Barley (Hordeum Vulgare L.). Plant Prod. Sci. 2010, 13, 45-52.

52. Ishibashi, Y.; Kasa, S.; Sakamoto, M.; Aoki, N.; Kai, K.; Yuasa, T.; Hanada, A.; Yamaguchi, S.; Iwaya-Inoue, M. A Role for Reactive Oxygen Species Produced by NADPH Oxidases in the Embryo and Aleurone Cells in Barley Seed Germination. PLoS ONE 2015, 10, e0143173. [CrossRef] [PubMed]

53. Kai, K.; Kasa, S.; Sakamoto, M.; Aoki, N.; Watabe, G.; Yuasa, T.; Iwaya-Inoue, M.; Ishibashi, Y. Role of Reactive Oxygen Species Produced by NADPH Oxidase in Gibberellin Biosynthesis During Barley Seed Germination. Plant Signal. Behav. 2016, 11, e1180492. [CrossRef] [PubMed]

54. Montiel, J.; Nava, N.; Cardenas, L.; Sanchez-Lopez, R.; Arthikala, M.K.; Santana, O.; Sanchez, F.; Quinto, C. A Phaseolus Vulgaris NADPH Oxidase Gene Is Required for Root Infection by Rhizobia. Plant Cell Physiol. 2012, 53, 1751-1767. [CrossRef] [PubMed]

55. Arthikala, M.K.; Sanchez-Lopez, R.; Nava, N.; Santana, O.; Cardenas, L.; Quinto, C. Rbohb, a Phaseolus Vulgaris NADPH Oxidase Gene, Enhances Symbiosome Number, Bacteroid Size, and Nitrogen Fixation in Nodules and Impairs Mycorrhizal Colonization. New Phytol. 2014, 202, 886-900. [CrossRef]

56. Marino, D.; Andrio, E.; Danchin, E.G.; Oger, E.; Gucciardo, S.; Lambert, A.; Puppo, A.; Pauly, N. A Medicago Truncatula NADPH Oxidase Is Involved in Symbiotic Nodule Functioning. New Phytol. 2011, 189, 580-592. [CrossRef]

57. Kayano, Y.; Tanaka, A.; Akano, F.; Scott, B.; Takemoto, D. Differential Roles of NADPH Oxidases and Associated Regulators in Polarized Growth, Conidiation and Hyphal Fusion in the Symbiotic Fungus Epichloe Festucae. Fungal Genet. Biol. 2013, 56, 87-97. [CrossRef]

58. Nordzieke, D.E.; Fernandes, T.R.; El Ghalid, M.; Turra, D.; Di Pietro, A. NADPH Oxidase Regulates Chemotropic Growth of the Fungal Pathogen Fusarium Oxysporum Towards the Host Plant. New Phytol. 2019, 224, 1600-1612. [CrossRef]

59. Zhang, Z.B.; Zhao, Y.L.; Feng, X.B.; Luo, Z.Y.; Kong, S.W.; Zhang, C.; Gong, A.D.; Yuan, H.; Cheng, L.; Wang, X.N. Genomic, Molecular Evolution, and Expression Analysis of Nox Genes in Soybean (Glycine Max). Genomics 2019, 111, 619-628. [CrossRef]

60. Lara-Ortíz, T.; Riveros-Rosas, H.; Aguirre, J. Reactive Oxygen Species Generated by Microbial NADPH Oxidase Noxa Regulate Sexual Development in Aspergillus Nidulans. Mol. Microbiol. 2003, 50, 1241-1255. [CrossRef]

61. Dirschnabel, D.E.; Nowrousian, M.; Cano-Dominguez, N.; Aguirre, J.; Teichert, I.; Kuck, U. New Insights into the Roles of NADPH Oxidases in Sexual Development and Ascospore Germination in Sordaria Macrospora. Genetics 2014, 196, 729-744. [CrossRef]

62. Cano-Dominguez, N.; Alvarez-Delfin, L.; Hansberg, W.; Aguirre, J. NADPH Oxidases Nox-1 and Nox-2 Require the Regulatory Subunit nor-1 to Control Cell Differentiation and Growth in Neurospora Crassa. Eukaryot. Cell 2018, 7, 1352-1361. [CrossRef] [PubMed]

63. Roca, M.G.; Weichert, M.; Siegmund, U.; Tudzynski, P.; Fleissner, A. Germling Fusion via Conidial Anastomosis Tubes in the Grey Mould Botrytis Cinerea Requires NADPH Oxidase Activity. Fungal Biol. 2012, 116, 379-387. [CrossRef] [PubMed]

64. Zhang, J.; Chen, C.; Zhang, D.; Li, H.; Li, P.; Ma, F. Reactive Oxygen Species Produced via Plasma Membrane NADPH Oxidase Regulate Anthocyanin Synthesis in Apple Peel. Planta 2014, 240, 1023-1035. [CrossRef] [PubMed] 
65. Tewari, R.K.; Watanabe, D.; Watanabe, M. Chloroplastic NADPH Oxidase-Like Activity-Mediated Perpetual Hydrogen Peroxide Generation in the Chloroplast Induces Apoptotic-Like Death of Brassica Napus Leaf Protoplasts. Planta 2012, 235, 99-110. [CrossRef] [PubMed]

66. Liu, B.; Zhao, S.; Tan, F.; Zhao, H.; Wang, D.; Si, H.; Chen, Q. Changes in Ros Production and Antioxidant Capacity during Tuber Sprouting in Potato. Food Chem. 2017, 237, 205-213. [CrossRef] [PubMed]

67. Kadota, Y.; Shirasu, K.; Zipfel, C. Regulation of the NADPH Oxidase Rbohd During Plant Immunity. Plant Cell Physiol. 2015, 56, 1472-1480. [CrossRef] [PubMed]

68. Wang, Y.J.; Wei, X.Y.; Jing, X.Q.; Chang, Y.L.; Hu, C.H.; Wang, X.; Chen, K.M. The Fundamental Role of Nox Family Proteins in Plant Immunity and Their Regulation. Int. J. Mol. Sci. 2016, 17, 805. [CrossRef]

69. Morales, J.; Kadota, Y.; Zipfel, C.; Molina, A.; Torres, M.A. The Arabidopsis NADPH Oxidases Rbohd and Rbohf Display Differential Expression Patterns and Contributions During Plant Immunity. J. Exp. Bot. 2016, 67, 1663-1676. [CrossRef]

70. Kadota, Y.; Sklenar, J.; Derbyshire, P.; Stransfeld, L.; Asai, S.; Ntoukakis, V.; Jones, J.D.; Shirasu, K.; Menke, F.; Jones, A.; et al. Direct Regulation of the NADPH Oxidase Rbohd by the Prr-Associated Kinase Bik1 During Plant Immunity. Mol. Cell 2014, 54, 43-55. [CrossRef]

71. Pogany, M.; von Rad, U.; Grun, S.; Dongo, A.; Pintye, A.; Simoneau, P.; Bahnweg, G.; Kiss, L.; Barna, B.; Durner, J. Dual Roles of Reactive Oxygen Species and NADPH Oxidase Rbohd in an Arabidopsis-Alternaria Pathosystem. Plant Physiol. 2009, 151, 1459-1475. [CrossRef]

72. Chaouch, S.; Queval, G.; Noctor, G. Atrbohf Is a Crucial Modulator of Defence-Associated Metabolism and a Key Actor in the Interplay between Intracellular Oxidative Stress and Pathogenesis Responses in Arabidopsis. Plant J. 2012, 69, 613-627. [CrossRef] [PubMed]

73. Liu, H.B.; Wang, X.D.; Zhang, Y.Y.; Dong, J.J.; Ma, C.; Chen, W.L. NADPH Oxidase Rbohd Contributes to Autophagy and Hypersensitive Cell Death During the Plant Defense Response in Arabidopsis Thaliana. Biol. Plant. 2015, 59, 570-580. [CrossRef]

74. Foley, R.C.; Gleason, C.A.; Anderson, J.P.; Hamann, T.; Singh, K.B. Genetic and Genomic Analysis of Rhizoctonia Solani Interactions with Arabidopsis; Evidence of Resistance Mediated through NADPH Oxidases. PLoS ONE 2013, 8, e56814. [CrossRef] [PubMed]

75. Zhen, Y.; Islam, M.R.; Badawi, M.A.; El-Bebany, A.F.; Daayf, F. Overexpression of Strboha in Arabidopsis Thaliana Enhances Defence Responses against Verticillium Dahliae. Physiol. Mol. Plant Pathol. 2015, 90, 105-114.

76. Zhang, Z.; Yang, F.; Na, R.; Zhang, X.; Yang, S.; Gao, J.; Fan, M.; Zhao, Y.; Zhao, J. Atrop1 Negatively Regulates Potato Resistance to Phytophthora Infestans via NADPH Oxidase-Mediated Accumulation of $\mathrm{H}_{2} \mathrm{O}_{2}$. BMC Plant Biol. 2014, 14, 392. [CrossRef] [PubMed]

77. Yoshioka, H.; Adachi, H.; Nakano, T.; Miyagawa, N.; Asai, S.; Ishihama, N.; Yoshioka, M. Hierarchical Regulation of NADPH Oxidase by Protein Kinases in Plant Immunity. Physiol. Mol. Plant Pathol. 2016, 95, 20-26. [CrossRef]

78. Lherminier, J.; Elmayan, T.; Fromentin, J.; Elaraqui, K.T.; Vesa, S.; Morel, J.; Verrier, J.L.; Cailleteau, B.; Blein, J.P.; Simon-Plas, F. NADPH Oxidase-Mediated Reactive Oxygen Species Production: Subcellular Localization and Reassessment of Its Role in Plant Defense. Mol. Plant-Microbe Interact. 2009, 22, 868-881. [CrossRef]

79. Dubiella, U.; Seybold, H.; Durian, G.; Komander, E.; Lassig, R.; Witte, C.P.; Schulze, W.X.; Romeis, T. Calcium-Dependent Protein Kinase/NADPH Oxidase Activation Circuit Is Required for Rapid Defense Signal Propagation. Proc. Natl. Acad. Sci. USA 2013, 110, 8744-8749. [CrossRef]

80. Yoshiaki, Y.; Goto, K.; Takai, R.; Iwano, M.; Takayama, S.; Isogai, A.; Che, F.S. Function of the Rice gp91phox Homologs OsrbohA and OsrbohE Genes in Ros-Dependent Plant Immune Responses. Plant Biotechnol. 2015, 22, 127-135.

81. Egan, M.J.; Wang, Z.Y.; Jones, M.A.; Smirnoff, M.; Talbot, N.J. Generation of Reactive Oxygen Species by Fungal NADPH Oxidases Is Required for Rice Blast Disease. Proc. Natl. Acad. Sci. USA 2007, 104, 11772-11777. [CrossRef]

82. Proels, R.K.; Oberhollenzer, K.; Pathuri, I.P.; Hensel, G.; Kumlehn, J.; Huckelhoven, R. Rbohf2 of Barley Is Required for Normal Development of Penetration Resistance to the Parasitic Fungus Blumeria Graminis F. sp. Hordei. Mol. Plant-Microbe Interact. 2010, 23, 1143-1150. [CrossRef] [PubMed] 
83. Trujillo, M.; Altschmied, L.; Schweizer, P.; Kogel, K.H.; Huckelhoven, R. Respiratory Burst Oxidase Homologue a of Barley Contributes to Penetration by the Powdery Mildew Fungus Blumeria Graminis F. sp. Hordei. J. Exp. Bot. 2006, 57, 3781-3891. [CrossRef]

84. Zhang, H.; Fang, Q.; Zhang, Z.; Wang, Y.; Zheng, X. The Role of Respiratory Burst Oxidase Homologues in Elicitor-Induced Stomatal Closure and Hypersensitive Response in Nicotiana Benthamiana. J. Exp. Bot. 2009, 60, 3109-3122. [CrossRef]

85. Chen, D.; Cao, Y.; Li, H.; Kim, D.; Ahsan, N.; Thelen, J.; Stacey, G. Extracellular Atp Elicits Dorn1-Mediated Rbohd Phosphorylation to Regulate Stomatal Aperture. Nat. Commun. 2017, 8, 2265. [CrossRef] [PubMed]

86. Toum, L.; Torres, P.S.; Gallego, S.M.; Benavides, M.P.; Vojnov, A.A.; Gudesblat, G.E. Coronatine Inhibits Stomatal Closure through Guard Cell-Specific Inhibition of NADPH Oxidase-Dependent Ros Production. Front. Plant Sci. 2016, 7, 1851. [CrossRef] [PubMed]

87. Song, C.J.; Steinebrunner, I.; Wang, X.; Stout, S.C.; Roux, S.J. Extracellular Atp Induces the Accumulation of Superoxide via NADPH Oxidases in Arabidopsis. Plant Physiol. 2006, 140, 1222-1232. [CrossRef]

88. Clark, G.; Wu, M.; Wat, N.; Onyirimba, J.; Pham, T.; Herz, N.; Ogoti, J.; Gomez, D.; Canales, A.A.; Aranda, G.; et al. Both the Stimulation and Inhibition of Root Hair Growth Induced by Extracellular Nucleotides in Arabidopsis Are Mediated by Nitric Oxide and Reactive Oxygen Species. Plant Mol. Biol. 2010, 74, 423-435. [CrossRef]

89. Clark, G.; Fraley, D.; Steinebrunner, I.; Cervantes, A.; Onyirimba, J.; Liu, A.; Torres, J.; Tang, W.; Kim, J.; Roux, S.J. Extracellular Nucleotides and Apyrases Regulate Stomatal Aperture in Arabidopsis. Plant Physiol. 2011, 156, 1740-1753. [CrossRef]

90. Clark, G.; Darwin, C.; Mehta, V.; Jackobs, F.; Perry, T.; Hougaard, K.; Roux, S. Effects of Chemical Inhibitors and Apyrase Enzyme Further Document a Role for Apyrases and Extracellular Atp in the Opening and Closing of Stomates in Arabidopsis. Plant Signal. Behav. 2013, 8, e26093. [CrossRef]

91. Giesbert, S.; Schurg, T.; Scheele, S.; Tudzynski, P. The NADPH Oxidase Cpnox1 Is Required for Full Pathogenicity of the Ergot Fungus Claviceps Purpurea. Mol. Plant Pathol. 2008, 9, 317-327. [CrossRef]

92. Chung, K.R. Reactive Oxygen Species in the Citrus Fungal Pathogen Alternaria Alternata: The Roles of Nadph-Dependent Oxidase. Physiol. Mol. Plant Pathol. 2014, 88, 10-17. [CrossRef]

93. Lima, M.R.M.; Alberto, C.P.D. Phaeomoniella Chlamydospora-Induced Oxidative Burst in Vitis Vinifera Cell Suspensions: Role of NADPH Oxidase and $\mathrm{Ca}^{2+}$. J. Phytopathol. 2012, 160, 129-134. [CrossRef]

94. Arthikala, M.K.; Montiel, J.; Sanchez-Lopez, R.; Nava, N.; Cardenas, L.; Quinto, C. Respiratory Burst Oxidase Homolog Gene a Is Crucial for Rhizobium Infection and Nodule Maturation and Function in Common Bean. Front. Plant Sci. 2017, 8, 2003. [CrossRef] [PubMed]

95. Montiel, J.; Arthikala, M.K.; Cardenas, L.; Quinto, C. Legume NADPH Oxidases Have Crucial Roles at Different Stages of Nodulation. Int. J. Mol. Sci. 2016, 17, 680. [CrossRef]

96. Kurusu, T.; Kuchitsu, K.; Tada, Y. Plant Signaling Networks Involving Ca ${ }^{2+}$ and Rboh/Nox-Mediated Ros Production under Salinity Stress. Front. Plant Sci. 2015, 6, 8. [CrossRef]

97. Ulrich, D.; Stephan, A.B.; Horie, T.; Luo, W.; Xu, G.H.; Schroeder, J.I. Plant Salt-Tolerance Mechanisms. Trends Plant Sci. 2014, 19, 371-379.

98. Ma, L.; Zhang, H.; Sun, L.; Jiao, Y.; Zhang, G.; Miao, C.; Hao, F. NADPH Oxidase Atrbohd and Atrbohf Function in Ros-Dependent Regulation of $\mathrm{Na}^{+} / \mathrm{K}^{+}$Homeostasis in Arabidopsis under Salt Stress. J. Exp. Bot. 2012, 63, 305-317. [CrossRef]

99. Ben Rejeb, K.; Benzarti, M.; Debez, A.; Bailly, C.; Savoure, A.; Abdelly, C. NADPH Oxidase-Dependent $\mathrm{H}_{2} \mathrm{O}_{2}$ Production Is Required for Salt-Induced Antioxidant Defense in Arabidopsis Thaliana. J. Plant Physiol. 2015, 174, 5-15. [CrossRef]

100. Ben Rejeb, K.; Lefebvre-De Vos, D.; Le Disquet, I.; Leprince, A.S.; Bordenave, M.; Maldiney, R.; Jdey, A.; Abdelly, C.; Savoure, A. Hydrogen Peroxide Produced by NADPH Oxidases Increases Proline Accumulation During Salt or Mannitol Stress in Arabidopsis Thaliana. New Phytol. 2015, 208, 1138-1148. [CrossRef]

101. Sakamoto, H.; Matsuda, O.; Iba, K. Itn1, a Novel Gene Encoding an Ankyrin-Repeat Protein That Affects the Aba-Mediated Production of Reactive Oxygen Species and Is Involved in Salt-Stress Tolerance in Arabidopsis Thaliana. Plant J. 2008, 56, 411-422. [CrossRef]

102. Liu, Y.; He, C. Regulation of Plant Reactive Oxygen Species (ROS) in Stress Responses: Learning from Atrbohd. Plant Cell Rep. 2016, 35, 995-1007. [CrossRef] 
103. Miller, G.; Schlauch, K.; Tam, R.; Cortes, D.; Torres, M.A.; Shulaev, V.; Dangl, J.L.; Mittler, R. The Plant NADPH Oxidase Rbohd Mediates Rapid Systemic Signaling in Response to Diverse Stimuli. Sci. Signal. 2009, 2, ra45. [CrossRef] [PubMed]

104. Mittler, R.; Blumwald, E. The Roles of Ros and Aba in Systemic Acquired Acclimation. Plant Cell 2015, 27, 64-70. [CrossRef] [PubMed]

105. Li, B.; Xing, D.; Zhang, L. Involvement of NADPH Oxidase in Sulfur Dioxide-Induced Oxidative Stress in Plant Cells. Photochem. Photobiol. Sci. 2007, 6, 628-634. [CrossRef] [PubMed]

106. Niu, M.; Huang, Y.; Sun, S.; Sun, J.; Cao, H.; Shabala, S.; Bie, Z. Root Respiratory Burst Oxidase Homologue-Dependent $\mathrm{H}_{2} \mathrm{O}_{2}$ Production Confers Salt Tolerance on a Grafted Cucumber by Controlling $\mathrm{Na}^{+}$Exclusion and Stomatal Closure. J. Exp. Bot. 2018, 69, 3465-3476. [CrossRef] [PubMed]

107. Xu, S.; Zhou, J.; Qin, Y.; Liu, L.; Chen, J. Water-Forming Nadh Oxidase Protects Torulopsis Glabrata against Hyperosmotic Stress. Yeast 2010, 27, 207-216. [PubMed]

108. Rodriguez, A.A.; Lascano, H.R.; Bustos, D.; Taleisnik, E. Salinity-Induced Decrease in NADPH Oxidase Activity in the Maize Leaf Blade Elongation Zone. J. Plant Physiol. 2007, 164, 223-230. [CrossRef]

109. Shiuan, L.I.; Wu, Y.S.; Chen, C.T.; Chen, G.H.; Hwang, S.G.; Jauh, G.Y.; Tzen, J.; Yang, C.Y. Atrboh I Confers Submergence Tolerance and Is Involved in Auxin-Mediated Signaling Pathways under Hypoxic Stress. Plant Growth Regul. 2017, 83, 277-285.

110. Yang, C.Y.; Hong, C.P. The NADPH Oxidase Rboh D Is Involved in Primary Hypoxia Signalling and Modulates Expression of Hypoxia-Inducible Genes under Hypoxic Stress. Environ. Exp. Bot. 2015, 115, 63-72. [CrossRef]

111. Liu, B.; Sun, L.; Ma, L.; Hao, F.S. Both Atrbohd and Atrbohf Are Essential for Mediating Responses to Oxygen Deficiency in Arabidopsis. Plant Cell Rep. 2017, 36, 947-957. [CrossRef]

112. Wu, Y.S.; Yang, C.Y. Physiological Responses and Expression Profile of NADPH Oxidase in Rice (Oryza Sativa) Seedlings under Different Levels of Submergence. Rice 2016, 9, 2. [CrossRef] [PubMed]

113. Yamauchi, T.; Yoshioka, M.; Fukazawa, A.; Mori, H.; Nishizawa, N.K.; Tsutsumi, N.; Yoshioka, H.; Nakazono, M. An NADPH Oxidase Rboh Functions in Rice Roots During Lysigenous Aerenchyma Formation under Oxygen-Deficient Conditions. Plant Cell 2017, 29, 775-790. [CrossRef] [PubMed]

114. Gupta, D.K.; Pena, L.B.; Romero-Puertas, M.C.; Hernandez, A.; Inouhe, M.; Sandalio, L.M. NADPH Oxidases Differentially Regulate Ros Metabolism and Nutrient Uptake under Cadmium Toxicity. Plant Cell Environ. 2017, 40, 509-526. [CrossRef]

115. Chaoui, A.; Jarrar, B.; Ferjani, E.E. Effects of Cadmium and Copper on Peroxidase, Nadh Oxidase and Iaa Oxidase Activities in Cell Wall, Soluble and Microsomal Membrane Fractions of Pea Roots. J. Plant Physiol. 2004, 161, 1225-1234. [CrossRef] [PubMed]

116. Groppa, M.D.; Ianuzzo, M.P.; Rosales, E.P.; Vazquez, S.C.; Benavides, M.P. Cadmium Modulates NADPH Oxidase Activity and Expression in Sunflower Leaves. Biol. Plant. 2012, 56, 167-171. [CrossRef]

117. Jakubowska, D.; Janicka-Russak, M.; Kabala, K.; Migocka, M.; Reda, M. Modification of Plasma Membrane NADPH Oxidase Activity in Cucumber Seedling Roots in Response to Cadmium Stress. Plant Sci. 2015, 234, 50-59. [CrossRef]

118. Jakubowska, D.; Janicka, M. The Role of Brassinosteroids in the Regulation of the Plasma Membrane $\mathrm{H}^{+}$-Atpase and NADPH Oxidase under Cadmium Stress. Plant Sci. 2017, 264, 37-47. [CrossRef]

119. Pourrut, B.; Perchet, G.; Silvestre, J.; Cecchi, M.; Guiresse, M.; Pinelli, E. Potential Role of Nadph-Oxidase in Early Steps of Lead-Induced Oxidative Burst in Vicia Faba Roots. J. Plant Physiol. 2008, 165, 571-579. [CrossRef]

120. Hao, F.S.; Wang, X.C.; Chen, J. Involvement of Plasma-Membrane NADPH Oxidase in Nickel-Induced Oxidative Stress in Roots of Wheat Seedlings. Plant Sci. 2006, 170, 151-158. [CrossRef]

121. Gupta, D.K.; Inouhe, M.; Rodriguez-Serrano, M.; Romero-Puertas, M.C.; Sandalio, L.M. Oxidative Stress and Arsenic Toxicity: Role of NADPH Oxidases. Chemosphere 2013, 90, 1987-1996. [CrossRef]

122. Sagi, M.; Davydov, O.; Orazova, S.; Yesbergenova, Z.; Ophir, R.; Stratmann, J.W.; Fluhr, R. Plant Respiratory Burst Oxidase Homologs Impinge on Wound Responsiveness and Development in Lycopersicon Esculentum. Plant Cell 2004, 16, 616-628. [CrossRef] [PubMed]

123. Kumar, G.N.; Iyer, S.; Knowles, N.R. Strboh a Homologue of NADPH Oxidase Regulates Wound-Induced Oxidative Burst and Facilitates Wound-Healing in Potato Tubers. Planta 2007, 227, 25-36. [CrossRef] [PubMed] 
124. Wu, J.; Wang, L.; Wunsche, H.; Baldwin, I.T. Narboh D, a Respiratory Burst Oxidase Homolog in Nicotiana Attenuata, Is Required for Late Defense Responses after Herbivore Attack. J. Integr. Plant Biol. 2013, 55, 187-198. [CrossRef] [PubMed]

125. Piotrovskii, M.S.; Shevyreva, T.A.; Zhestkova, I.M.; Trofimova, M.S. Activation of Plasmalemmal NADPH Oxidase in Etiolated Maize Seedlings Exposed to Chilling Temperatures. Russ. J. Plant Physiol. 2011, 58, 290-298. [CrossRef]

126. Kawarazaki, T.; Kimura, S.; Iizuka, A.; Hanamata, S.; Nibori, H.; Michikawa, M.; Imai, A.; Abe, M.; Kaya, H.; Kuchitsu, K. A Low Temperature-Inducible Protein Atsrc2 Enhances the Ros-Producing Activity of NADPH Oxidase Atrbohf. Biochim. Biophys. Acta 2013, 1833, 2775-2780. [CrossRef]

127. Zhang, Y.; Li, Y.; He, Y.; Hu, W.; Zhang, Y.; Wang, X.; Tang, H. Identification of NADPH Oxidase Family Members Associated with Cold Stress in Strawberry. FEBS Open Bio 2018, 8, 593-605. [CrossRef]

128. Yoshioka, H.; Numata, N.; Nakajima, K.; Katou, S.; Kawakita, K.; Rowland, O.; Jones, J.D.G.; Doke, N. Nicotiana Benthamiana gp91 ${ }^{\text {(Phox) }}$ Homologs Nbrboha and Nbrbohb Participate in $\mathrm{H}_{2} \mathrm{O}_{2}$ Accumulation and Resistance to Phytophthora Infestans. Plant Cell 2003, 15, 706-718. [CrossRef]

129. Kiraly, L.; Hafez, Y.M.; Fodor, J.; Kiraly, Z. Suppression of Tobacco Mosaic Virus-Induced Hypersensitive-Type Necrotization in Tobacco at High Temperature Is Associated with Downregulation of NADPH Oxidase and Superoxide and Stimulation of Dehydroascorbate Reductase. J. Gen. Virol. 2008, 89, 799-808. [CrossRef]

130. Jiang, M.; Zhang, J. Involvement of Plasma-Membrane NADPH Oxidase in Abscisic Acid- and Water Stress-Induced Antioxidant Defense in Leaves of Maize Seedlings. Planta 2002, 215, 1022-1030. [CrossRef]

131. Duan, Z.Q.; Bai, L.; Zhao, Z.G.; Zhang, G.P.; Cheng, F.M.; Jiang, L.X.; Chen, K.M. Drought-Stimulated Activity of Plasma Membrane Nicotinamide Adenine Dinucleotide Phosphate Oxidase and Its Catalytic Properties in Rice. J. Integr. Plant Biol. 2009, 51, 1104-1115. [CrossRef]

132. Rohollahi, I.; Khoshkholghsima, N.; Nagano, H.; Hoshino, Y.; Yamada, T. Respiratory Burst Oxidase-D Expression and Biochemical Responses in Festuca Arundinacea under Drought Stress. Crop. Sci. 2018, 58, 435-442. [CrossRef]

133. Brightman, A.O.; Barr, R.; Crane, F.L.; Morre, D.J. Auxin-Stimulated Nadh Oxidase Purified from Plasma Membrane of Soybean. Plant Physiol. 1988, 86, 1264-1269. [CrossRef] [PubMed]

134. Morre, D.J.; Gomez-Rey, M.L.; Schramke, C.; Em, O.; Lawler, J.; Hobeck, J.; Morre, D.M. Use of Dipyridyl-Dithio Substrates to Measure Directly the Protein Disulfide-Thiol Interchange Activity of the Auxin Stimulated Nadh: Protein Disulfide Reductase (Nadh Oxidase) of Soybean Plasma Membranes. Mol. Cell. Biochem. 1999, 200, 7-13. [CrossRef] [PubMed]

135. Cheng, X.; Li, G.; Manzoor, M.A.; Wang, H.; Abdullah, M.; Su, X.; Zhang, J.; Jiang, T.; Jin, Q.; Cai, Y.; et al. In Silico Genome-Wide Analysis of Respiratory Burst Oxidase Homolog (Rboh) Family Genes in Five Fruit-Producing Trees, and Potential Functional Analysis on Lignification of Stone Cells in Chinese White Pear. Cells 2019, 8, 520. [CrossRef] [PubMed]

136. Li, Z.; Wang, F.; Zhao, Q.; Liu, J.; Cheng, F. Involvement of NADPH Oxidase Isoforms in the Production of O2- Manipulated by Aba in the Senescing Leaves of Early-Senescence-Leaf (Esl) Mutant Rice (Oryza Sativa). PLoS ONE 2018, 13, e0190161. [CrossRef] [PubMed]

137. Hao, F.S.; Zhang, J.G.; Yu, Z.L.; Chen, J. Involvement of NADPH Oxidase Ntrbohd in the Rapid Production of $\mathrm{H}_{2} \mathrm{O}_{2}$ Induced by Aba in Cultured Tobacco Cell Line by-2. Prog. Nat. Sci. 2008, 18, 267-271. [CrossRef]

138. Jiang, M.; Zhang, J. Crosstalk between Calcium and Reactive Oxygen Species Originated from NADPH Oxidase in Abscisic Acid-Induced Antioxidant Defence in Leaves of Maize Seedlings. Plant Cell Environ. 2003, 26, 929-939. [CrossRef]

139. Chen, H.J.; Huang, C.S.; Huang, G.J.; Chow, T.J.; Lin, Y.H. NADPH Oxidase Inhibitor Diphenyleneiodonium and Reduced Glutathione Mitigate Ethephon-Mediated Leaf Senescence, $\mathrm{H}_{2} \mathrm{O}_{2}$ Elevation and Senescence-Associated Gene Expression in Sweet Potato (Ipomoea Batatas). J. Plant Physiol. 2013, 170, 1471-1483. [CrossRef]

140. Kaur, G.; Pati, P.K. Analysis of Cis-Acting Regulatory Elements of Respiratory Burst Oxidase Homolog (Rboh) Gene Families in Arabidopsis and Rice Provides Clues for Their Diverse Functions. Comput. Biol. Chem. 2016, 62, 104-118. [CrossRef]

141. Gadjev, I.; Vanderauwera, S.; Gechev, T.S.; Laloi, C.; Minkov, I.N.; Shulaev, V.; Apel, K.; Inze, D.; Mittler, R.; Van Breusegem, F. Transcriptomic Footprints Disclose Specificity of Reactive Oxygen Species Signaling in Arabidopsis. Plant Physiol. 2006, 141, 436-445. [CrossRef] 
142. Petrov, V.; Vermeirssen, V.; De Clercq, I.; Van Breusegem, F.; Minkov, I.; Vandepoele, K.; Gechev, T.S. Identification of Cis-Regulatory Elements Specific for Different Types of Reactive Oxygen Species in Arabidopsis Thaliana. Gene 2012, 499, 52-60. [CrossRef] [PubMed]

143. Arthur, J.S.; Ley, S.C. Mitogen-Activated Protein Kinases in Innate Immunity. Nat. Rev. Immunol. 2013, 13, 679-692. [CrossRef] [PubMed]

144. Meng, X.; Zhang, S. Mapk Cascades in Plant Disease Resistance Signaling. Annu. Rev. Phytopathol. 2013, 51, 245-266. [CrossRef] [PubMed]

145. Tsuda, K.; Somssich, I.E. Transcriptional Networks in Plant Immunity. New Phytol. 2015, 206, $932-947$. [CrossRef] [PubMed]

146. Adachi, H.; Nakano, T.; Miyagawa, N.; Ishihama, N.; Yoshioka, M.; Katou, Y.; Yaeno, T.; Shirasu, K.; Yoshioka, H. Wrky Transcription Factors Phosphorylated by Mapk Regulate a Plant Immune NADPH Oxidase in Nicotiana Benthamiana. Plant Cell 2015, 27, 2645-2663. [CrossRef] [PubMed]

147. Ishihama, N.; Yamada, R.; Yoshioka, M.; Katou, S.; Yoshioka, H. Phosphorylation of the Nicotiana Benthamiana Wrky8 Transcription Factor by Mapk Functions in the Defense Response. Plant Cell 2011, 23, 1153-1170. [CrossRef]

148. Mersmann, S.; Bourdais, G.; Rietz, S.; Robatzek, S. Ethylene Signaling Regulates Accumulation of the Fls2 Receptor and Is Required for the Oxidative Burst Contributing to Plant Immunity. Plant Physiol. 2010, 154, 391-400. [CrossRef]

149. Boudsocq, M.; Willmann, M.R.; McCormack, M.; Lee, H.; Shan, L.; He, P.; Bush, J.; Cheng, S.H.; Sheen, J. Differential Innate Immune Signalling via $\mathrm{Ca}^{2+}$ Sensor Protein Kinases. Nature 2010, 464, 418-422. [CrossRef]

150. Asai, S.; Ohta, K.; Yoshioka, H. Mapk Signaling Regulates Nitric Oxide and NADPH Oxidase-Dependent Oxidative Bursts in Nicotiana Benthamiana. Plant Cell 2008, 20, 1390-1406. [CrossRef]

151. Kovtun, Y.; Chiu, W.L.; Tena, G.; Sheen, J. Functional Analysis of Oxidative Stress-Activated Mitogen-Activated Protein Kinase Cascade in Plants. Proc. Natl. Acad. Sci. USA 2000, 97, 2940-2945. [CrossRef]

152. Lin, F.; Ding, H.; Wang, J.; Zhang, H.; Zhang, A.; Zhang, Y.; Tan, M.; Dong, W.; Jiang, M. Positive Feedback Regulation of Maize NADPH Oxidase by Mitogen-Activated Protein Kinase Cascade in Abscisic Acid Signalling. J. Exp. Bot. 2009, 60, 3221-3238. [CrossRef] [PubMed]

153. Sirichandra, C.; Gu, D.; Hu, H.C.; Davanture, M.; Lee, S.; Djaoui, M.; Valot, B.; Zivy, M.; Leung, J.; Merlot, S.; et al. Phosphorylation of the Arabidopsis Atrbohf NADPH Oxidase by Ost1 Protein Kinase. FEBS Lett. 2009, 583, 2982-2986. [CrossRef] [PubMed]

154. Nibau, C.; Wu, H.M.; Cheung, A.Y. Rac/Rop Gtpases: 'Hubs' for Signal Integration and Diversification in Plants. Trends Plant Sci. 2006, 11, 309-315. [CrossRef] [PubMed]

155. Shin, L.J.; Huang, H.E.; Chang, H.; Lin, Y.H.; Feng, T.Y.; Ger, M.J. Ectopic Ferredoxin I Protein Promotes Root Hair Growth through Induction of Reactive Oxygen Species in Arabidopsis Thaliana. J. Plant Physiol. 2011, 168, 434-440. [CrossRef] [PubMed]

156. Oda, T.; Hashimoto, H.; Kuwabara, N.; Akashi, S.; Hayashi, K.; Kojima, C.; Wong, H.L.; Kawasaki, T.; Shimamoto, K.; Sato, M.; et al. Structure of the N-Terminal Regulatory Domain of a Plant NADPH Oxidase and Its Functional Implications. J. Biol. Chem. 2010, 285, 1435-1445. [CrossRef]

157. Kobayashi, M.; Ohura, I.; Kawakita, K.; Yokota, N.; Fujiwara, M.; Shimamoto, K.; Doke, N.; Yoshioka, H. Calcium-Dependent Protein Kinases Regulate the Production of Reactive Oxygen Species by Potato NADPH Oxidase. Plant Cell 2007, 19, 1065-1080. [CrossRef]

158. Ogasawara, Y.; Kaya, H.; Hiraoka, G.; Yumoto, F.; Kimura, S.; Kadota, Y.; Hishinuma, H.; Senzaki, E.; Yamagoe, S.; Nagata, K.; et al. Synergistic Activation of the Arabidopsis NADPH Oxidase Atrbohd by Ca2+ and Phosphorylation. J. Biol. Chem. 2008, 283, 8885-8892. [CrossRef]

159. Waszczak, C.; Carmody, M.; Kangasjarvi, J. Reactive Oxygen Species in Plant Signaling. Annu. Rev. Plant Biol. 2018, 69, 209-236. [CrossRef]

160. McAinsh, M.R.; Clayton, H.; Mansfield, T.A.; Hetherington, A.M. Changes in Stomatal Behavior and Guard Cell Cytosolic Free Calcium in Response to Oxidative Stress. Plant Physiol. 1996, 111, 1031-1042. [CrossRef]

161. Pei, Z.M.; Murata, Y.; Benning, G.; Thomine, S.; KluÈsener, B.; Allen, G.J.; Grill, E.; Schroeder, J.I. Calcium Channels Activated by Hydrogen Peroxide Mediate Abscisic Acid Signalling in Guard Cells. Nature 2000, 406, 732-734. [CrossRef] 


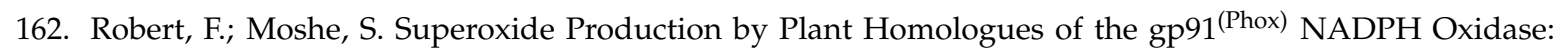
Mmodulation of Activity by Calcium and by Tobacco Mosaic Virus Infection. Plant Physiol. Biochem. 2001, $126,1281-1290$.

163. Xing, T.; Wang, X.J.; Malik, K.; Miki, B.L. Ectopic Expression of an Arabidopsis Calmodulin-Like Domain Protein Kinase-Enhanced NADPH Oxidase Activity and Oxidative Burst in Tomato Protoplasts. Mol. Plant-Microbe Interact. 2001, 14, 1261-1264. [CrossRef] [PubMed]

164. Ludwig, A.A.; Saitoh, H.; Felix, G.; Freymark, G.; Miersch, O.; Wasternack, C.; Boller, T.; Jones, J.D.G.; Romeis, T. Ethylene-Mediated Crosstalk between Calcium-Dependent Protein Kinase and Mapk Signaling Controls Stress Responses in Plants. Proc. Natl. Acad. Sci. USA 2005, 102, 10736-10741. [CrossRef] [PubMed]

165. Asano, T.; Hayashi, N.; Kobayashi, M.; Aoki, N.; Miyao, A.; Mitsuhara, I.; Ichikawa, H.; Komatsu, S.; Hirochika, H.; Kikuchi, S.; et al. A Rice Calcium-Dependent Protein Kinase Oscpk12 Oppositely Modulates Salt-Stress Tolerance and Blast Disease Resistance. Plant J. 2012, 69, 26-36. [CrossRef]

166. Boudsocq, M.; Sheen, J. Cdpks in Immune and Stress Signaling. Trends Plant Sci. 2013, 18, 30-40. [CrossRef]

167. Kudla, J.; Batistic, O.; Hashimoto, K. Calcium Signals: The Lead Currency of Plant Information Processing. Plant Cell 2010, 22, 541-563. [CrossRef]

168. Luan, S. The Cbl-Cipk Network in Plant Calcium Signaling. Trends Plant Sci. 2009, 14, 37-42. [CrossRef]

169. De la Torre, F.; Gutierrez-Beltran, E.; Pareja-Jaime, Y.; Chakravarthy, S.; Martin, G.B.; del Pozo, O. The Tomato Calcium Sensor Cbl10 and Its Interacting Protein Kinase Cipk6 Define a Signaling Pathway in Plant Immunity. Plant Cell 2013, 25, 2748-2764. [CrossRef]

170. Drerup, M.M.; Schlucking, K.; Hashimoto, K.; Manishankar, P.; Steinhorst, L.; Kuchitsu, K.; Kudla, J. The Calcineurin B-Like Calcium Sensors Cbl1 and Cbl9 together with Their Interacting Protein Kinase Cipk26 Regulate the Arabidopsis NADPH Oxidase Rbohf. Mol. Plant 2013, 6, 559-569. [CrossRef]

171. Batistič, O.; Waadt, R.; Steinhorst, L.; Held, K.; Kudla, J. Cbl-Mediated Targeting of Cipks Facilitates the Decoding of Calcium Signals Emanating from Distinct Cellular Stores. Plant J. 2009, 61, 211-222. [CrossRef]

172. Weinl, S.; Kudla, J. The Cbl-Cipk Ca ${ }^{2+}$-Decoding Signaling Network: Function and Perspectives. New Phytol. 2009, 184, 517-528. [CrossRef]

173. Hashimoto, K.; Kudla, J. Calcium Decoding Mechanisms in Plants. Biochimie 2011, 93, 2054-2059. [CrossRef] [PubMed]

174. Kimura, S.; Kaya, H.; Kawarazaki, T.; Hiraoka, G.; Senzaki, E.; Michikawa, M.; Kuchitsu, K. Protein Phosphorylation Is a Prerequisite for the $\mathrm{Ca}^{2+}$-Dependent Activation of Arabidopsis NADPH Oxidases and May Function as a Trigger for the Positive Feedback Regulation of Ca2+ and Reactive Oxygen Species. BBA Mol. Cell Res. 2012, 1823, 398-405. [CrossRef] [PubMed]

175. Antolin-Llovera, M.; Ried, M.K.; Binder, A.; Parniske, M. Receptor Kinase Signaling Pathways in Plant-Microbe Interactions. Annu. Rev. Phytopathol. 2012, 50, 451-473. [CrossRef] [PubMed]

176. Vij, S.; Giri, J.; Dansana, P.K.; Kapoor, S.; Tyagi, A.K. The Receptor-Like Cytoplasmic Kinase (Osrlck) Gene Family in Rice: Organization, Phylogenetic Relationship, and Expression During Development and Stress. Mol. Plant 2008, 1, 732-750. [CrossRef] [PubMed]

177. Lin, W.; Ma, X.; Shan, L.; He, P. Big Roles of Small Kinases: The Complex Functions of Receptor-Like Cytoplasmic Kinases in Plant Immunity and Development. J. Integr. Plant Biol. 2013, 55, 1188-1197. [CrossRef]

178. Li, L.; Li, M.; Yu, L.; Zhou, Z.; Liang, X.; Liu, Z.; Cai, G.; Gao, L.; Zhang, X.; Wang, Y.; et al. The Fls2-Associated Kinase Bik1 Directly Phosphorylates the NADPHOxidase Rbohd to Control Plant Immunity. Cell Host Microbe 2014, 15, 329-338. [CrossRef]

179. Akamatsu, A.; Wong, H.L.; Fujiwara, M.; Okuda, J.; Nishide, K.; Uno, K.; Imai, K.; Umemura, K.; Kawasaki, T.; Kawano, Y.; et al. An Oscebip/Oscerk1-Osracgef1-Osrac1 Module Is an Essential Early Component of Chitin-Induced Rice Immunity. Cell Host Microbe 2013, 13, 465-476. [CrossRef]

180. Lu, D.; Wu, S.; Gao, X.; Zhang, Y.; Shan, L.; He, P. A Receptor-Like Cytoplasmic Kinase, Bik1, Associates with a Flagellin Receptor Complex to Initiate Plant Innate Immunity. Proc. Natl. Acad. Sci. USA 2010, 107, 496-501. [CrossRef]

181. Zhang, J.; Li, W.; Xiang, T.; Liu, Z.; Laluk, K.; Ding, X.; Zou, Y.; Gao, M.; Zhang, X.; Chen, S.; et al. Receptor-Like Cytoplasmic Kinases Integrate Signaling from Multiple Plant Immune Receptors and Are Targeted by a Pseudomonas Syringae Effector. Cell Host Microbe 2010, 7, 290-301. [CrossRef] 
182. Liu, Z.; Wu, Y.; Yang, F.; Zhang, Y.; Chen, S.; Xie, Q.; Tian, X.; Zhou, J.M. Bik1 Interacts with Peprs to Mediate Ethylene-Induced Immunity. Proc. Natl. Acad. Sci. USA 2013, 110, 6205-6210. [CrossRef] [PubMed]

183. Zipfel, C.; Kunze, G.; Chinchilla, D.; Caniard, A.; Jones, J.D.; Boller, T.; Felix, G. Perception of the Bacterial Pamp Ef-Tu by the Receptor Efr Restricts Agrobacterium-Mediated Transformation. Cell 2006, 125, 749-760. [CrossRef]

184. Tang, J.; Han, Z.; Sun, Y.; Zhang, H.; Gong, X.; Chai, J. Structural Basis for Recognition of an Endogenous Peptide by the Plant Receptor Kinase Pepr1. Cell Res. 2015, 25, 110-120. [CrossRef] [PubMed]

185. Gimenez-Ibanez, S.; Hann, D.R.; Ntoukakis, V.; Petutschnig, E.; Lipka, V.; Rathjen, J.P. Avrptob Targets the Lysm Receptor Kinase Cerk1 to Promote Bacterial Virulence on Plants. Curr. Biol. 2009, 19, 423-429. [CrossRef] [PubMed]

186. Liu, T.; Liu, Z.; Song, C.; Hu, Y.; Han, Z.; She, J.; Fan, F.; Wang, J.; Jin, C.; Chang, J.; et al. Chitin-Induced Dimerization Activates a Plant Immune Receptor. Science 2012, 336, 1160-1164. [CrossRef] [PubMed]

187. Yamaguchi, K.; Yamada, K.; Ishikawa, K.; Yoshimura, S.; Hayashi, N.; Uchihashi, K.; Ishihama, N.; Kishi-Kaboshi, M.; Takahashi, A.; Tsuge, S.; et al. A Receptor-Like Cytoplasmic Kinase Targeted by a Plant Pathogen Effector Is Directly Phosphorylated by the Chitin Receptor and Mediates Rice Immunity. Cell Host Microbe 2013, 13, 347-357. [CrossRef]

188. Nissen, K.S.; Willats, W.G.T.; Malinovsky, F.G. Understanding Crrlk11 Function: Cell Walls and Growth Control. Trends Plant Sci. 2016, 21, 516-527. [CrossRef]

189. Stegmann, M.; Monaghan, J.; Smakowska-Luzan, E.; Rovenich, H.; Lehner, A.; Holton, N.; Belkhadir, Y.; Zipfel, C. The Receptor Kinase Fer Is a Ralf-Regulated Scaffold Controlling Plant Immune Signaling. Science 2017, 355, 287-289. [CrossRef]

190. Franck, C.M.; Westermann, J.; Boisson-Dernier, A. Plant Malectin-Like Receptor Kinases: From Cell Wall Integrity to Immunity and Beyond. Annu. Rev. Plant Biol. 2018, 69, 301-328. [CrossRef]

191. Couto, D.; Zipfel, C. Regulation of Pattern Recognition Receptor Signalling in Plants. Nat. Rev. Immunol. 2016, 16, 537-552. [CrossRef]

192. Shi, H.; Shen, Q.; Qi, Y.; Yan, H.; Nie, H.; Chen, Y.; Zhao, T.; Katagiri, F.; Tang, D. Br-Signaling Kinase1 Physically Associates with Flagellin Sensing2 and Regulates Plant Innate Immunity in Arabidopsis. Plant Cell 2013, 25, 1143-1157. [CrossRef] [PubMed]

193. Chinchilla, D.; Zipfel, C.; Robatzek, S.; Kemmerling, B.; Nurnberger, T.; Jones, J.D.; Felix, G.; Boller, T. A Flagellin-Induced Complex of the Receptor Fls2 and Bak1 Initiates Plant Defence. Nature 2007, 448, 497-500. [CrossRef] [PubMed]

194. Schulze, B.; Mentzel, T.; Jehle, A.K.; Mueller, K.; Beeler, S.; Boller, T.; Felix, G.; Chinchilla, D. Rapid Heteromerization and Phosphorylation of Ligand-Activated Plant Transmembrane Receptors and Their Associated Kinase Bak1. J. Biol. Chem. 2010, 285, 9444-9451. [CrossRef] [PubMed]

195. Wang, J.; Grubb, L.E.; Wang, J.; Liang, X.; Li, L.; Gao, C.; Ma, M.; Feng, F.; Li, M.; Li, L.; et al. A Regulatory Module Controlling Homeostasis of a Plant Immune Kinase. Mol. Cell 2018, 69, 493-504. [CrossRef] [PubMed]

196. Feng, F.; Yang, F.; Rong, W.; Wu, X.; Zhang, J.; Chen, S.; He, C.; Zhou, J.M. A Xanthomonas Uridine 5'-Monophosphate Transferase Inhibits Plant Immune Kinases. Nature 2012, 485, 114-118. [CrossRef]

197. Ranf, S.; Eschen-Lippold, L.; Frohlich, K.; Westphal, L.; Scheel, D.; Lee, J. Microbe-Associated Molecular Pattern-Induced Calcium Signaling Requires the Receptor-Like Cytoplasmic Kinases, Pbl1 and Bik1. BMC Plant Biol. 2014, 14, 374. [CrossRef]

198. Monaghan, J.; Matschi, S.; Romeis, T.; Zipfel, C. The Calcium-Dependent Protein Kinase Cpk28 Negatively Regulates the Bik1-Mediated Pamp-Induced Calcium Burst. Plant Signal. Behav. 2015, 10, e1018497. [CrossRef]

199. Liang, X.; Ding, P.; Lian, K.; Wang, J.; Ma, M.; Li, L.; Li, L.; Li, M.; Zhang, X.; Chen, S.; et al. Arabidopsis Heterotrimeric G Proteins Regulate Immunity by Directly Coupling to the Fls2 Receptor. eLife 2016, 5, e13568. [CrossRef]

200. Zhang, M.X.; Chiang, Y.; Toruño, T.Y.; Lee, D.; Ma, M.; Liang, X.; Lal, N.K.; Lemos, M.; Lu, Y.; Ma, S.; et al. The Map4 Kinase Sik1 Ensures Robust Extracellular Ros Burst and Antibacterial Immunity in Plants. Cell Host Microbe 2018, 24, 379-391. [CrossRef] 
201. Shinya, T.; Motoyama, N.; Ikeda, A.; Wada, M.; Kamiya, K.; Hayafune, M.; Kaku, H.; Shibuya, N. Functional Characterization of Cebip and Cerk1 Homologs in Arabidopsis and Rice Reveals the Presence of Different Chitin Receptor Systems in Plants. Plant Cell Physiol. 2012, 53, 1696-1706. [CrossRef]

202. Cao, Y.; Liang, Y.; Tanaka, K.; Nguyen, C.T.; Jedrzejczak, R.P.; Joachimiak, A.; Stacey, G. The Kinase Lyk5 Is a Major Chitin Receptor in Arabidopsis and Forms a Chitin-Induced Complex with Related Kinase Cerk1. eLife 2014, 3, e03766. [CrossRef] [PubMed]

203. Shinya, T.; Yamaguchi, K.; Desaki, Y.; Yamada, K.; Narisawa, T.; Kobayashi, Y.; Maeda, K.; Suzuki, M.; Tanimoto, T.; Takeda, J.; et al. Selective Regulation of the Chitin-Induced Defense Response by the Arabidopsis Receptor-Like Cytoplasmic Kinase Pbl27. Plant J. 2014, 79, 56-66. [CrossRef] [PubMed]

204. Kawasaki, T.; Yamada, K.; Yoshimura, S.; Yamaguchi, K. Chitin Receptor-Mediated Activation of Map Kinases and Ros Production in Rice and Arabidopsis. Plant Signal. Behav. 2017, 12, e1361076. [CrossRef] [PubMed]

205. Brenner, D.; Brechmann, M.; Röhling, S.; Tapernoux, M.; Mock, T.; Winter, D.; Lehmann, W.D.; Kiefer, F.; Thome, M.; Krammer, P.H.; et al. Phosphorylation of Carma1 by Hpk1 Is Critical for Nf-Kb Activation in T Cells. Proc. Natl. Acad. Sci. USA 2009, 106, 14508-14513. [CrossRef] [PubMed]

206. Leberer, E.; Thomas, D.Y.; Whiteway, M. Pheromone Signalling and Polarized Morphogenesis in Yeast. Curr. Opin. Genet. Dev. 1997, 7, 59-66. [CrossRef]

207. Yu, X.; Feng, B.; He, P.; Shan, L. From Chaos to Harmony: Responses and Signaling Upon Microbial Pattern Recognition. Annu. Rev. Phytopathol. 2017, 55, 109-137. [CrossRef]

208. Willmanna, R.; Lajunena, H.M.; Erbsb, G.; Newmanb, M.; Kolba, D.; Tsudac, K.; Katagiric, F.; Fliegmannd, J.; Bonof, J.; Cullimoref, J.V.; et al. Arabidopsis Lysin-Motif Proteins Lym1 Lym3 Cerk1 Mediate Bacterial Peptidoglycan Sensing and Immunity to Bacterial Infection. Proc. Natl. Acad. Sci. USA 2011, 108, 19824-19829. [CrossRef]

209. Wan, J.; Tanaka, K.; Zhang, X.C.; Son, G.H.; Brechenmacher, L.; Nguyen, T.H.; Stacey, G. Lyk4, a Lysin Motif Receptor-Like Kinase, Is Important for Chitin Signaling and Plant Innate Immunity in Arabidopsis. Plant Physiol. 2012, 160, 396-406. [CrossRef]

210. Yamaguchi, K.; Yamada, K.; Kawasaki, T. Receptor-Like Cytoplasmic Kinases Are Pivotal Components in Pattern Recognition Receptor-Mediated Signaling in Plant Immunity. Plant Signal. Behav. 2013, 8, e25662. [CrossRef]

211. Ao, Y.; Li, Z.; Feng, D.; Xiong, F.; Liu, J.; Li, J.F.; Wang, M.; Wang, J.; Liu, B.; Wang, H.B. Oscerk1 and Osrlck176 Play Important Roles in Peptidoglycan and Chitin Signaling in Rice Innate Immunity. Plant J. 2014, 80, 1072-1084. [CrossRef]

212. Liu, B.; Li, J.F.; Ao, Y.; Qu, J.; Li, Z.; Su, J.; Zhang, Y.; Liu, J.; Feng, D.; Qi, K.; et al. Lysin Motif-Containing Proteins Lyp4 and Lyp6 Play Dual Roles in Peptidoglycan and Chitin Perception in Rice Innate Immunity. Plant Cell 2012, 24, 3406-3419. [CrossRef] [PubMed]

213. Shimizu, T.; Nakano, T.; Takamizawa, D.; Desaki, Y.; Ishii-Minami, N.; Nishizawa, Y.; Minami, E.; Okada, K.; Yamane, H.; Kaku, H.; et al. Two Lysm Receptor Molecules, Cebip and Oscerk1, Cooperatively Regulate Chitin Elicitor Signaling in Rice. Plant J. 2010, 64, 204-214. [CrossRef]

214. Hayafunea, M.; Berisiob, R.; Marchettic, R.; Silipoc, A.; Kayamaa, M.; Desakia, Y.; Arimaa, S.; Squegliab, F.; Ruggierob, A.; Tokuyasud, K.; et al. Chitin-Induced Activation of Immune Signaling by the Rice Receptor Cebip Relies on a Unique Sandwich-Type Dimerization. Proc. Natl. Acad. Sci. USA 2013, 111, e404-e413. [CrossRef] [PubMed]

215. Kishi-Kaboshi, M.; Okada, K.; Kurimoto, L.; Murakami, S.; Umezawa, T.; Shibuya, N.; Yamane, H.; Miyao, A.; Takatsuji, H.; Takahashi, A.; et al. A Rice Fungal Mamp-Responsive Mapk Cascade Regulates Metabolic Flow to Antimicrobial Metabolite Synthesis. Plant J. 2010, 63, 599-612. [CrossRef] [PubMed]

216. Yamada, K.; Yamaguchi, K.; Yoshimura, S.; Terauchi, A.; Kawasaki, T. Conservation of Chitin-Induced Mapk Signaling Pathways in Rice and Arabidopsis. Plant Cell Physiol. 2017, 58, 993-1002. [CrossRef]

217. Wang, C.; Wang, G.; Zhang, C.; Zhu, P.; Dai, H.; Yu, N.; He, Z.; Xu, L.; Wang, E. Oscerk1-Mediated Chitin Perception and Immune Signaling Requires Receptor-Like Cytoplasmic Kinase 185 to Activate an Mapk Cascade in Rice. Mol. Plant 2017, 10, 619-633. [CrossRef]

218. Van Breusegem, F.; Bailey-Serres, J.; Mittler, R. Unraveling the Tapestry of Networks Involving Reactive Oxygen Species in Plants. Plant Physiol. 2008, 147, 978-984. [CrossRef] 
219. Nakashima, A.; Chen, L.; Thao, N.P.; Fujiwara, M.; Wong, H.L.; Kuwano, M.; Umemura, K.; Shirasu, K.; Kawasaki, T.; Shimamoto, K. Rack1 Functions in Rice Innate Immunity by Interacting with the Rac1 Immune Complex. Plant Cell 2008, 20, 2265-2279. [CrossRef]

220. Cheng, Z.; Li, J.F.; Niu, Y.; Zhang, X.C.; Woody, O.Z.; Xiong, Y.; Djonovic, S.; Millet, Y.; Bush, J.; McConkey, B.J.; et al. Pathogen-Secreted Proteases Activate a Novel Plant Immune Pathway. Nature 2015, 521, 213-216. [CrossRef]

221. Wong, H.L.; Kawasaki, T.; Shimamoto, K. Rac Gtpase and the Regulation of NADPH Oxidase in Rice Innate Immunity Response. In Advances in Genetics, Genomics and Control of Rice Blast Disease; Wang, G.L., Valent, B., Eds.; Springer: Dordrecht, The Netherlands, 2009; pp. 173-178.

222. Wong, H.L.; Pinontoan, R.; Hayashi, K.; Tabata, R.; Yaeno, T.; Hasegawa, K.; Kojima, C.; Yoshioka, H.; Iba, K.; Kawasaki, T.; et al. Regulation of Rice NADPH Oxidase by Binding of Rac Gtpase to Its N-Terminal Extension. Plant Cell 2007, 19, 4022-4034. [CrossRef]

223. Duan, Q.; Kita, D.; Li, C.; Cheung, A.Y.; Wu, H.M. Feronia Receptor-Like Kinase Regulates Rho Gtpase Signaling of Root Hair Development. Proc. Natl. Acad. Sci. USA 2010, 107, 17821-17826. [CrossRef]

224. Wennerberg, K.; Rossman, K.L.; Der, C.J. The Ras Superfamily at a Glance. J. Cell Sci. 2005, 118, 843-846. [CrossRef] [PubMed]

225. Kaothien, P.; Ok, S.H.; Shuai, B.; Wengier, D.; Cotter, R.; Kelley, D.; Kiriakopolos, S.; Muschietti, J.; McCormick, S. Kinase Partner Protein Interacts with the Leprk1 and Leprk2 Receptor Kinases and Plays a Role in Polarized Pollen Tube Growth. Plant J. 2005, 42, 492-503. [CrossRef] [PubMed]

226. Li, C.; Yeh, F.L.; Cheung, A.Y.; Duan, Q.; Kita, D.; Liu, M.C.; Maman, J.; Luu, E.J.; Wu, B.W.; Gates, L.; et al. Glycosylphosphatidylinositol-Anchored Proteins as Chaperones and Co-Receptors for Feronia Receptor Kinase Signaling in Arabidopsis. eLife 2015, 4, e06587. [CrossRef] [PubMed]

227. Haruta, M.; Sabat, G.; Stecker, K.; Minkoff, B.B.; Sussman, M.R. A Peptide Hormone and Its Receptor Protein Kinase Regulate Plant Cell Expansion. Science 2014, 343, 408-411. [CrossRef]

228. Zhao, C.; Zayed, O.; Yu, Z.; Jiang, W.; Zhu, P.; Hsu, C.C.; Zhang, L.; Tao, W.A.; Lozano-Duran, R.; Zhu, J.K. Leucine-Rich Repeat Extensin Proteins Regulate Plant Salt Tolerance in Arabidopsis. Proc. Natl. Acad. Sci. USA 2018, 115, 13123-13128. [CrossRef]

229. Suharsono, U.; Fujisawa, Y.; Kawasaki, T.; Iwasaki, Y.; Satoh, H.; Shimamoto, K. The Heterotrimeric G Protein A Subunit Acts Upstream of the Small Gtpase Rac in Disease Resistance of Rice. Proc. Natl. Acad. Sci. USA 2002, 99, 13307-13312. [CrossRef]

230. Daugaard, M.; Nitsch, R.; Razaghi, B.; McDonald, L.; Jarrar, A.; Torrino, S.; Castillo-Lluva, S.; Rotblat, B.; Li, L.; Malliri, A.; et al. Hace1 Controls Ros Generation of Vertebrate Rac1-Dependent NADPH Oxidase Complexes. Nat. Commun. 2013, 4, 2180. [CrossRef]

231. Kwak, J.M.; Mori, I.C.; Pei, Z.M.; Leonhardt, N.; Torres, M.A.; Dangl, J.L.; Bloom, R.E.; Bodde, S.; Jones, J.D.G.; Schroeder, J.I. NADPH Oxidase Atrbohd and Atrbohf Genes Function in Ros-Dependent Aba Signaling in Arabidopsis. EMBO J. 2003, 22, 2623-2633. [CrossRef]

232. Melotto, M.; Underwood, W.; Koczan, J.; Nomura, K.; He, S.Y. Plant Stomata Function in Innate Immunity against Bacterial Invasion. Cell 2006, 126, 969-980. [CrossRef]

233. Mustilli, A.C. Arabidopsis Ost1 Protein Kinase Mediates the Regulation of Stomatal Aperture by Abscisic Acid and Acts Upstream of Reactive Oxygen Species Production. Plant Cell 2002, 14, 3089-3099. [CrossRef] [PubMed]

234. Yu, F.; Qian, L.; Nibau, C.; Duan, Q.; Kita, D.; Levasseur, K.; Li, X.; Lu, C.; Li, H.; Hou, C.; et al. Feronia Receptor Kinase Pathway Suppresses Abscisic Acid Signaling in Arabidopsis by Activating Abi2 Phosphatase. Proc. Natl. Acad. Sci. USA 2012, 109, 14693-14698. [CrossRef]

235. Park, S.Y.; Fung, P.; Nishimura, N.; Jensen, D.R.; Fujii, H.; Zhao, Y.; Lumba, S.; Santiago, J.; Rodrigues, A.; Chow, T.F.; et al. Abscisic Acid Inhibits Type 2c Protein Phosphatases via the Pyr/Pyl Family of Start Proteins. Science 2009, 324, 1068-1071. [CrossRef] [PubMed]

236. Chen, J.; Yu, F.; Liu, Y.; Du, C.; Li, X.; Zhu, S.; Wang, X.; Lan, W.; Rodriguez, P.L.; Liu, X.; et al. Feronia Interacts with Abi2-Type Phosphatases to Facilitate Signaling Crosstalk between Abscisic Acid and Ralf Peptide in Arabidopsis. Proc. Natl. Acad. Sci. USA 2016, 113, e5519-e5527. [CrossRef] [PubMed]

237. Zhang, Y.; Zhu, H.; Zhang, Q.; Li, M.; Yan, M.; Wang, R.; Wang, L.; Welti, R.; Zhang, W.; Wang, X. Phospholipase Dalpha1 and Phosphatidic Acid Regulate NADPH Oxidase Activity and Production of 
Reactive Oxygen Species in Aba-Mediated Stomatal Closure in Arabidopsis. Plant Cell 2009, 21, 2357-2377. [CrossRef] [PubMed]

238. Girish, M.; Zhang, W.H.; Deng, F.; Zhao, J.; Wang, X.M. A Bifurcating Pathway Directs Abscisic Acid Effects on Stomatal Closure and Opening in Arabidopsis. Science 2006, 312, 264-266.

239. Desikan, R.; Last, K.; Harrett-Williams, R.; Tagliavia, C.; Harter, K.; Hooley, R.; Hancock, J.T.; Neill, S.J. Ethylene-Induced Stomatal Closure in Arabidopsis Occurs via Atrbohf-Mediated Hydrogen Peroxide Synthesis. Plant J. 2006, 47, 907-916. [CrossRef]

240. Alisa, H.; Gregory, P.; Ryan Clarence, A. An Endogenous Peptide Signal in Arabidopsis Activates Components of the Innate Immune Response. Proc. Natl. Acad. Sci. USA 2006, 103, 10098-10103.

241. Bartels, S.; Lori, M.; Mbengue, M.; van Verk, M.; Klauser, D.; Hander, T.; Boni, R.; Robatzek, S.; Boller, T. The Family of Peps and Their Precursors in Arabidopsis: Differential Expression and Localization but Similar Induction of Pattern-Triggered Immune Responses. J. Exp. Bot. 2013, 64, 5309-5321. [CrossRef]

242. Maruta, T.; Inoue, T.; Tamoi, M.; Yabuta, Y.; Yoshimura, K.; Ishikawa, T.; Shigeoka, S. Arabidopsis NADPH Oxidases, Atrbohd and Atrbohf, Are Essential for Jasmonic Acid-Induced Expression of Genes Regulated by Myc2 Transcription Factor. Plant Sci. 2011, 180, 655-660. [CrossRef]

243. Hettenhausen, C.; Schuman, M.C.; Wu, J.Q. Mapk Signaling: A Key Element in Plant Defense Response to Insects. Insect Sci. 2015, 22, 157-164. [CrossRef]

244. Rodriguez, M.C.; Petersen, M.; Mundy, J. Mitogen-Activated Protein Kinase Signaling in Plants. Annu. Rev. Plant Biol. 2010, 61, 621-649.

245. Liu, Y.K. Roles of Mitogen-Activated Protein Kinase Cascades in Aba Signaling. Plant Cell Rep. 2012, 31, 1-12. [CrossRef]

246. Liu, Y.; Kong, X.; Pan, J.; Li, D. Vip1: Linking Agrobacterium-Mediated Transformation to Plant Immunity? Plant Cell Rep. 2010, 29, 805-812. [CrossRef]

247. Teige, M.; Scheikl, E.; Eulgem, T.; Doczi, R.; Ichimura, K.; Shinozaki, K.; Dangl, J.L.; Hirt, H. The Mkk2 Pathway Mediates Cold and Salt Stress Signaling in Arabidopsis. Mol. Cell 2004, 15, 141-152. [CrossRef]

248. Pitzschke, A.; Djamei, A.; Bitton, F.; Hirt, H. A Major Role of the Mekk1-Mkk1/2-Mpk4 Pathway in Ros Signalling. Mol. Plant 2009, 2, 120-137. [CrossRef]

249. Asai, T.; Tena, G.; Plotnikova, J.; Willmann, M.R.; Chiu, W.L.; Gomez-Gomez, L.; Boller, T.; Ausubel, F.M.; Sheen, J. Map Kinase Signalling Cascade in Arabidopsis Innate Immunity. Nature 2002, 415, 977-983. [CrossRef]

250. Zhang, J.; Shao, F.; Li, Y.; Cui, H.; Chen, L.; Li, H.; Zou, Y.; Long, C.; Lan, L.; Chai, J.; et al. A Pseudomonas Syringae Effector Inactivates Mapks to Suppress Pamp-Induced Immunity in Plants. Cell Host Microbe 2007, 1, 175-185. [CrossRef]

251. Macho, A.P.; Boutrot, F.; Rathjen, J.P.; Zipfel, C. Aspartate Oxidase Plays an Important Role in Arabidopsis Stomatal Immunity. Plant Physiol. 2012, 159, 1845-1856. [CrossRef]

252. Durrant, W.E.; Dong, X. Systemic Acquired Resistance. Annu. Rev. Phytopathol. 2004, 42, 185-209. [CrossRef]

253. De Geyter, N.; Gholami, A.; Goormachtig, S.; Goossens, A. Transcriptional Machineries in Jasmonate-Elicited Plant Secondary Metabolism. Trends Plant Sci. 2012, 17, 349-359. [CrossRef]

254. Overmyer, K.; Tuominen, H.; Kettunen, R.; Betz, C.; Langebartels, C.; Sandermann, H.; Kangasjarvi, J. Ozone-Sensitive Arabidopsis Rcd1 Mutant Reveals Opposite Roles for Ethylene and Jasmonate Signaling Pathways in Regulating Superoxide-Dependent Cell Death. Plant Cell 2000, 12, 1849-1862. [CrossRef]

255. Tintor, N.; Ross, A.; Kanehara, K.; Yamada, K.; Fan, L.; Kemmerling, B.; Nurnberger, T.; Tsuda, K.; Saijo, Y. Layered Pattern Receptor Signaling via Ethylene and Endogenous Elicitor Peptides During Arabidopsis Immunity to Bacterial Infection. Proc. Natl. Acad. Sci. USA 2013, 110, 6211-6216. [CrossRef]

256. Flury, P.; Klauser, D.; Schulze, B.; Boller, T.; Bartels, S. The Anticipation of Danger: Microbe-Associated Molecular Pattern Perception Enhances Atpep-Triggered Oxidative Burst. Plant Physiol. 2013, 161, 2023-2035. [CrossRef]

257. Browse, J. Jasmonate Passes Muster: A Receptor and Targets for the Defense Hormone. Annu. Rev. Plant Biol. 2009, 60, 183-205. [CrossRef]

258. Xia, X.J.; Wang, Y.J.; Zhou, Y.H.; Tao, Y.; Mao, W.H.; Shi, K.; Asami, T.; Chen, Z.; Yu, J.Q. Reactive Oxygen Species Are Involved in Brassinosteroid-Induced Stress Tolerance in Cucumber. Plant Physiol. 2009, 150, 801-814. [CrossRef] 
259. Elmayan, T.; Fromentin, J.; Riondet, C.; Alcaraz, G.; Blein, J.P.; Simon-Plas, F. Regulation of Reactive Oxygen Species Production by a 14-3-3 Protein in Elicited Tobacco Cells. Plant Cell Environ. 2007, 30, 722-732. [CrossRef]

260. Tsuruhara, A.; Suzuki, H.; Tezuka, T. Inhibition of the Activity of Nad(P)H-Dependent Oxidase in Pistils of Lilium Longiflorum by Camp. Plant Cell Physiol. 1999, 40, 1093-1098. [CrossRef]

261. Souabni, H.; Thoma, V.; Bizouarn, T.; Chatgilialoglu, C.; Siafaka-Kapadai, A.; Baciou, L.; Ferreri, C.; Houee-Levin, C.; Ostuni, M.A. trans Arachidonic Acid Isomers Inhibit Nadph-Oxidase Activity by Direct Interaction with Enzyme Components. Biochim. Biophys. Acta 2012, 1818, 2314-2324. [CrossRef]

262. Arnaud, D.; Hwang, I. A Sophisticated Network of Signaling Pathways Regulates Stomatal Defenses to Bacterial Pathogens. Mol. Plant 2015, 8, 566-581. [CrossRef]

263. Yun, B.W.; Feechan, A.; Yin, M.; Saidi, N.B.; Bihan, T.L.; Yu, M.; Moore, J.W.; Kang, J.G.; Kwon, E.; Spoel, S.H.; et al. S-Nitrosylation of NADPH Oxidase Regulates Cell Death in Plant Immunity. Nature 2011, 478, $264-268$. [CrossRef]

(C) 2020 by the authors. Licensee MDPI, Basel, Switzerland. This article is an open access article distributed under the terms and conditions of the Creative Commons Attribution (CC BY) license (http://creativecommons.org/licenses/by/4.0/). 